Aus der Klinik für Mund-, Kiefer- und Gesichtschirurgie (Prof. Dr. med. Dr. med. dent. H. Schliephake) im Zentrum Zahn-, Mund- und Kieferheilkunde der Medizinischen Fakultät der Universität Göttingen

\title{
Das Knochenremodeling bei Osteoporose am Tiermodell des Göttinger Minischweines
}

\author{
INAUGURAL-DISSERTATION \\ zur Erlangung des Doktorgrades \\ der Medizinischen Fakultät der \\ Georg-August-Universität zu Göttingen
}

vorgelegt von

Niklas Rainer Trautmann

aus

Göttingen

Göttingen 2018 
Dekan:

Referent:

Ko-Referent:
Prof. Dr. rer. nat. H. K. Kroemer

Prof. Dr. med. Dr. med. dent. K. G. Wiese

Prof. Dr. med. S. Sehmisch

Datum der mündlichen Prüfung: 20. März 2019 
Hiermit erkläre ich, die Dissertation mit dem Titel „Das Knochenremodeling bei Osteoporose am Tiermodell des Göttinger Minischweines" eigenständig angefertigt und keine anderen als die von mir angegebenen Quellen und Hilfsmittel verwendet zu haben.

Göttingen, den 08. Juni 2018 


\section{Inhaltsverzeichnis}

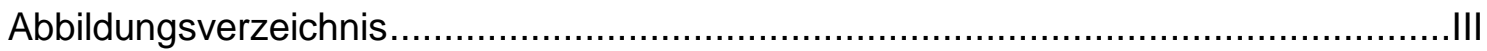

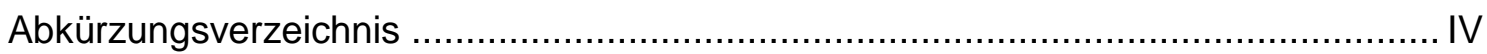

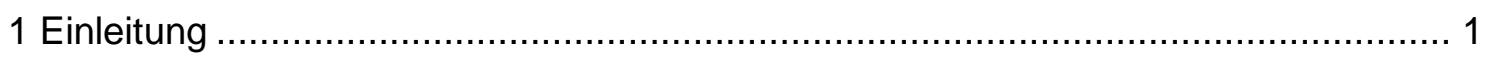

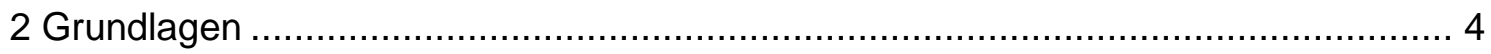

2.1 Der Knochen.................................................................................. 4

2.1.1 Aufbau und Funktion des Röhrenknochens .......................................... 4

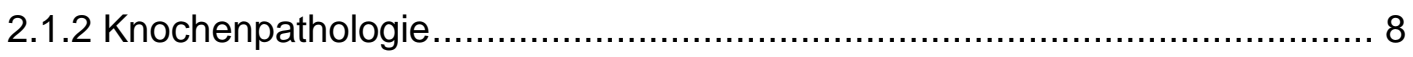

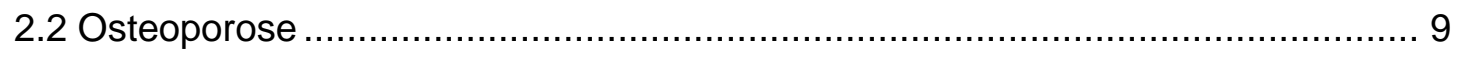

2.2.1 Pathophysiologie und Klinik ........................................................

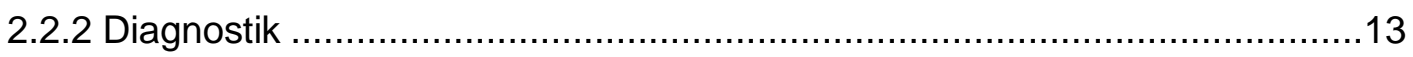

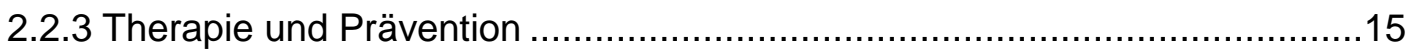

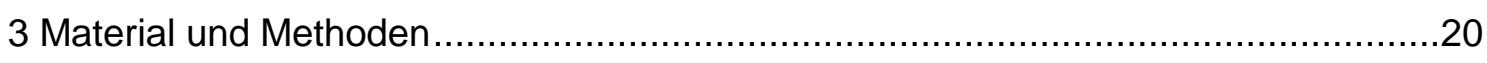

3.1 Design und zeitliche Staffelung der Untersuchung .....................................20

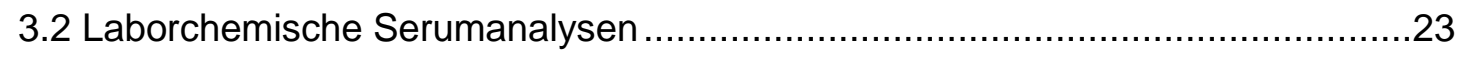

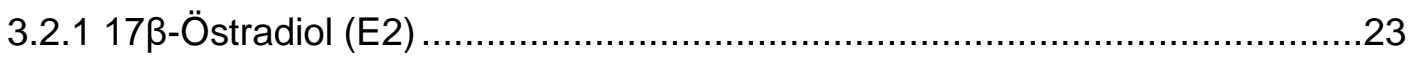

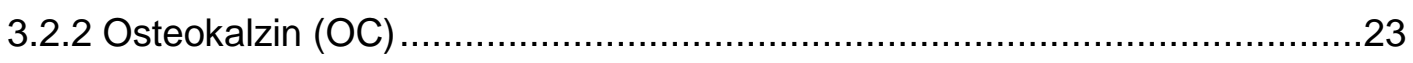

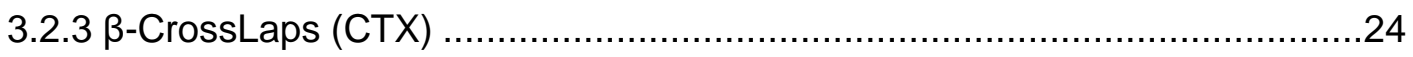

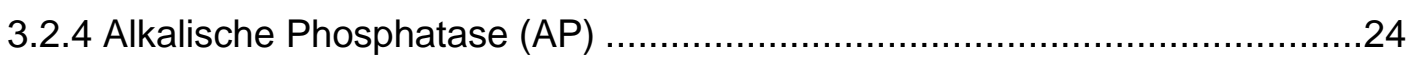

3.3 Periphere quantitative Computertomographie (pQCT) ….............................25

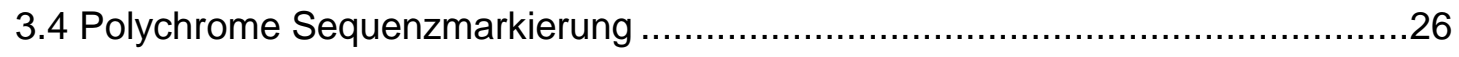

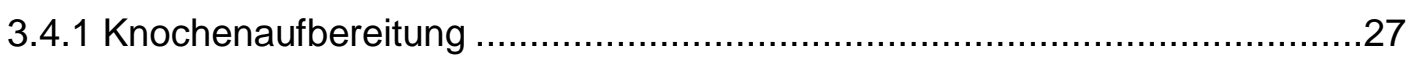

3.4.2 Auflichtfluoreszenzmikroskopie und Digitalisierung ...............................28

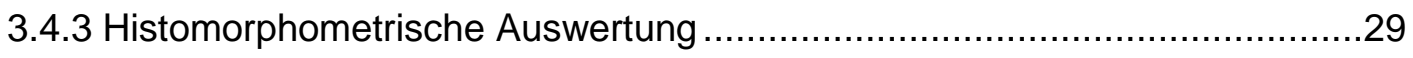

3.4.4 Berechnung der Knochenapposition.................................................29

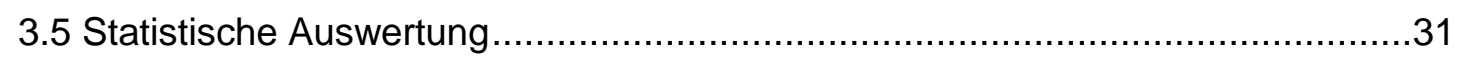

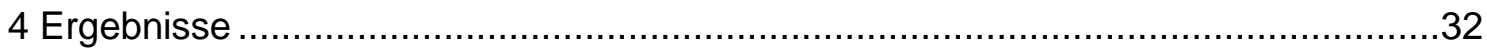

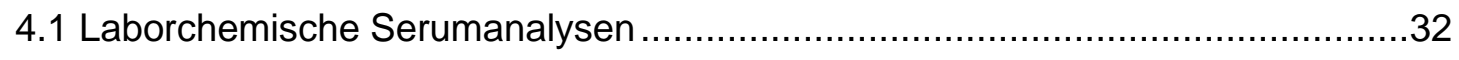

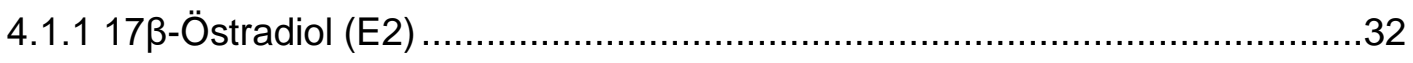

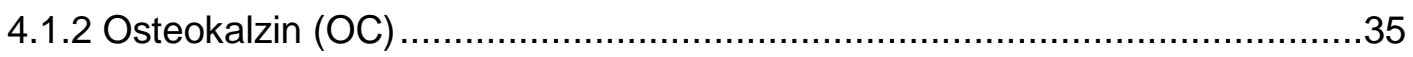

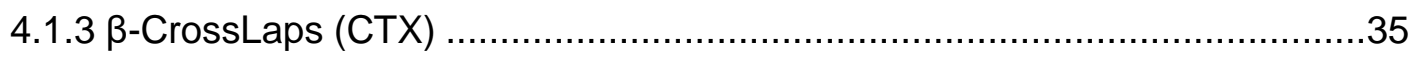

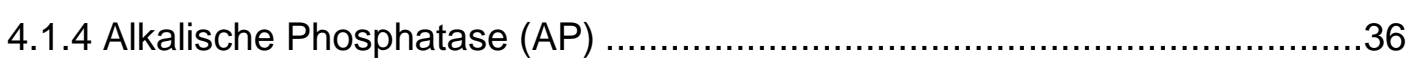

4.2 Periphere quantitative Computertomographie (pQCT) ...................................36

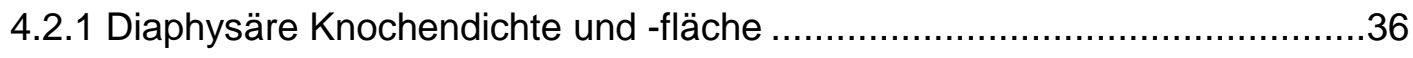

4.2.2 Epiphysäre Knochendichte und -fläche .............................................38

4.2.3 Korrelation zwischen Knochendichte und fläche.................................40 


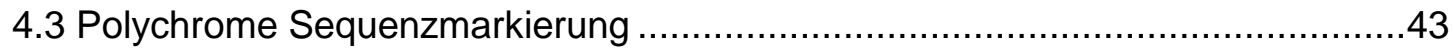

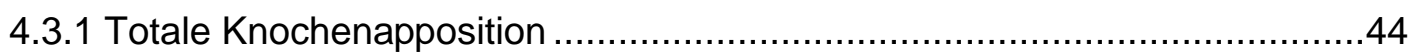

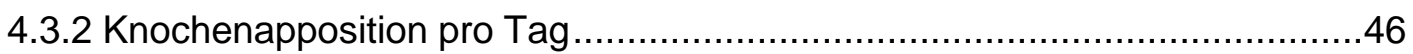

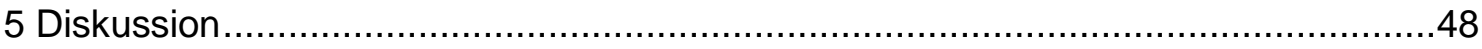

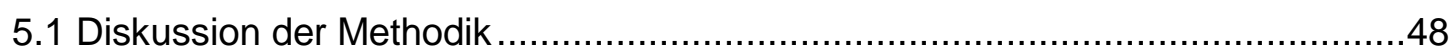

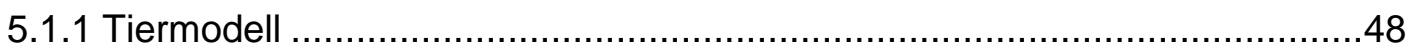

5.1.2 Laborchemische Serumanalysen ..................................................... 51

5.1.3 Periphere quantitative Computertomographie (pQCT) .............................52

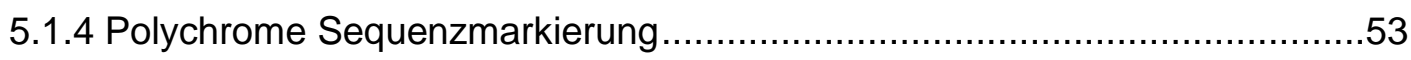

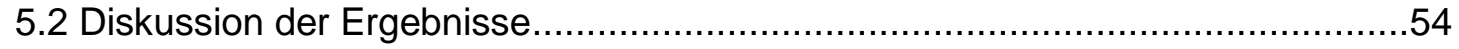

5.2.1 Laborchemische Serumanalysen ...................................................54

5.2.2 Periphere quantitative Computertomographie (pQCT) ..............................57

5.2.3 Polychrome Sequenzmarkierung ........................................................61

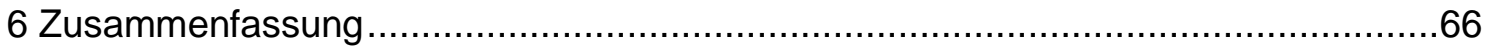

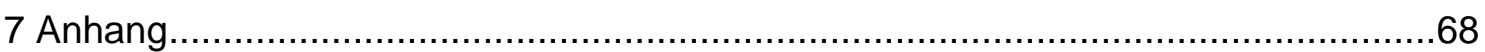

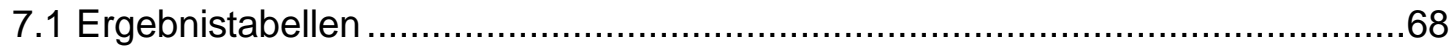

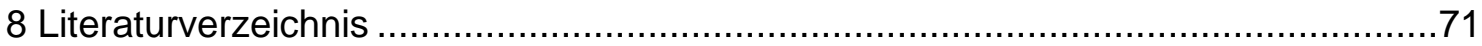




\section{Abbildungsverzeichnis}

Abb. 1 Schematische Darstellung eines Röhrenknochens............................. 5

Abb. 2 Schematischer Aufbau eines Osteons.............................................. 6

Abb. 3 Schematische Einteilung der Osteoporoseformen.............................. 10

Abb. 4 Die fünf Säulen der Osteoporosediagnostik im Schema.................... 13

Abb. 5 Schematische Darstellung häufig angewandter Medikamente in der spezifischen Osteoporosetherapie mit ihren pharmakologischen Ansatzpunkten.

Abb. $6 \quad$ Zeitlicher Versuchsablauf................................................................ 21

Abb. 7 Exemplarischer Querschnitt durch Diaphyse und proximale Epiphyse mittels $\mathrm{PQCT}$

Abb. 8 Schematische Darstellung der fluoreszenzmikroskopisch sichtbaren Farbstoffbanden......................................................................... 30

Abb. 9 Postoperativer Verlauf von OC, E2, CTX und AP............................ 33

Abb. 10 Relative Laborwerte nach Ovarektomie im zeitlichen Verlauf.............. 34

Abb. 11 Knochendichte im Bereich der Diaphyse......................................... 37

Abb. 12 Knochenfläche im Bereich der Diaphyse........................................... 38

Abb. 13 Knochendichte im Bereich der Epiphyse.......................................... 39

Abb. 14 Knochenfläche im Bereich der Epiphyse............................................ 40

Abb. 15 Korrelation zwischen kortikaler Knochendichte und fläche................ 41

Abb. 16 Korrelation zwischen trabekulärer Knochendichte und -fläche............ 42

Abb. 17 Fluoreszenzmikroskopische Betrachtung des periostalen Knochens

Abb. 18 Fluoreszenzmikroskopische Betrachtung des endokortikalen Knochens

Abb. 19 Fluoreszenzmikroskopische Betrachtung angefärbter Osteone.

Abb. 20 Totale Knochenapposition im Bereich der Osteone, des periostalen und des endokortikalen Knochens

Abb. 21 Apposition pro Tag für Alizarin und Tetrazyklin.... 


\title{
Abkürzungsverzeichnis
}

\author{
Alizarin Alizarinkomplexon \\ AP alkalische Phosphatase \\ $\mathrm{Cl} \quad$ Konfidenzintervall / confidence interval \\ CTX C-terminales Telopeptid des Typ-I-Kollagens / $\beta$-CrossLaps \\ DVO Dachverband Osteologie e.V. \\ DXA Zwei-Spektren-Röntgenabsorptiometrie / dual-energy x-ray \\ absorptiometry \\ ECLIA Elektrochemilumineszenz-Immunoassay \\ E2 Östradiol / 17ß-Östradiol \\ FRAX Fracture Risk Assessment Tool \\ h Stunde \\ HRT Hormonersatztherapie / hormone replacement therapy \\ IE Internationale Einheit \\ IFCC International Federation of Clinical Chemistry and Laboratory Medicine \\ IMP Implantateinbringung \\ i.m. intramuskulär \\ IOF International Osteoporosis Foundation \\ i.v. intravenös \\ KG Körpergewicht \\ $\mathrm{kg} \quad$ Kilogramm \\ LK Laborkontrolle \\ Mikro-CT Mikro-Computertomographie \\ MW Mittelwert \\ n Stichprobenumfang \\ OC Osteokalzin / N-MID Osteokalzin \\ OP Operation \\ OVX Ovarektomie \\ $\mathrm{p} \quad \mathrm{p}$-Wert / Überschreitungswahrscheinlichkeit \\ PBM peak bone mass \\ pg Pikogramm \\ PINP Prokollagen Typ I N-Propeptid \\ PQCT periphere quantitative Computertomographie
}


Abkürzungsverzeichnis

$\begin{array}{ll}\text { PTH } & \text { Parathormon } \\ r & \text { Korrelationskoeffizient } \\ r^{2} & \text { Bestimmtheitsmaß } \\ \text { RANKL } & \text { receptor activator of nuclear factor } k \text { B ligand } \\ \text { S.c. } & \text { subkutan } \\ \text { SD } & \text { Standardabweichung / standard deviation } \\ \text { SEM } & \text { Standardfehler / standard error of the mean } \\ \text { SERM } & \text { selektiver Östrogenrezeptormodulator } \\ \text { Sham } & \text { Scheinoperation / sham operation } \\ \text { Tetrazyklin } & \text { Tetrazyklinhydrochlorid } \\ \text { u } & \text { atomare Atommasse / unified atomic mass unit } \\ \text { WHI } & \text { Women's Health Initiative } \\ \text { WHO } & \text { Weltgesundheitsorganisation / World Health Organization }\end{array}$




\section{Einleitung}

Die Osteoporose nimmt unter den Skeletterkrankungen eine herausragende Stellung ein. Die besondere sozialmedizinische und sozioökonomische Relevanz der Erkrankung ist dabei auf ihre enge Kopplung an das höhere Lebensalter zurückzuführen und auf das Auftreten von Frakturen im Krankheitsspätstadium (Scheidt-Nave 2001). Osteoporosebedingte Frakturen betreffen dabei zumeist die Wirbelsäule, den distalen Radius und den Oberschenkelhals. Für einen Großteil der Patienten stellt insbesondere die Schenkelhalsfraktur ein einschneidendes Ereignis dar, welches auf der Basis eines oft schon vorher labilen Gesundheitszustandes gravierende Folgen wie dauerhafte Hilfsbedürftigkeit, Verlust des häuslichen Umfeldes oder auch den Tod nach sich ziehen kann (Scheidt-Nave 2001). So ist innerhalb eines Jahres nach Hüftgelenksfraktur eine Mortalität von 20 Prozent zu verzeichnen (Kanis 2010; Leibson et al. 2002) und etwa jeder zweite Betroffene ist anschließend nicht mehr in der Lage, ein unabhängiges Leben zu führen (Kanis 2010). Bonnaire et al. (2005) gehen bei älteren Patienten mit endoprothetisch versorgter Schenkelhalsfraktur sogar von einer Einjahresmortalität zwischen 25 und 30 Prozent aus.

Über ihre Bedeutung als individueller Schicksalsschlag hinaus besitzt die osteoporotisch bedingte Fraktur aber eben auch eine erhebliche ökonomische Relevanz für die Allgemeinheit. So belaufen sich die jährlich in Deutschland durch Schenkelhalsfrakturen hervorgerufenen Behandlungskosten auf circa zweieinhalb Milliarden Euro (Stöckle et al. 2005). Der Osteoporose ist insofern eine ähnliche gesellschaftliche Bedeutung zuzuschreiben wie anderen in der öffentlichen Wahrnehmung weit präsenteren chronischen Erkrankungen. Von der WHO wird die Osteoporose deshalb auch zu den zehn weltweit bedeutendsten Volkskrankheiten gezählt (Kyvernitakis und Hadji 2016). Eine genaue Angabe der Krankheitsprävalenz wird durch die späte klinische Manifestation einerseits und die vielfach nur unvollständige Frakturerfassung andererseits erschwert. Anhand von Hochrechnungen aus anonymisierten Krankenkassendaten von 1,7 Millionen über 50-Jährigen aus den Jahren 2006 bis 2009 ergaben sich für das Jahr 2009 jedoch deutschlandweit 6,3 Millionen Osteoporose-Patienten und eine Schätzung von 885000 Neuerkrankungen pro Jahr, wobei 52 Prozent der Betroffenen innerhalb des Beobachtungszeitraumes mindestens eine Fraktur erlitten (Hadji et al. 2013). Diese Zahlen lassen erahnen, welche sozioökonomische Bedeutung diesem Krankheitsbild zugrunde liegt, wobei die Dunkelziffer der von der Erkrankung Betroffenen noch höher liegen dürfte. Aufgrund des demographischen Wandels ist von einer Zunahme der 
Schenkelhalsfrakturen um das Drei- bis Fünffache bis zum Jahr 2050 im Vergleich zu 1990 auszugehen (Bonnaire et al. 2005).

Angesichts der erheblichen und tendenziell noch zunehmenden sozioökonomischen Bedeutung der Osteoporose erscheint eine detailliertere Auseinandersetzung mit der Erkrankung sinnvoll und geboten. Zur Erforschung ihrer pathophysiologischen Grundlagen und Erprobung neuer Therapieansätze hat sich dabei vor allem das ovarektomierte Nagetiermodell etabliert. Östrogenmangel-bedingte Knochenverluste konnten für dieses Modell bereits vielfach beobachtet werden (Wronski et al. 1985; Bagi et al. 1996; Ferretti et al. 2010; Yoon et al. 2012). Die Übertragbarkeit der am Nagetiermodell gewonnenen Erkenntnisse auf den Menschen ist jedoch begrenzt. So sind die Knochen von Nagetieren offensichtlich einer wesentlich geringeren Belastung ausgesetzt als die des Menschen. Weiterhin unterliegen Teile des Skelettsystems der Ratte einem kontinuierlichen Wachstumsprozess (Lelovas et al. 2008), während sich die humanen Epiphysenfugen im Zuge der Adoleszenz vollständig schließen. Auch für das kortikale Remodeling wurden vielfach grundlegende Unterschiede zwischen Mensch und Ratte beschrieben (Jee und Yao 2001; Reinwald und Burr 2008; Lelovas et al. 2008).

Die beschriebene Problematik lässt sich in weiten Teilen durch den Einsatz von Großtiermodellen umgehen, die in vielerlei Hinsicht besser auf den Menschen übertragbar sind. Ein Beispiel für ein solches Großtiermodell stellt das Göttinger Minischwein dar. Hierbei handelt es sich um ein in den 1960er-Jahren an der Universität Göttingen entwickeltes Tiermodell (Larzul 2013), das durch einen proportionalen Minderwuchs charakterisiert ist, also eine Größenreduktion aller Körperteile bei weitgehend erhaltenen Proportionen (Simianer und Köhn 2010). Es weist viele anatomische und physiologische Ähnlichkeiten zum Menschen auf, ist einfach zu handhaben und sein Einsatz ruft weniger ethische Bedenken hervor als der anderer traditioneller Nicht-Nagetier-Modelle (Jeppesen und Skydsgaard 2015). Das Göttinger Minischwein wurde bereits für Untersuchungen auf verschiedensten Gebieten herangezogen (Lange et al. 1997; Debus et al. 1999; Laube et al. 2003; Larena-Avellaneda et al. 2004; Würzler et al. 2004). Die Anzahl an Studien, die sich den Grundlagen seines ossären Stoffwechsels widmen, ist allerdings sehr überschaubar. Zwar wurden ovarektomierte Mini- und Mikroschweine im Allgemeinen durchaus schon mehrfach als Tiermodelle in der Osteoporoseforschung eingesetzt, die dabei gemachten Beobachtungen sind aber nicht immer einheitlich (Mosekilde et al. 1993b; Borah et al. 2002; Kim et al. 2013). Auch sind die Auswirkungen eines Östrogenmangels auf den Knochenstoffwechsel am Schwein bei weitem nicht so umfassend erforscht wie am Rattenmodell. 
Ziel dieser Arbeit war es daher, die der Osteoporose zugrundeliegenden pathophysiologischen Prozesse hinsichtlich zeitlicher und topographischer Aspekte am ovarektomierten Großtiermodell des Göttinger Minischweines genauer zu untersuchen und die Eignung dieses Tiermodells für die Erforschung der Osteoporose zu überprüfen.

Im Fokus der Untersuchungen sollte dabei insbesondere das kortikale Remodeling unter Östrogenmangel stehen. Hierzu wurden eine laborchemische Verlaufsanalyse ausgewählter Knochenumsatzmarker sowie eine polychrome Sequenzmarkierung durchgeführt. Außerdem erfolgte eine osteodensitometrische Untersuchung mittels peripherer quantitativer Computertomographie (pQCT). 


\section{Grundlagen}

\subsection{Der Knochen}

Mit dem Begriff „Osteologie“ wird das die Knochenerkrankungen betreffende Fachwissen umschrieben, ein interdisziplinäres Wissensgebiet (Jakob et al. 2016). Die Beschäftigung mit Skeletterkrankungen und die Behandlung von Frakturen hat in vielen Kulturen eine jahrtausendealte Tradition, doch in den letzten 100 Jahren hat sich die osteologische Forschung besonders rapide entwickelt (Gotte 2001). Das ist zum einen ganz allgemein auf die enormen medizinischen Innovationen dieser Zeit zurückzuführen, zum anderen aber auch auf die zunehmende Relevanz ossärer Pathologien in einer alternden Gesellschaft und das daraus erwachsene Interesse an ihrer Behandlung. Erkrankungen des Knochens und der Gelenke stellen heute die weltweit häufigste Ursache für chronische Schmerzen und körperliche Funktionsbeeinträchtigungen dar (Lange 2006). Dieser Bedeutung trug die Weltgesundheitsorganisation WHO Rechnung und rief im Jahr 2000 das Knochen- und Gelenkjahrzehnt aus (The Bone and Joint Decade) (Lange 2006). Auch nach Ablauf dieses Jahrzehnts hat die Osteologie ihre herausragende Bedeutung als ein wichtiger und sich stark entwickelnder Sektor der Medizin (Roth et al. 2015) nicht verloren. Es ist zu erwarten, dass ungelöste osteologische Fragestellungen auch in Zukunft zu den wesentlichen Herausforderungen der Orthopädie gehören (Gotte 2001).

\subsubsection{Aufbau und Funktion des Röhrenknochens}

In Anbetracht der zunehmenden Bedeutung des Knochens erscheint es lohnend, sich seinen anatomischen Aufbau zu vergegenwärtigen:

Am Röhrenknochen eines erwachsenen Menschen unterscheidet man die mittig liegende, röhrenförmige Diaphyse von den sich an ihrem proximalen und distalen Ende jeweils anschließenden Meta- und Epiphysen. Die äußere Begrenzung des Knochens stellt dabei die vom Periost umgebene Kortikalis oder Substantia compacta dar, die vor allem im Bereich der Diaphyse stark ausgeprägt ist und mit ihrer hohen Dichte in besonderem Maße für die mechanische Belastbarkeit verantwortlich ist. Unterhalb der Kortikalis und von dieser umhült befindet sich die Substantia spongiosa. Diese besteht aus trabekulärem Knochen, dem sich die innere Knochenhaut, das Endost, auflegt. Die Spongiosa ist insbesondere in den Epiphysen zu finden und wird vom die hämatopoe- 
tischen Stammzellen enthaltenden roten Knochenmark umgeben. Beim Erwachsenen findet sich das rote Knochenmark nur noch in den Epiphysen, da es in den Diaphysen bereits weitgehend vom gelben Knochenmark, dem sogenannten Fettmark, verdrängt worden ist.

Der reife humane Knochen mit der zuvor beschriebenen Differenzierung zwischen Kortikalis und Spongiosa wird als Lamellenknochen bezeichnet. Im Gegensatz zum noch unreifen Geflechtknochen, der im Rahmen fetaler Knochenbildungsprozesse sowie bei der Frakturheilung zunächst entsteht, besitzt Lamellenknochen eine geordnete Struktur und erreicht dadurch eine wesentlich höhere Belastbarkeit (Abbildung 1).

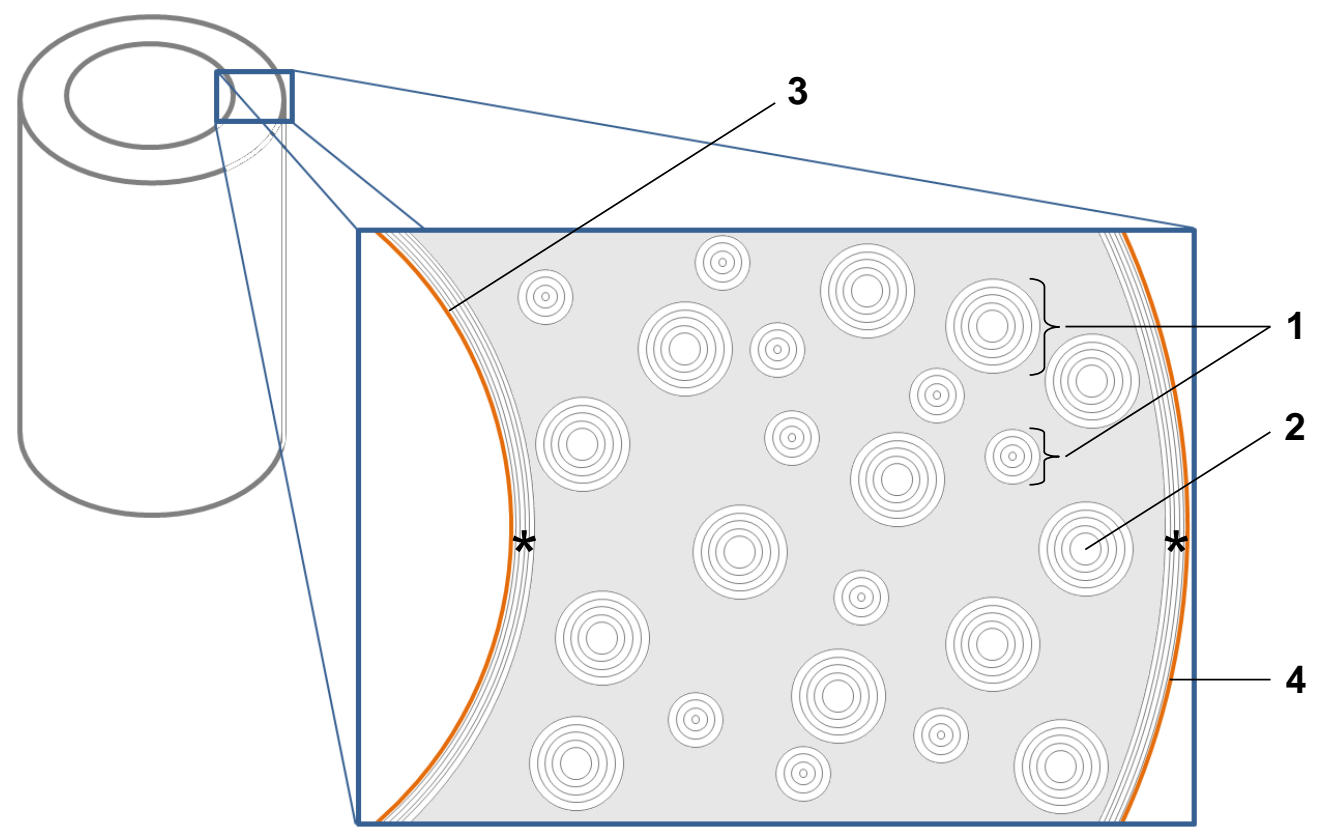

Abb. 1: Schematische Darstellung eines Röhrenknochens. Die Ausschnittsvergrößerung zeigt einen Querschnitt durch die diaphysäre Kortikalis. Die angeschnittenen Osteone (1) sind als konzentrische Kreise mit zentral verlaufendem Havers-Kanal (2) dargestellt. Zwischen den einzelnen Osteonen liegen die Schaltlamellen (graue Fläche). Der Richtung Markhöhle beziehungsweise Peripherie abschließenden inneren und äußeren Generallamelle (jeweils mit Stern markiert) legt sich das Endost (3) beziehungsweise Periost (4) auf. 
Die Belastbarkeit des reifen Knochens beruht auf dem Zusammenwirken seiner beiden Hauptbestandteile: Einem vor allem durch Kollagen geprägten organischen Grundgerüst einerseits und einem anorganischen Mineralanteil andererseits. Der Mineralanteil macht etwa 70 Prozent des Knochens aus und besteht größtenteils aus Calcium und Phosphat in Form eines Salzes mit hydroxylapatitähnlicher Struktur (Issever und Link 2011). Im Rahmen der Knochenbildung wird von den zuständigen Zellen, den Osteoblasten, zunächst jedoch nur das sogenannte Osteoid sezerniert, die vorläufige kollagenhaltige Knochengrundsubstanz, die erst im späteren Verlauf mineralisiert wird. Durch die Kombination von organischer Matrix und anorganischem Mineralsalzanteil wird dann die für den Knochen charakteristische Stabilität und Elastizität erreicht.

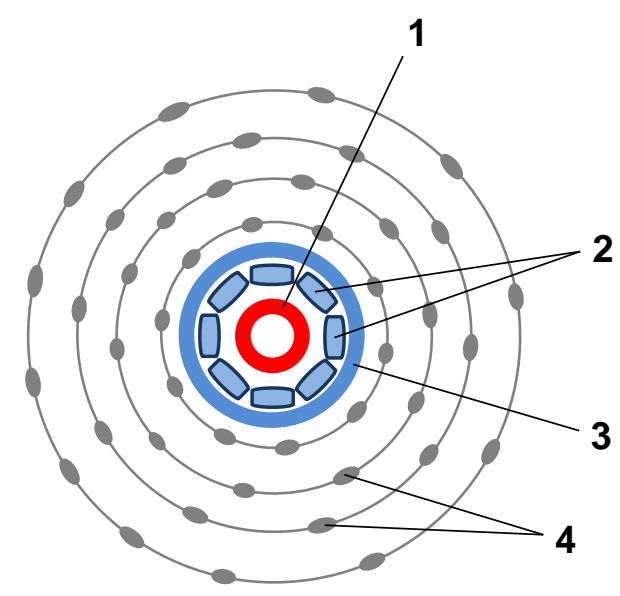

Abb. 2: Schematischer Aufbau eines Osteons. Von zentral nach peripher sind dargestellt: 1: Havers-Gefäß, 2: Osteoblasten, 3: Osteoid, 4: Osteozyten

Feingeweblich betrachtet ist die Kortikalis des lamellären Knochens in Längsrichtung von zahlreichen feinen Kanälen durchzogen, den sogenannten Havers-Kanälen. Hierbei handelt es sich um die Hinterlassenschaften von sich durch die Knochenmatrix fressenden Osteoklasten, den mehrkernigen, auf Knochenresorption spezialisierten Zellen des ossären Systems. Die einzelnen Havers-Kanäle führen Blutgefäße und sind durch quer verlaufende Kanäle, die als Volkmann-Kanäle bezeichnet werden, untereinander sowie mit ihrer Umgebung verbunden. Im histologischen Querschnitt durch die Kortikalis sind die Havers-Kanäle als Zentren der sogenannten Osteone zu erkennen. 
Diese umfassen den zentral verlaufenden Kanal und die inn konzentrisch umgebenden Knochenlamellen (Abbildung 2). Die Knochenlamellen werden dabei durch an der Innenwand des Resorptionskanals sitzende Osteoblasten allmählich von peripher nach zentral gebildet. Im Zuge der Knochenbildung lagern die Osteoblasten das bereits erwähnte Osteoid schichtweise ab und werden dabei nach und nach selbst eingemauert. Die eingemauerten Osteoblasten werden später Osteozyten genannt und stehen durch feine Kanälchen, die sogenannten Canaliculi, untereinander in Verbindung. Zwischen den einzelnen Osteonen finden sich unvollständige Knochenlamellen älterer, bereits teilweise wieder resorbierter Osteone. Diese werden als Schaltlamellen bezeichnet. Nach außen sowie innen schließt die Kortikalis jeweils mit einer die gesamte Zirkumferenz umgebenden Generallamelle ab.

Der Kortikalis legt sich außen das Periost an. Der unmittelbar unterhalb dieser dünnen ossären Haut liegende Knochen wird daher auch periostaler Knochen genannt. Der zur Markhöhle hin gelegene oberflächliche kortikale Knochen wird nomenklatorisch als endokortikaler Knochen bezeichnet (Dempster et al. 2013) und seinerseits dort, wo er nicht direkt in die Spongiosa übergeht, von Endost bedeckt. Der endokortikale Knochen und die ebenfalls von Endost umgebenen spongiösen Knochenoberflächen werden unter dem Begriff des endostalen Knochens zusammengefasst (Dempster et al. 2013). Bei Peri- und Endost handelt es sich um dünne Knochenhäute, die unter anderem Vorläuferzellen für die Knochenbildung enthalten. Auf den trabekulären Knochenoberflächen der Spongiosa ist eine weitere Zellart des skelettalen Systems zu finden, die zytoplasmaarmen, auch als bone lining cells bezeichneten Knochenbelegzellen. Ihre konkrete Funktion ist bislang nicht eindeutig geklärt. Neben einer möglichen Beteiligung an katabolen Prozessen wird innen allerdings eine Membranfunktion zwischen flüssigem Knochenkompartiment und Extrazellularflüssigkeit des Knochenmarks sowie eine Rolle in der Signalübertragung zwischen Osteozytennetzwerk und Osteoklasten zugeschrieben (Dierkes et al. 2009).

Die Belastbarkeit eines Knochens ist nicht als eine vorgegebene, konstante Größe zu verstehen. Seine innere Architektur und äußere Form passen sich vielmehr den je nach Inanspruchnahme auf ihn einwirkenden Kräften an, wie Wolff bereits 1892 festgestellt und in seinem "Gesetz der Transformation der Knochen“ erklärt hatte. Man weiß heute, dass diese Anpassung durch eine kontinuierliche Veränderung der skelettalen Mikroarchitektur im Sinne eines ständigen Remodelings gelingt. Es handelt sich dabei um einen umfassenden Prozess, der im Erwachsenenalter jährlich circa acht bis zehn Prozent des Skeletts betrifft (Bartl 2012; Kanis 2010). Die zuvor geschil- 
derte fortlaufende Ausbildung neuer Osteone innerhalb der Substantia compacta ist dabei als intrakortikales Remodeling zu verstehen, das häufig auch als osteonales Remodeling bezeichnet wird. Aber auch die Spongiosa unterliegt einem kontinuierlichen Umbauprozess. Im Zuge dessen werden die Trabekel durch Knochenresorption und -neubildung entlang der innerhalb des Knochens verlaufenden Hauptbelastungslinien trajektoriell ausgerichtet. Der beschriebene Prozess läuft prinzipiell in beide Richtungen ab: Eine vermehrte Belastung im Rahmen eines körperlichen Trainings kann also ebenso zur Ausbildung zusätzlicher Trabekel führen wie eine längere körperliche Inaktivität eine Verringerung der Trabekelzahl zur Folge haben wird.

Abgesehen vom Einfluss körperlicher Belastung spielen auch der Calcium- und Phosphathaushalt sowie die kalzitropen Hormone Vitamin D und Parathormon (PTH) im Knochenstoffwechsel eine wichtige Rolle. Entscheidend sind daher neben genetischen Faktoren und dem Ausmaß der körperlichen Belastung indirekt auch Aspekte wie Ernährung, Nährstoffaufnahme, Nierenfunktion oder sogar Lichtexposition. Bei Betrachtung der hormonellen Einflussnahme auf den Knochenstoffwechsels darf neben den kalzitropen Hormonen auch die weitreichende Rolle weiblicher Geschlechtshormone

nicht unerwähnt bleiben: Östrogene senken den Knochenumsatz, verbessern die Calciumabsorption und reduzieren die Calciumausscheidung, was eine erhöhte Knochendichte und ein vermindertes Frakturrisiko zur Folge hat (Schulte 1997).

Im Laufe des Lebens nimmt mit dem Wachstum auch die Knochenmasse zunächst bis zu einem bestimmten Maximalwert zu, der sogenannten peak bone mass (PBM). Diese wird von Behre et al. als „die individuelle, im Laufe des Lebens, spätestens bis zum 35. Lebensjahr, erworbene maximale Knochenmasse“ (Behre et al 2001, S. 378) beschrieben. 80 Prozent der maximal erreichten Knochendichte sind dabei genetisch bedingt (Bartl 2012). Nach Erreichen der PBM ist mit zunehmendem Alter ein gewisser kontinuierlicher Verlust an Knochenmasse als physiologisch anzusehen. So wird die Knochenmasse eines Gesunden ab dem 35. Lebensjahr jährlich um circa ein Prozent reduziert (Förtsch et al. 2014). Wenn diese Reduktion der Knochenmasse jedoch wesentlich höher ausfällt als üblich und ein pathologisches Ausmaß erreicht, so spricht man von Osteoporose.

\subsubsection{Knochenpathologie}

Genau wie die anderen Funktionseinheiten des Körpers kann auch der Knochen von vielfältigen Pathologien betroffen sein. Die vermutlich greifbarste von innen stellt die Fraktur dar. In ihrer Folge kann der Knochen seiner Rolle als Stützorgan nicht mehr 
adäquat nachkommen, möglich sind außerdem massive Blutverluste, Infektionen oder persistierende Funktionsstörungen nach inadäquater Frakturheilung.

Das skelettale System kann aber auch schon während seiner Entwicklung diversen Störungen unterliegen. Hierzu zählen unter anderem die Skelettdysplasien. Diese meist genetisch bedingten Erkrankungen können schon in frühen Entwicklungsjahren als Wachstumsstörungen in Erscheinung treten. Sie gehen typischerweise mit für die jeweilige Erkrankung charakteristischen Proportionsstörungen einher. Als Beispiel sei der extremitätenbetonte Minderwuchs bei Achondroplasie genannt.

Am Knochen können sich auch zahlreiche unterschiedliche Malignome manifestieren, deren Identifizierung und Behandlung aufgrund ihrer niedrigen Inzidenz und der häufig schwierigen Differentialdiagnose in der Regel dem Spezialisten vorbehalten bleibt. Wesentlich häufiger als die primären Knochentumoren sind sekundäre ossäre Metastasen, die als Absiedlungen maligner Prozesse anderen Organsystemen entstammen. Sie können eine verminderte Belastbarkeit und ein erhöhtes Frakturrisiko der betroffenen Knochen zur Folge haben.

Kommt es aufgrund eines Vitamin-D-Mangels zu einer gestörten Knochenmineralisation, so ist bei Kindern von Rachitis die Rede, bei Erwachsenen von Osteomalazie. Knochenschmerzen und -verformungen sind die Folge. Zahlreiche weitere renale und endokrine Funktionsstörungen manifestieren sich ebenfalls am Knochen, ihre Aufzählung würde den hier gesetzten Rahmen sprengen.

Unter allen osteologischen Krankheitsbildern kommt die bei weitem größte sozioökonomische Bedeutung der Osteoporose zu. Sie ist maßgeblich an der Entstehung vieler Frakturen beteiligt. Die Osteoporose betrifft deutschlandweit etwa zehn Prozent der Bevölkerung und stellt damit eine Volkskrankheit dar, deren Prävalenz infolge des demographischen Wandels auch in Zukunft weiter ansteigen wird (Förtsch et al. 2014).

\subsection{Osteoporose}

Die Leitlinie des Dachverbands Osteologie e.V. (DVO) aus dem Jahr 2014 definiert die Osteoporose als „eine systemische Skeletterkrankung, die durch eine niedrige Knochenmasse und eine mikroarchitektonische Verschlechterung des Knochengewebes charakterisiert ist, mit einem konsekutiven Anstieg der Knochenfragilität und der Neigung zu Frakturen“ (Leitlinie Osteoporose 2014, S. 18). Sie bezieht sich dabei auf die 
Consensus Development Conference von 1993 und Kanis (2007). Diese quantitative und qualitative Beeinträchtigung des osteoporotischen Knochens wird charakteristischerweise erst im Rahmen eines Frakturereignisses auffällig, von dem an per definitionem von einer manifesten Osteoporose zu sprechen ist (Jakob 2005).

Am häufigsten sind Frauen nach der Menopause von der Osteoporose betroffen. Im Rahmen dieser postmenopausalen oder auch Typ-I-Osteoporose genannten Form treten innerhalb von drei bis vier Jahren nach Menopauseneintritt ausgeprägte Knochenmasseverluste auf, die sich 15-20 Jahre später auch klinisch in Form von Frakturen manifestieren können (Mikosch und Gosch 2013). In Deutschland kommt es bei etwa 25 Prozent der über 50-jährigen Frauen zu einer Osteoporose (Dören und Schneider 1996). Von einer senilen oder Typ-II-Osteoporose spricht man bei sich nach dem 70. bis 75. Lebensjahr entwickelnden Erkrankungsformen (Pietschmann und Peterlik 1999). Sie betrifft Frauen doppelt so häufig wie Männer und kann durch eine altersbedingte unzureichende Vitamin-D3-Synthese sowie genetische Faktoren bedingt sein (Schmolke 2001). Die Unterscheidung zwischen den beiden Osteoporosetypen spielt im klinischen Altag eine untergeordnete Rolle. Gemeinsam mit der seltenen idiopathischen Osteoporose, welche bei Kindern beziehungsweise jungen Erwachsenen beider Geschlechter trotz unauffälliger Gonadenfunktion auftritt (Schmolke 2001), bilden Typ-I- und Typ-II-Osteoporose die Gruppe der primären Osteoporosen (Abbildung $3)$.

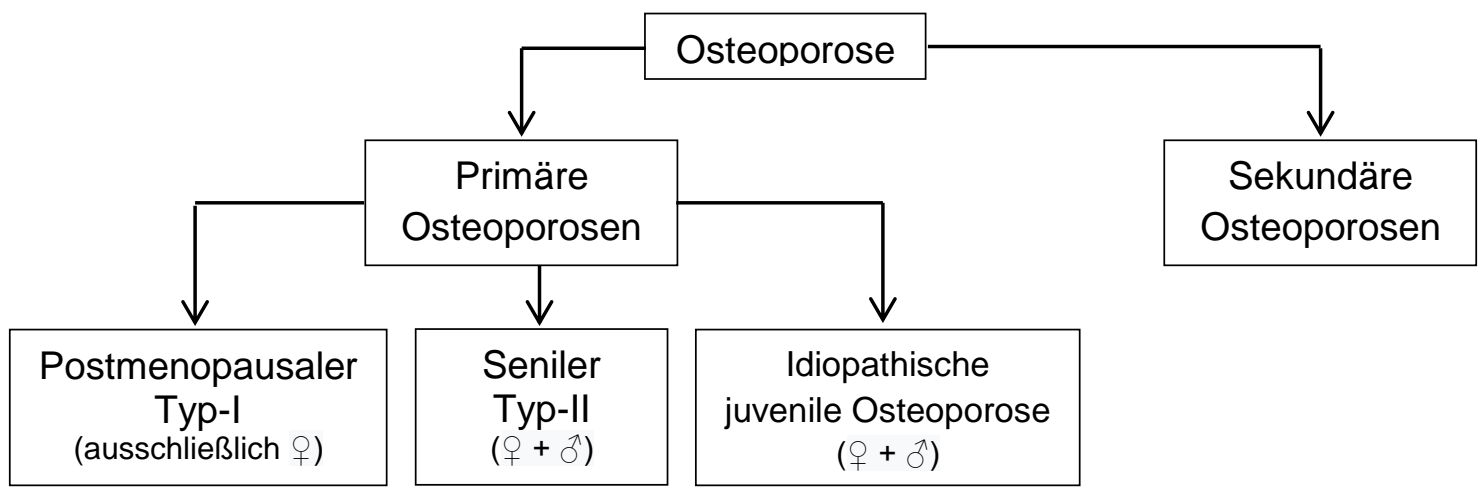

Abb. 3: Schematische Einteilung der Osteoporoseformen. 
Von diesen abzugrenzen sind die sekundären Osteoporosen, bei denen der dominierende zur Osteoporose führende Pathomechanismus auf anderweitigen definierten Erkrankungen beruht (Jakob 2005). Auch körperliche Inaktivität, Medikamenteneinnahmen, ein gesteigerter Alkoholkonsum oder eine gestörte Nährstoffaufnahme können dieser Erkrankungsform zugrunde liegen. Die sekundären Osteoporosen bedürfen zumeist primär einer Behandlung der jeweiligen Grunderkrankung. Eine der Therapie vorausgehende laborchemische Differenzialdiagnostik spielt in diesen Fällen deshalb eine herausragende Rolle (Kyvernitakis und Hadji 2016). Insgesamt sind sekundäre Osteoporosen aber nur für weniger als fünf Prozent aller Osteoporosefälle verantwortlich (Schmolke 2001). In dieser Arbeit soll es vor allem um die viel häufigere postmenopausale Typ-I-Osteoporose gehen, die hier auch - soweit nicht explizit anders erwähnt - mit dem Begriff „Osteoporose“ gemeint ist.

\subsubsection{Pathophysiologie und Klinik}

Im Knochen eines gesunden Erwachsenen finden ständig parallel Auf- und Abbauprozesse statt. Diese haben Reparaturvorgänge zur Erhaltung der Knochenstabilität zum Ziel sowie eine Anpassung des Knochens an die auf inn einwirkenden Kräfte. Im Normalfall halten sich Auf- und Abbauprozesse die Waage, so dass die Knochenmasse als weitgehend konstant angesehen werden kann. Kommt es jedoch zu Störungen dieses Gleichgewichts, kann eine Abnahme der Knochenmasse resultieren.

Bereits 1963 sahen Bassan et al. die Ursache der im Zuge einer Osteoporose verringerten Knochenmasse in einem Ungleichgewicht zwischen Knochenbildung und -resorption. Für Behre et al. (2001) ist die Entstehung der Osteoporose in erster Linie auf eine verminderte PBM und eine erhöhte Knochenresorption zurückzuführen. Sie bringen damit zum Ausdruck, dass im Rahmen resorptiver Prozesse gleichen AusmaBes eine pathologisch reduzierte Knochenmasse bei einer Person mit ohnehin schon geringer Ausgangsmasse wesentlich schneller erreicht wird als bei einer mit einem höheren Ausgangswert.

Die postmenopausale Osteoporose manifestiert sich im namensgebenden Lebensabschnitt. Ursächlich für die Erkrankung ist der innerhalb der frühen postmenopausalen Jahre erheblich reduzierte Östrogenspiegel, der den Knochenumsatz beschleunigt und einen vorhersehbaren Anstoß für den Knochenverlust darstellt (Reinwald und Burr 2008). Dies liegt daran, dass im Rahmen der beschleunigten Umsatzrate die Osteoklastenaktivität gegenüber der der Osteoblasten netto überwiegt (Kanis 2010). Des Weiteren bewirkt der zugrundeliegende Östrogenmangel eine verkürzte Lebensdauer 
der Osteoblasten sowie eine gesteigerte Apoptose von Osteozyten (Siggelkow 2015). Die resultierende Störung des Knochenstoffwechsels zeigt sich dabei in Form einer verringerten Knochenfestigkeit zuerst an spongiosareichen Knochen wie den Wirbelkörpern, da die Spongiosa ein besonders stoffwechselaktives Knochenkompartiment darstellt (Kasperk 2008).

Die durch Osteoporose verringerte Knochenfestigkeit macht sich im Altag zunächst nicht bemerkbar. Klinische Beschwerden sind typischerweise erst im Rahmen osteoporoseinduzierter Frakturen zu erwarten (Schulte 1997). Die erkrankungsbedingten Frakturen treten dabei meist an den Wirbelkörpern des oberen Lumbalbereichs, am Oberschenkelhals oder am Radius im Zuge nicht-adäquater Traumata auf (Kasperk 2008). Deutschlandweit sind jährlich allein circa 85000 Schenkelhalsfrakturen ohne adäquates Trauma zu verzeichnen (Schulte 1997), alle zwei bis drei Minuten kommt es zu einer neuen Wirbelkörperfraktur (Kurth und Pfeilschifter 2007).

Neben der Bedeutung der Fraktur als akutes und einschneidendes Ereignis sind auch langfristige Beeinträchtigungen wie chronische Schmerzen infolge der anatomischen Veränderungen von Relevanz. Diese spielen insbesondere bei den häufigen, aber oft übersehenen osteoporotischen Wirbelkörperfrakturen eine Rolle. Als Hinweis auf derartige Frakturereignisse ist eine Verringerung der Körpergröße um mehr als $4 \mathrm{~cm} z u$ werten (Därr et al. 2008). In der Folge können dorsale Hautfalten in Form des sogenannten Tannenbaumphänomens und eine als „Witwenbuckel“ bezeichnete Hyperkyphosierung der Brustwirbelsäule auftreten (Issever und Link 2011). Von klinischer Relevanz sind letztlich allerdings weniger die geschilderten Symptome selbst sondern vielmehr die mit innen verbundenen Schmerzen und die aus innen resultierenden Funktionsstörungen. So kann ein frakturbedingt verringerter Rippenbogen-BeckenAbstand aufgrund einer Kompression des Bauchraumes mit abdominellen Beschwerden verbunden sein (Kasperk 2008). Auch kardiopulmonale Symptome sind infolge multipler Wirbelkörperfrakturen möglich. Osteoporosebedingte anatomische Verformungen können insofern erhebliche funktionelle Einschränkungen zur Folge haben (Dimai 2009), die in vielen Fällen den Alltag der Patienten durch chronische Schmerzen beeinträchtigen. Insbesondere die Wirbelsäulenosteoporose ist häufig durch einen Verlust an Lebensqualität charakterisiert (Scheidt-Nave 2001). 


\subsubsection{Diagnostik}

Für den einzelnen Patienten beschreibt Kasperk (2008) den Begriff der „Osteoporose“ zunächst als ein Symptom, welches als Hinweis auf eine verringerte Knochenfestigkeit zu verstehen sei und aus dem erst nach Ausschluss anderweitiger Grunderkrankungen eine Diagnose werde. Für diesen Schritt ist folglich eine entsprechende Diagnostik notwendig. Diese Osteoporosediagnostik basiert auf fünf Hauptsäulen, die von anamnestischer Risikoerfassung, klinischer Untersuchung, konventioneller Röntgendiagnostik, Knochendichtemessung und Labordiagnostik gebildet werden (Bieglmayer et al. 2012; Dimai 2009) (Abbildung 4).

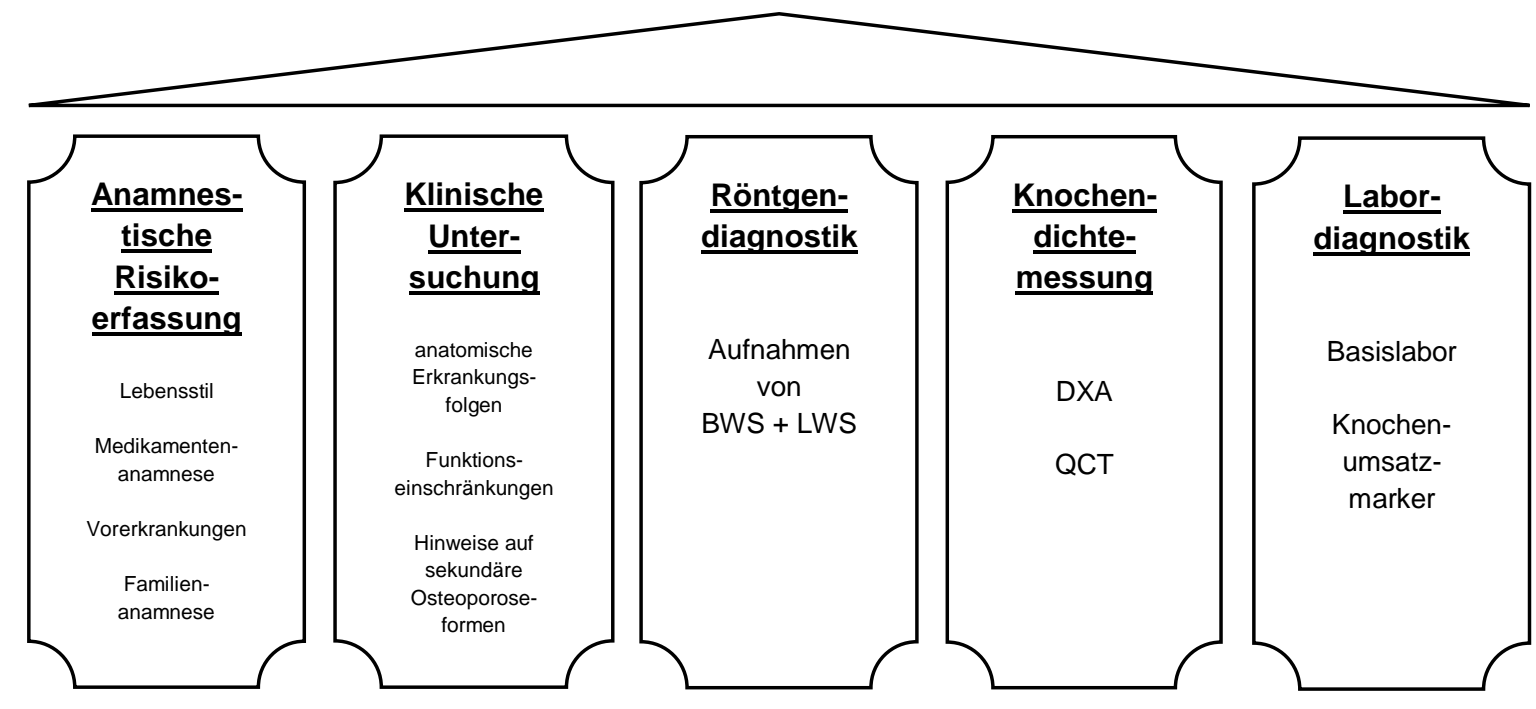

Abb. 4: Die fünf Säulen der Osteoporosediagnostik im Schema.

Eine ausführliche Anamnese sollte mit Fragen nach Lebensstil, Medikamenteneinnahme, Vorerkrankungen, Frakturen und familiärer Krankengeschichte das Risiko einer Osteoporoseerkrankung ermitteln. Wirbelsäulenbeschwerden und vor allem eine deutliche Abnahme der Körpergröße können wichtige anamnestische Hinweise auf eine manifeste Osteoporose sein. Bei der Anamneseerhebung können auch standardisierte krankheitsbezogene Fragebögen zum Einsatz kommen, wie das computerbasierte Fracture Risk Assessment Tool (FRAX). Dieses wurde von der WHO entwickelt und ermöglicht die Berechnung der individuellen Zehn-Jahres-Wahrscheinlichkeit für das Auftreten einer großen osteoporoseinduzierten Fraktur anhand leicht zu erfassender klinischer Risikofaktoren (Kanis et al. 2016). 
An die Anamnese sollte sich eine umfassende klinische Untersuchung insbesondere des Rückens und der Wirbelsäule anschließen: Die bereits erwähnten sich von der Dornfortsatzreihe aus beiderseits nach laterokaudal ausbreitenden Hautfalten im Sinne eines Tannenbaumphänomens sind charakteristisch für eine osteoporosebedingte Höhenabnahme der Wirbelkörper. Auch ein ausgeprägter Rundrücken mit vermehrter Kyphosierung der Brustwirbelsäule weist oft auf eine osteoporotische Wirbelkörpersinterung hin, ebenso wie ein verminderter Abstand zwischen Rippenbogen und Beckenkamm oder ein verstärkt hervortretendes Abdomen. Eine frische osteoporotische Wirbelfraktur kann gegebenenfalls durch einen im Bereich des entsprechenden Wirbelsäulenabschnittes provozierbaren Klopf- beziehungsweise Stauchungsschmerz lokalisiert werden.

Bei durch Anamnese oder klinische Untersuchung begründetem Osteoporoseverdacht sollten konventionelle Röntgenaufnahmen der Brust- und Lendenwirbelsäule angefertigt werden. Sie erlauben eine eindeutige Identifizierung osteoporotischer Wirbelkörperfrakturen. Die entsprechenden radiologischen Korrelate reichen von einer gesteigerten Bikonkavität der Wirbelkörper bis hin zur Flachwirbelbildung als Folge eines vollständigen Wirbelkollapses (Jergas und Schmid 1999). Auch lediglich geringfügige Höhenminderungen der Wirbel sind möglich. Eine vermehrte Strahlentransparenz der Wirbelkörper mit rahmenartiger Betonung der Wirbelkonturen und Akzentuierung vertikaler Trabekelstrukturen kann gegebenenfalls schon vor der Manifestation von Wirbelfrakturen auf eine verminderte Knochenmasse im Sinne einer Osteopenie hinweisen, ihre Beurteilung unterliegt jedoch wesentlich der subjektiven Einschätzung des Betrachters.

Eine besondere Bedeutung kommt im Rahmen der Osteoporosediagnostik der Knochendichtemessung zu. Für ihre Durchführung stehen verschiedene Messmethoden zur Verfügung. Die Zwei-Spektren-Röntgenabsorptiometrie beziehungsweise dualenergy $x$-ray absorptiometry (DXA) stellt allerdings den diagnostischen Goldstandard für die Osteoporose dar (Kyvernitakis und Hadji 2016). Untersucht werden dabei in der Regel die Lendenwirbelsäule und das proximale Femur. Die sich beim Vergleich der jeweiligen Knochendichte mit der eines jungen Referenzpatientenkollektivs ergebenden Standardabweichungen werden als sogenannter T-Score bezeichnet. Unter Rückgriff auf die Referenzpopulation des National Health and Nutrition Examination Survey III hat die WHO diagnostische Schwellenwerte für den T-Score festgelegt und damit definiert, ab wann eine mittels DXA gemessene Knochendichte als osteopen oder als osteoporotisch zu bezeichnen ist (Issever und Link 2011). Eine Diagnosestellung, die sich allein auf die osteodensitometrischen Ergebnisse stützt, ist jedoch nicht ratsam. 
Vielmehr sollte eine reduzierte Knochendichte als Risikofaktor für eine osteoporotische Fraktur gesehen und stets in Relation zu weiteren Risikofaktoren wie beispielsweise Geschlecht, Alter und bereits erlittener Frakturen gesetzt werden (Rintelen 2016).

Bei Nachweis einer deutlich reduzierten Knochendichte wird eine weiterführende labormedizinische Diagnostik erforderlich. Das dabei eingesetzte Basislabor hat vor allem einen Ausschluss eventueller sekundärer Osteoporoseformen sowie anderweitiger Osteopathien zum Ziel (Lange et al. 2011). Bei Vorliegen einer primären Osteoporose mit einer über Jahre hinweg gestörten Bilanz zwischen Knochenan- und -abbau ist die laborchemische Untersuchung dagegen meist unauffällig (Kasperk 2008). Für einen detaillierteren Einblick in die Dynamik der Knochenumbauvorgänge eignen sich darüber hinaus spezielle laborchemische Knochenstoffwechselmarker, auch Knochenumsatzmarker beziehungsweise bone turnover marker genannt. Hierunter werden üblicherweise im Blut oder Urin gemessene biochemische Produkte verstanden, welche die metabolische Knochenaktivität widerspiegeln, ohne selbst eine Rolle in der Kontrolle des skelettalen Stoffwechsels zu spielen (Vasikaran et al. 2011b). Der klinische Einsatz dieser Biomarker hat in den letzten Jahren zugenommen (Obermayer-Pietsch und Schwetz 2016). Ohne selbst krankheitsspezifisch zu sein geben sie Einblick in die Dynamik von Knochenauf- oder -abbau, spielen eine Rolle für therapeutische Überlegungen und können zudem auch im Zuge eines Therapiemonitorings eingesetzt werden (Schulte 1997).

Weder DXA noch Knochenumsatzmarker sind für eine Einschätzung der Gesamtsituation jedoch allein ausreichend. Entscheidend ist vielmehr die zusätzliche Berücksichtigung der anamnestischen Informationen und Befunde in ihrer Gesamtheit, um ein individuelles Risikoprofil erstellen und anhand dessen eine Therapieentscheidung treffen zu können.

\subsubsection{Therapie und Prävention}

Mit Hilfe einer antiosteoporotischen Therapie können heutzutage im Mittel 50 Prozent der osteoporoseassoziierten Frakturen verhindert werden (Siggelkow 2015). Sie umfasst mittlerweile eine Vielzahl an Wirkstoffklassen und Präparaten mit unterschiedlichen Ansatzpunkten (Abbildung 5). Je nach eingesetztem Medikament beruht der therapeutische Effekt entweder vermehrt auf einer Hemmung der Knochenresorption oder auf einer Förderung der Knochenneubildung. Da es sich bei der Osteoporose um eine chronische Erkrankung handelt, stellt auch ihre Behandlung eine Langzeittherapie dar, welche im Zuge eines antiresorptiven Ansatzes nach Frakturereignis beispielsweise für 
mindestens drei bis vier Jahre angesetzt werden sollte (Kyvernitakis und Hadji 2016). Voraussetzung für eine erfolgreiche spezifische Osteoporosetherapie sind dabei stets eine Sturzprophylaxe und eine Basistherapie (Förtsch et al. 2014).

Eine ausreichende Zufuhr von Calcium und Vitamin D sind sowohl für die Prävention als auch für die Therapie der Osteoporose essentiell. Die sogenannte Basistherapie stellt eine Supplementationstherapie dar, die die Sicherstellung der täglichen Aufnahme von 1000 mg Calcium und 1000 bis 2000 Internationalen Einheiten (IE) Vitamin D zum Ziel hat (Kyvernitakis und Hadji 2016). Dabei ist eine Calciumzufuhr in Form einer calciumreichen Ernährung bei normalem Ernährungsverhalten ausreichend (Förtsch et al. 2014), eine zusätzliche Supplementierung sollte nur durchgeführt werden, falls eine entsprechende Zufuhr über die Nahrung nicht möglich ist (Ziller 2013).

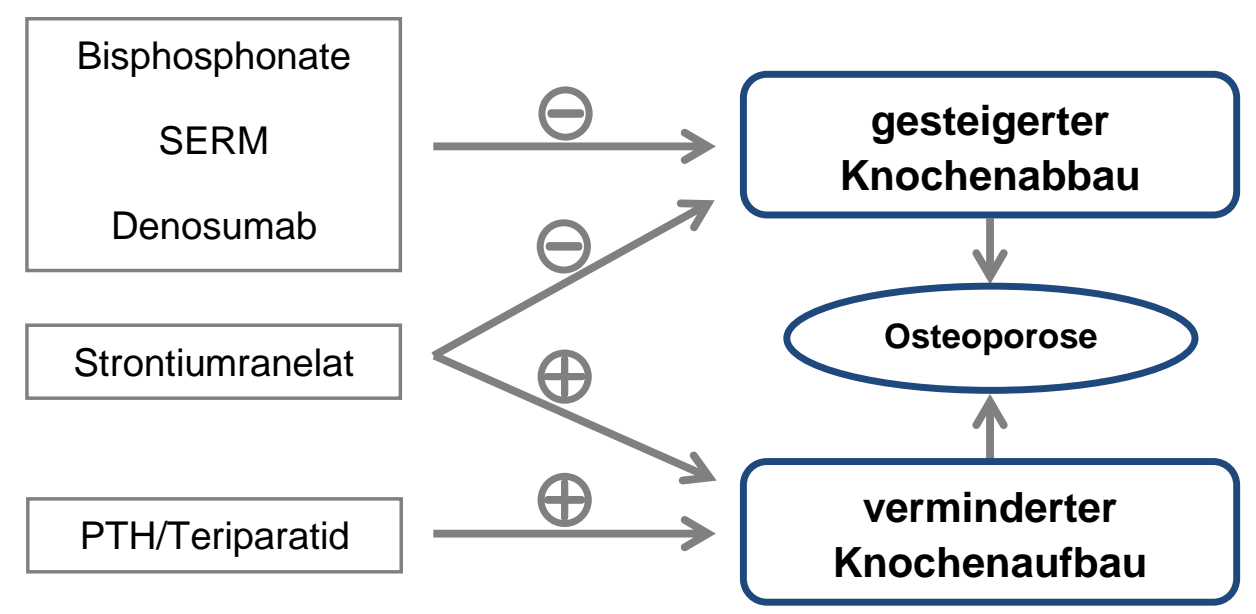

Abb. 5: Schematische Darstellung häufig angewandter Medikamente in der spezifischen Osteoporosetherapie mit ihren pharmakologischen Ansatzpunkten.

Wenn eine über die Basistherapie hinausgehende, spezifische medikamentöse Osteoporosetherapie erforderlich ist, so werden heute bei weitem am häufigsten Bisphosphonate eingesetzt. Sie bewirken vorwiegend eine Hemmung der Osteoklasten und werden daher zur Gruppe der Antiresorptiva gezählt. Aufgrund ihrer ausgeprägten Affinität zu Hydroxyapatit zeigen sie ein hochselektives Targeting des Knochengewebes (Scriba 2000). Verfügbar sind sowohl oral als auch parenteral applizierbare Präparate. 
Die Therapieintervalle unterscheiden sich zwischen den einzelnen Wirkstoffen sowie Applikationsformen deutlich. Nach einem Einnahmezeitraum von fünf bis sieben Jahren kann eine Therapieänderung oder -pause erwogen werden (Mikosch und Gosch 2013). Dies ist möglich, da die Substanzen langfristig im Knochen gebunden werden und auch nach Beendigung der Einnahme ihre Wirkung zunächst weiter entfalten können. Die Ausscheidung der Bisphosphonate erfolgt renal. Im Zuge einer eingeschränkten Nierenfunktion ist daher eine Dosisreduktion vorzunehmen (Scriba 2000).

Mit selektiven Östrogenrezeptormodulatoren (SERM) wie Raloxifen oder Bazedoxifen steht zur Behandlung der Osteoporose eine weitere Wirkstoffgruppe zur Verfügung. Diese Präparate wirken gewebespezifisch und zeigen am Knochen östrogenagonistische Effekte, während sie beispielsweise am Brustgewebe östrogenantagonistische Wirkungen entfalten (Kyvernitakis und Hadji 2016). Mit dem Einsatz von SERM in der Osteoporosetherapie lässt sich der progrediente Knochenmasseverlust im Zuge einer Osteoklastenhemmung umkehren, wodurch eine signifikante Reduktion vertebraler Frakturen erreicht werden konnte (Ziller 2013). Unter Raloxifen-Therapie ist jedoch gleichzeitig auch ein erhöhtes Risiko für thromboembolische Ereignisse zu beobachten (Preisinger 2014; Ziller 2013).

Strontiumranelat nimmt in gewisser Weise eine Sonderstellung unter den Antiosteoporotika ein. Durch seinen Einsatz wird sowohl die Knochenneubildung angeregt als auch die -resorption gehemmt (Birkhäuser 2013; Mikosch und Gosch 2013). Dieser Effekt wird dadurch erzielt, dass der Wirkstoff einerseits die Replikation von Osteoblastenvorstufen sowie die Bildung ossären Kollagens unterstützt, andererseits zugleich die Differenzierung von osteoklastären Vorstufen sowie die Aktivität reifer Osteoklasten hemmt (Dimai 2005). Wegen seines erhöhten kardiovaskulären Risikos ist es mittlerweile jedoch nur noch in Fällen einer schweren Osteoporose bei postmenopausalen Frauen und bei Männern mit hohem Frakturrisiko zugelassen, wenn alternative Therapeutika nicht infrage kommen (Neuerburg et al. 2015; Harbeck und Lehnert 2016).

Obwohl das physiologischerweise von der Nebenschilddrüse sezernierte Parathormon (PTH) normalerweise eine stimulierende Wirkung auf die Osteoklasten hat, kommt es auch in der Osteoporosetherapie zum Einsatz. Werden PTH oder sein Analogon Teriparatid nämlich pulsatil verabreicht, so lässt sich ein osteoanaboler Effekt erzielen (Mikosch und Gosch 2013). Dabei wirkt Teriparatid zu Therapiebeginn zunächst über eine Aktivierung ruhender Knochenbelegzellen, während es im weiteren Verlauf die Osteozytenapoptose hemmt und die Osteoblastenproliferation stimuliert (Kyvernitakis und Hadji 2016). Aufgrund ihrer hohen Therapiekosten sind Parathormonpeptide allerdings 
der Behandlung von Patienten mit besonders hohem Frakturrisiko vorbehalten (Kanis 2010).

Zu den neuesten Therapieoptionen gehört der monoklonale Antikörper Denosumab. Dieser ist gegen den receptor activator of nuclear factor $\kappa B$ ligand (RANKL) gerichtet und unterbricht somit die Interaktion zwischen RANKL und seinem Rezeptor, wodurch in der Folge die Entwicklung und Aktivierung von Osteoklasten gehemmt wird (Lange et al. 2011). Einer der Vorteile dieses Pharmakons ist, dass es auch bei eingeschränkter Nierenfunktion eingesetzt werden kann (Mikosch und Gosch 2013).

Menopausale Symptome sind die häufigste Ursache für die Einleitung einer Hormonersatztherapie (HRT) (Radkohl und Leb 1996). Unter Berücksichtigung der Ätiologie der Osteoporose stellt die HRT zunächst auch ein besonders naheliegendes Konzept zur Prävention und Therapie dieser Erkrankung dar. Tatsächlich können im Zuge der HRT verabreichte Östrogene den Knochenstoffwechsel verringern und die Knochendichte erhöhen (Ziller 2013). Das bei postmenopausalen Frauen unter alleiniger Östrogentherapie gesteigerte Endometriumkarzinomrisiko (Ortmann et al. 2000) lässt sich durch eine kontinuierlich mit Gestagenen kombinierte HRT vermeiden (Rabe et al. 2005). Nach der Jahrtausendwende kam es aufgrund von kontrollierten, randomisierten Studien wie der Women's Health Initiative (WHI)-Studie zu einem Umdenken beim Einsatz der HRT. Im Rahmen der WHI-Studie konnte bei postmenopausalen Frauen, die eine kombinierte Östrogen-Progesteron-Therapie erhielten, ein vermehrtes Auftreten von Mammakarzinomen, koronaren Herzerkrankungen, Hirninsulten und thromboembolischen Ereignissen nachgewiesen werden, die Placebogruppe wies sogar einen um 15 Prozent besseren globalen Risiko-Nutzen-Index auf als die mit kombinierter HRT behandelte Versuchsgruppe (Heinemann und Parhofer 2003). Infolge der Studie kam es daher zu einer Neubewertung der HRT (Ortmann et al. 2003). Für die primäre Osteoporoseprävention bei perimenopausalen Frauen mit hohem Osteoporoserisiko beziehungsweise mit bekannter Osteopenie beschrieben Rabe et al. 2005 die HRT dennoch als nach wie vor wirksamste Option. Die DVO-Leitlinie Osteoporose aus dem Jahr 2014 empfiehlt jedoch den frakturpräventiven Einsatz von Östrogenen nur noch in Ausnahmefällen.

Es lässt sich somit feststellen, dass zur medikamentösen Behandlung der Osteoporose heute eine Vielzahl von Therapieansätzen zur Verfügung steht. In Kombination mit einer Calcium- und Vitamin-D-Supplementation können dabei sowohl Bisphosphonate als auch Strontiumranelat, Raloxifen und Parathormonpeptide das Risiko vertebraler Frakturen senken (Kanis 2010). Diese umfassende Auswahl an Wirkstoffen gewinnt 
insbesondere dann an Bedeutung, wenn im Verlauf der langjährigen Therapie eine Umstellung der Medikation erforderlich wird.

Abgesehen von der Osteoporosetherapie ist aber auch die Erkrankungsprävention von entscheidender sozialer und wirtschaftlicher Bedeutung, gerade angesichts einer kontinuierlich alternden Gesellschaft und sich gleichzeitig verknappender Ressourcen (Scheidt-Nave 2001). Insofern sollte primärpräventiv bereits früh im Lebensverlauf eine Steigerung der individuellen PBM angestrebt werden. Zu den dafür erforderlichen Maßnahmen sind unter anderem eine angemessene Calciumzufuhr, eine hinreichende körperliche Belastung und die Vermeidung längerer sexualhormondefizitärer Phasen in der postpubertären Zeit zu zählen (Schulte 1997). Auch im höheren Alter sowie bei möglicherweise bereits diagnostizierter Osteoporose spielt die Prävention eine entscheidende Rolle. Neben der bereits erwähnten und auch im Zuge der Prophylaxe eingesetzten Basistherapie sollte eine regelmäßige Bewegung und altersentsprechende körperliche Belastung angestrebt werden. Hierdurch kann zum einen ein osteoanaboler Reiz gesetzt, zum anderen die Koordination und Muskelkraft trainiert beziehungsweise erhalten werden. Die Frakturrisikofaktoren Rauchen und starker Alkoholkonsum sollten im Sinne einer Lebensstilanpassung vermieden werden (Kanis 2010). Zur Vermeidung eines Frakturereignisses ist bei bekannter Osteoporose nicht zuletzt auch eine Sturzprophylaxe mit Identifizierung und Beseitigung etwaiger Risikokonstellationen im häuslichen Umfeld anzustreben. 


\section{Material und Methoden}

Zum besseren Verständnis des Krankheitsbildes der Osteoporose und zur ErschlieBung eventueller künftiger therapeutischer Ansätze sollten mit den Versuchen dieser Arbeit die Auswirkungen der Erkrankung auf das Remodeling des Knochens genauer untersucht werden. Unter Einsatz eines Großtiermodells sollten nähere Informationen über den zeitlichen Ablauf und die genaue Lokalisation des osteoporotischen Prozesses gewonnen werden. Als geeignete Verfahren zum Sammeln dieser Informationen wurden im Zuge der Versuchsplanung eine laborchemische Verlaufsanalyse mit Knochenumsatzmarkern, die periphere quantitative Computertomographie (pQCT) und die polychrome Sequenzmarkierung erachtet. Mit dem Einsatz von Knochenumsatzmarkern wurde das Ziel verfolgt, detailliertere Erkenntnisse über den zeitlichen Ablauf der Osteoporoseentwicklung zu gewinnen. Die pQCT erschien geeignet, um Informationen über die genaue Lokalisation des Krankheitsprozesses im Knochen zu liefern. Die polychrome Sequenzmarkierung sollte schließlich weitere Erkenntnisse über feingewebliche Lokalisation und zeitlichen Ablauf der Erkrankung beisteuern.

\subsection{Design und zeitliche Staffelung der Untersuchung}

Die Untersuchungen dieser Arbeit wurden am Großtiermodell des Göttinger Minischweines durchgeführt. Die Tierversuche wurden vom Niedersächsischen Landesamt für Verbraucherschutz und Lebensmittelsicherheit unter dem Aktenzeichen Az 33.42502-04-041/07 genehmigt.

Es wurden insgesamt zehn weibliche Tiere aus dem Versuchsgut Relliehausen in Dassel eingesetzt, welche in eine Versuchs- und eine Kontrollgruppe zu je fünf Exemplaren aufgeteilt wurden. Während die Tiere der Versuchsgruppe zu Beginn der Untersuchung einer beidseitigen Ovarektomie unterzogen und im weiteren Verlauf mit calcium- sowie phosphatarmem Futter ernährt wurden, erhielten die Tiere der Kontrollgruppe lediglich eine Sham-Operation ohne Entfernung der Ovarien und in der Folge eine Ernährung mit einem gewöhnlichen Calcium- sowie Phosphatgehalt. Ziel hierbei war es, innerhalb der Versuchsgruppe eine mit der postmenopausalen Osteoporose vergleichbare Stoffwechselsituation zu erzeugen. 
Die Unterbringung der Schweine während des Versuchszeitraumes erfolgte in Einzellaufställen im Versuchsgut Holtensen. Hier hatten die Tiere unbeschränkten Zugang zu Wasser und erhielten pro Tag jeweils $500 \mathrm{~g}$ Futter. Dabei handelte es sich in beiden Versuchstiergruppen um Futter der Firma Altromin (Altromin Spezialfutter GmbH \& Co. KG, Lage, Deutschland) ohne Sojazusatz, um die osteoanabole Wirkung der in Soja enthaltenen Isoflavone (Foth 2007) zu vermeiden. Das Futter der ovarektomierten Schweine wies im Vergleich zur Kontrollgruppe einen reduzierten Calciumanteil von 0,16 Prozent und einen reduzierten Phosphatanteil von 0,59 Prozent auf. Die Kontrolltiere erhielten dagegen Futter mit einem Calciumanteil von 0,96 Prozent und einem Phosphatanteil von 0,71 Prozent.

Der Versuchszeitraum erstreckte sich über 237 Tage von der Ovarektomie beziehungsweise Sham-Operation bis zum Tod der Tiere (Abbildung 6). Innerhalb dieser Zeitspanne wurden regelmäßig ausgewählte Serum-Laborwerte kontrolliert. Hierzu erfolgten Laborkontrollen (LK) zu Versuchsbeginn sowie am 84., 143., 167., 187., 209. und 237. Tag.

Allen Versuchstieren wurden zusätzlich im Rahmen der polychromen Sequenzmarkierung am 143. Tag Alizarinkomplexon (Alizarin) und am 209. Tag Tetrazyklinhydrochlorid (Tetrazyklin) subcutan (s.c.) injiziert.

Für weitere Versuchsreihen, die jedoch nicht Thema dieser Arbeit sind, wurden allen Tieren während der ersten Operation außerdem sechs Seitenzähne im linken Unterkiefer extrahiert, um dann an gleicher Stelle zum Zeitpunkt der ersten Farbstoffapplikation am 143. Tag im Zuge einer zweiten Operation je drei Zahnimplantate einzupflanzen.

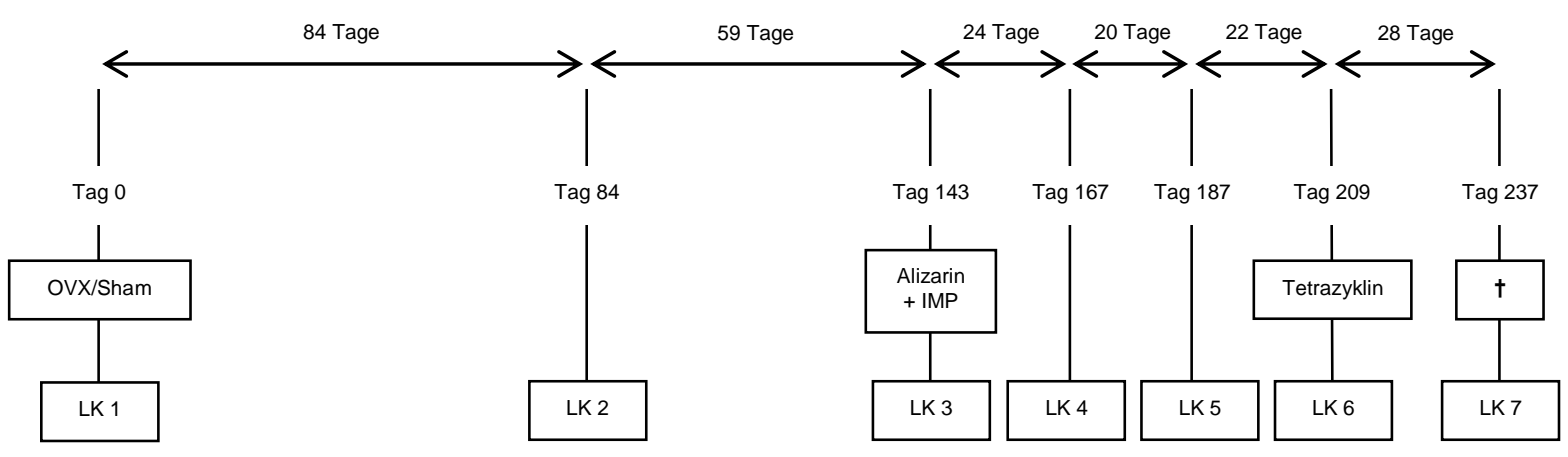

Abb. 6: Zeitlicher Versuchsablauf. OVX = Ovarektomie, Sham = Sham-Operation, $L K=$ Laborkontrolle, Alizarin $=$ Alizarinkomplexon, Tetrazyklin $=$ Tetrazyklinhydrochlorid, IMP = Implantateinbringung, $\dagger=$ Tötung . 
Die Ovarektomie beziehungsweise Sham-Operation markiert den Beginn des Versuchszeitraumes. Hierzu erhielten die Tiere zunächst zur Sedierung Azaperon (300320 mg) intramuskulär (i.m.) und im Anschluss daran Thiopental-Natrium (230-375 mg) als Hypnotikum intravenös (i.v.). Zur Aufrechterhaltung der Narkose während des Eingriffes wurde eine kontinuierliche Ketamininfusion (2,5-5 mg/kg KG/h) verabreicht und eine Beatmung über Tubus mit einem Distickstoffmonoxid-Sauerstoff-Gemisch im Verhältnis 4:1 durchgeführt. Zur Analgesie wurde des Weiteren Piritramid (75-100 $\mu \mathrm{g} / \mathrm{kg}$ $\mathrm{KG} / \mathrm{h}$ ) eingesetzt. Bei Bedarf wurde die Narkose um i.v. verabreichtes Diazepam ergänzt.

Die Ovarektomie der Tiere aus der Versuchsgruppe wurde über eine mediane Laparotomie mit Schnittführung in Höhe des vierten und fünften Mammakomplexes durchgeführt. Die beidseitige Entfernung der Ovarien erfolgte im Anschluss an deren Präparation mit Hilfe eines Elektrokauters. Zum Abschluss des Eingriffes wurde eine umfangreiche Blutstillung durchgeführt und dann der mehrschichtige Wundverschluss vorgenommen.

Die Tiere der Kontrollgruppe erhielten einen modifizierten Eingriff im Sinne einer ShamOperation, bei der im Unterschied zum oben beschriebenen Vorgehen beide Ovarien in situ belassen wurden. Die anderweitigen Operationsschritte sowie die Narkose variierten zwischen Versuchs- und Kontrollgruppe nicht.

Das Ende des Versuchszeitraumes wird durch die Tötung der Schweine definiert. Hierzu erhielten die Tiere Azaperon in einer letalen Dosierung. Nach Eintritt des Todes wurde mit der Präparation der für die weiteren Versuche benötigten Knochen begonnen. Die in dieser Arbeit untersuchten linken Tibiae wurden dafür im Verbund mit der jeweiligen Fibula entnommen, von umliegendem Muskel- sowie Bindegewebe freipräpariert und in wiederverschließbaren Plastikbeuteln einzeln bis zur weiteren Aufbereitung eingefroren. Diese Lagerungsart wurde gewählt, um einem möglichen Verblassen der im Gewebe fixierten Fluorochrome, auch Fading genannt, entgegenzuwirken. So konnten Rahn und Perren (1972) für Alizarin bei tiefgefroren und gefriergetrocknet aufbewahrten Knochenproben keine Abschwächung der Fluoreszenz beobachten. 


\subsection{Laborchemische Serumanalysen}

Um Veränderungen im Hormonhaushalt und Knochenstoffwechsel der Versuchstiere im Laufe des Experimentes beurteilen zu können, wurden zu Beginn des Versuchszeitraumes, im dritten, fünften, sechsten, siebten und achten Monat sowie zu Versuchsende Blutproben entnommen (Tag 0, 84, 143, 167, 187, 209 und 237). Anhand dieser wurden jeweils die aktuellen Serumkonzentrationen von 17ß-Östradiol (E2), N-MID Osteokalzin (OC), $\beta$-CrossLaps (CTX) sowie die Aktivität der Alkalischen Phosphatase (AP) bestimmt.

Für die Analyse der E2-, OC- und CTX-Serumkonzentrationen wurden Elektrochemilumineszenz-Immunoassays (ECLIA) nach der Elecsys ${ }^{\circledR}-$ Methode der Firma Roche (Roche Diagnostics $\mathrm{GmbH}$, Mannheim, Deutschland) verwendet.

\subsubsection{7ß-Östradiol (E2)}

Mit $17 \beta$-Östradiol (E2), dem biologisch aktivsten Vertreter der Östrogene (Leidenberger et al. 2009), wurde ein Parameter zur Beurteilung des Einflusses der Ovarektomie auf den Hormonhaushalt gewählt.

Der E2-Test wurde dabei nach dem Kompetitionsprinzip durchgeführt. Hierbei konkurriert das in der Probe enthaltene E2 mit einem hinzugefügten Ruthenium-Komplexmarkierten E2-Derivat um die Bindungsstellen eines spezifischen Antikörpers. Der dabei entstehende Immunkomplex wird an hinzugefügte Mikropartikel fixiert. Die quantitative E2-Bestimmung erfolgt schließlich unter Zuhilfenahme eines Photoelektronenvervielfachers mittels Elektrochemilumineszenzemission (Roche Informationsblatt: Estradiol II, 2007).

\subsubsection{Osteokalzin (OC)}

Die Bestimmung von N-MID Osteokalzin (OC) diente im Versuchszusammenhang der Einschätzung des Knochenumsatzes. Das Protein wird von Osteoblasten gebildet und stellt einen hochspezifischen Marker des Knochenanbaus dar (Schulte 1997). Das synthetisierte OC wird zum Großteil an die Knochenmatrix gebunden, 20 - 30 Prozent gelangen jedoch in die systemische Zirkulation und können daher dort als Biomarker der Knochenformation während der Osteoblastenentwicklung genutzt werden (ObermayerPietsch und Schwetz 2016). 
Für die laborchemische OC-Bestimmung wurde eine Technik gewählt, die sowohl das im Blutkreislauf instabile Osteokalzin selbst als auch das wesentlich stabilere N-MIDFragment berücksichtigt. Die Probe wird dazu mit zwei spezifischen Antikörpern versetzt, welche an unterschiedlichen Bindungsstellen des OC angreifen. Der dabei entstehende Sandwichkomplex wird daraufhin mittels beigefügter Mikropartikel gebunden. Wie beim E2-Test wird für die eigentliche Messung anschließend die Chemilumineszenz quantitativ detektiert (Roche Informationsblatt:N-MID Osteocalcin, 2007).

\subsection{3 $\beta$-CrossLaps (CTX)}

Als $\beta$-CrossLaps (CTX) werden die beim Knochenabbau freigesetzten C-terminalen Telopeptide des Typ-I-Kollagens bezeichnet. Bei katabolem Knochenstoffwechsel ist mit ihrer vermehrten Freisetzung zu rechnen, so dass ihre Serumkonzentrationen genutzt werden können, um das Ausmaß der Knochenresorption abzuschätzen. CTX sind dabei bei Raumtemperatur besonders stabil und stellen die zur Zeit am weitesten verbreiteten Serumbiomarker für den ossären Stoffwechsel dar (Obermayer-Pietsch und Schwetz 2016).

Analog zum OC-Test wurde auch die CTX-Analyse nach dem Sandwichprinzip mit anschließender Elektrochemilumineszenzmessung durchgeführt. Die beiden hierbei verwendeten Antikörper binden spezifisch an zwei innerhalb des freigesetzten CTX aufeinander folgende, lineare Peptide (Roche Informationsblatt: $\beta$-CrossLaps/Serum, 1999).

\subsubsection{Alkalische Phosphatase (AP)}

Unter dem Begriff Alkalische Phosphatase (AP) werden Isoenzyme verschiedener Gewebe zusammengefasst. Die einzelnen Unterformen sind dabei im Knochen und auch in zahlreichen anderen Geweben wie der Leber, dem Intestinum, den Nieren sowie den Keimzellen zu finden. Entsprechend vielfältig können etwaige Aktivitätserhöhungen begründet sein. Dennoch wurde die AP als bei Knochenpathologien etablierter, wenn auch unspezifischer Laborparameter ergänzend zu den zuvor erwähnten Umsatzmarkern bestimmt.

Die AP-Bestimmung erfolgte nach der durch die International Federation of Clinical Chemistry (IFCC) empfohlenen Methode (Tietz et al. 1983b; Tietz et al. 1983a) mittels eines entsprechenden Tests der Firma Roche (Roche Diagnostics GmbH, Mannheim, Deutschland). Hierbei wird die Probe mit einer definierten Menge p-Nitrophenylphosphat versetzt, welches daraufhin durch die im Serum enthaltene AP gespalten 
wird. Die Enzymaktivität kann anschließend anhand einer photometrischen Analyse des dabei gebildeten p-Nitrophenols ermittelt werden (Roche Informationsblatt: ALP, 2004).

\subsection{Periphere quantitative Computertomographie (pQCT)}

Die quantitative Erfassung der Knochendichte ist im Zuge der Osteoporosediagnostik von zentraler Bedeutung. Im vorliegenden Fall erfolgten die osteodensitometrischen Messungen post mortem. Hierzu wurden die bereits vom umliegenden Gewebe befreiten Tibiaknochen mittels PQCT untersucht. Die quantitative Computertomographie hat nämlich den Vorteil, als einziges densitometrisches Verfahren die Knochendichte von Kortikalis und Trabekeln getrennt voneinander erfassen zu können (Issever und Link 2011).
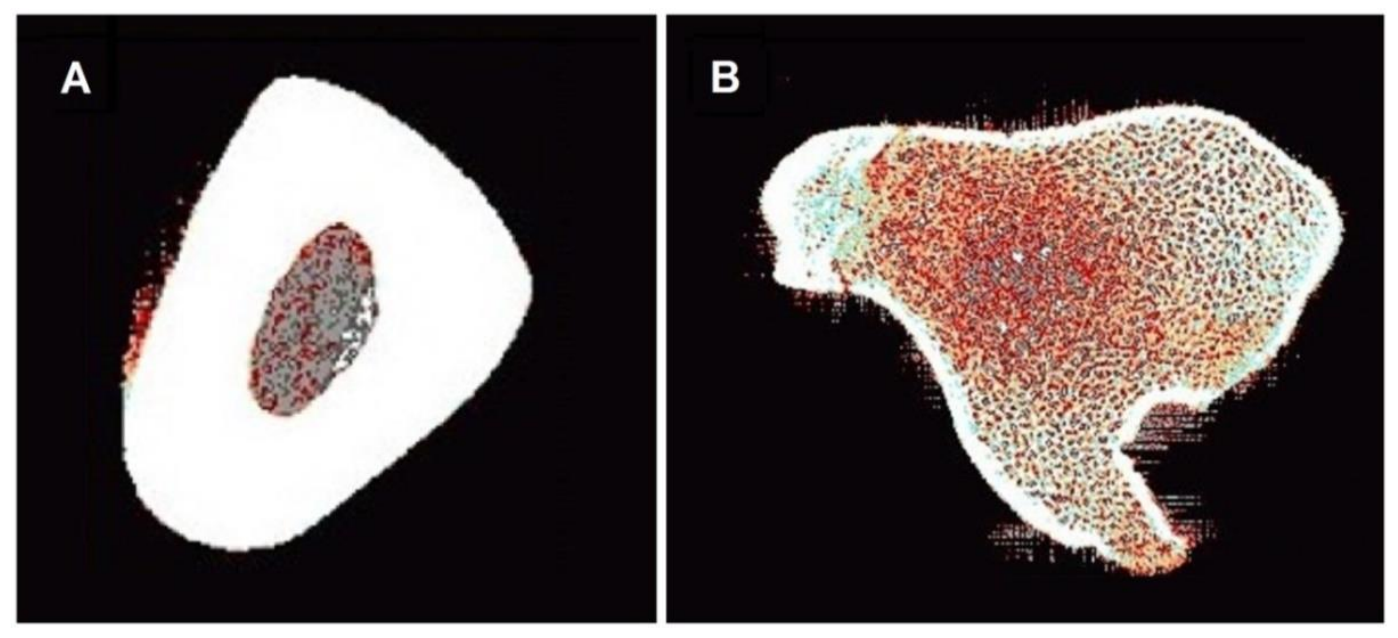

Abb. 7: Exemplarischer Querschnitt durch Diaphyse (A) und proximale Epiphyse (B) mittels $p Q C T$

Die Untersuchung wurde mit einem pQCT-Gerät des Typs „XCT Research SA+“ (Stratec Medizintechnik GmbH, Pforzheim, Deutschland) in Verbindung mit der zugehörigen Bediensoftwareversion 5.40 durchgeführt. Das Gerät wurde im Vorfeld der Messungen mit Hilfe eines Referenzphantoms kalibriert. Die Analyse erfolgte dann anhand von senkrecht zur Longitudinalachse der Tibia geführten Schnittebenen. Dabei wurden für jede der zehn Tibiae Messungen in jeweils drei Ebenen sowohl im Bereich der Diaphy- 
se als auch im Bereich der proximalen Epiphyse angefertigt (Abbildung 7). Die einzelnen Ebenen hatten einen Abstand von jeweils einem Millimeter zueinander. Für beide Messregionen wurden dann Knochendichte und -fläche sowohl für den trabekulären Knochen als auch für den kortikalen Knochen gemessen. Des Weiteren wurde für Knochendichte und -fläche jeweils auch ein durchschnittlicher Gesamtwert errechnet.

\subsection{Polychrome Sequenzmarkierung}

Um die Knochenapposition während des Versuchszeitraumes zwischen Versuchs- und Kontrollgruppe vergleichen zu können, wurde eine polychrome Sequenzmarkierung durchgeführt. Im Zuge des Markierungsprozesses sollten zwei fluoreszierende Farbstoffmarker zu wenigstens zwei unterschiedlichen Zeitpunkten verabreicht werden, um so Aussagen zur Dynamik des Knochenbildungsprozesses zu ermöglichen (van Gaalen et al. 2010). Nach Applikation stehen die Farbstoffmoleküle dem Stoffwechsel zur Verfügung und werden in den zum entsprechenden Zeitpunkt mineralisierten Knochen eingelagert und somit fixiert. Nach Probenentnahme und entsprechender -aufbereitung kann dann anhand von Bandenmessungen die jeweilige Knochenapposition fluoreszenzmikroskopisch beurteilt und quantifiziert werden.

Im Zuge der Auswahl der verwendeten Fluorochrome wurde darauf geachtet, dass diese bei fluoreszenzmikroskopischer Betrachtung deutlich voneinander abgrenzbar sind. Während mit Tetrazyklinhydrochlorid (Tetrazyklin) dabei ein etablierter, gelblich fluoreszierender Farbstoff Verwendung fand, handelt es sich bei Alizarinkomplexon (Alizarin) um einen Marker mit intensiver roter Fluoreszenz, der ein günstiges Verhältnis zwischen für die Knochenmarkierung erforderlicher und letaler Dosis besitzt (Rahn und Perren 1972).

Die beiden Fluorochrome wurden jeweils subcutan (s.c.) verabreicht. Am 143. Tag des Versuchszeitraumes erfolgte auf diesem Weg zunächst die Applikation von Alizarin. Hierzu wurden den Tieren jeweils $30 \mathrm{mg}$ des in sterilem, destilliertem Wasser gelösten und mit Natriumhydrogencarbonat gepufferten Farbstoffes pro kg Körpergewicht (KG) injiziert. Für die Verabreichung von Tetrazyklin am 209. Tag wurde der Farbstoff in einer sterilen Natriumchloridlösung gelöst und in einer Dosierung von 25 mg pro kg KG verabreicht. 


\subsubsection{Knochenaufbereitung}

Um ein mögliches Ausbleichen der im Knochen fixierten Fluorochrome zu verhindern, wurde während der einzelnen Arbeitsschritte der Knochenaufbereitung stets darauf geachtet, die Lichtexposition der Präparate auf ein Minimum zu beschränken. Die Präparate wurden dazu zwischenzeitlich entweder mit Aluminiumfolie abgedeckt oder in einer lichtundurchlässigen Box aufbewahrt.

Zu Beginn der Aufbereitung wurde jeweils ein circa $2 \mathrm{~cm}$ langes Segment aus der distalen Diaphyse der Tibia mit Hilfe eines EXAKT-Trennsystems (EXAKT Advanced Technologies $\mathrm{GmbH}$, Norderstedt, Deutschland) herausgesägt. Die dabei gewonnenen Knochenblöcke wurden in einer phosphatgepufferten vierprozentigen Formalinlösung für zwei Wochen fixiert und anschließend zur Entfernung überschüssiger Formalinreste in destilliertem Wasser gespült. Im nächsten Arbeitsschritt wurden die Präparate mit Hilfe einer aufsteigenden Alkoholreihe dehydriert, indem sie für je zwei Tage in Ethanollösungen ansteigender Konzentrationen, beginnend mit 70 Prozent bis hin zu 100 Prozent, gegeben wurden. Die entwässerten Knochensegmente wurden dann in Gießformen gelegt und in Kunststoff eingebettet. Hierzu wurden die Formen mit Methylacrylat aufgefüllt und unter Vakuum für zehn Minuten von Lufteinschlüssen befreit. Bis zur vollständigen Aushärtung des Kunststoffes wurden sie dann bei $-8^{\circ}$ Celsius gelagert.

Die Präparate wurden nun aus ihren Formen gelöst und mit Hilfe einer „RotoPol-35“Schleifmaschine (Struers ApS, Ballerup, Dänemark) so weit von überschüssigem Kunststoff befreit, bis das Einbettungsmaterial allseits eine gleichmäßige, dünne, die Tibiasegmente umgebende Schicht ausmachte. Die so entstandenen Blöcke wurden anschließend einseitig auf je einem Objektträger mit Cyanacrylat-Klebstoff fixiert, um ihre Handhabung zu verbessern. Im Anschluss wurde unter Zuhilfenahme eines EXAKT-Trennsystems (EXAKT Advanced Technologies GmbH, Norderstedt, Deutschland) jeweils eine saubere Schnittfläche senkrecht zur Knochenlängsachse geschaffen und in einem mehrstufigen Prozess mittels eines EXAKT-Schleifsystems (EXAKT Advanced Technologies $\mathrm{GmbH}$, Norderstedt, Deutschland) mit Schleifscheiben zunehmender Körnung bis zu einem Wert von 1200 geebnet. Diese Schnittfläche wurde wiederum mit Cyanacrylat auf einem Objektträger fixiert, so dass durch einen weiteren, parallel zum Objektträger geführten Schnitt eine dünne Knochenscheibe transversaler Schnittführung entstand. In gleicher Weise konnten so pro Tibia drei auf einem Objektträger fixierte Schnitte angefertigt werden. Diese wurden anschließend in mehreren Arbeitsschritten mit Schleifscheiben zunehmender Körnung bis auf eine Dicke von 
circa 60 Mikrometern $(\mu \mathrm{m})$ abgeschliffen. Zuletzt wurden die Präparate mit einer Körnung von 4000 poliert.

Auf diese Weise wurden pro Versuchstier drei Trenn-Dünnschliff-Präparate angefertigt, wodurch insgesamt 30 Präparate für die weiteren Untersuchungen zur Verfügung standen.

\subsubsection{Auflichtfluoreszenzmikroskopie und Digitalisierung}

Für die fluoreszenzmikroskopische Untersuchung der wie unter 3.4.1 beschrieben hergestellten Trenn-Dünnschliff-Präparate wurde ein „Axioskop 2 plus“ Fotomikroskop (Carl Zeiss AG, Oberkochen, Deutschland) in Verbindung mit einer durch ein elektronisches „ebq 100 ISOLATED“ Vorschaltgerät (Leistungselektronik Jena GmbH, Jena, Deutschland) versorgten „HBO 100“ Quecksilberdampf-Kurzbogenlampe (Carl Zeiss AG, Oberkochen, Deutschland) verwendet. Die Digitalisierung der mikroskopischen Bilder erfolgte mittels einer „AxioCam MRc 5“ Digitalkamera (Carl Zeiss AG, Oberkochen, Deutschland), welche mittels der Bediensoftware „AxioVision Release 4.8“ (Carl Zeiss AG, Oberkochen, Deutschland) gesteuert wurde.

Unter Anregungslicht und Verwendung entsprechender Filter stellten sich bei der auflichtmikroskopischen Betrachtung der Präparate die im Knochen fixierten Farbstoffe als fluoreszierende Banden dar. Alizarin konnte dabei anhand seiner rötlichen, Tetrazyklin anhand seiner gelblichen Fluoreszenz ausgemacht werden. Entsprechend der physiologischerweise zuletzt mineralisierten Regionen im Knochenquerschnitt ließen sich Banden periostal, endostal sowie innerhalb einzelner Osteone finden. Während die Banden periostal und endostal weitestgehend ubiquitär zu finden waren, zeigten sich die fluoreszierenden Farbstoffe bei Betrachtung der Osteone nur innerhalb jener Osteone, welche im direkten Anschluss an den jeweiligen Applikationszeitpunkt mineralisiert worden waren.

Um zu verdeutlichen, dass es sich bei dem endostal betrachteten Knochen um kortikalen und nicht um spongiösen Knochen handelt, wird im Folgenden der zutreffendere Terminus „endokortikal“ anstelle von „endostal“ verwendet, wie es auch die gängige Nomenklatur vorsieht (Dempster et al. 2013). Sind die Osteone gemeint, kommt mitunter der Begriff „osteonal“ zum Einsatz.

Im Rahmen der Digitalisierung wurde der Tibiaquerschnitt zunächst in seiner Vollständigkeit bei fünf- bis zehnfacher Vergrößerung betrachtet, um anschließend bei 20- 
facher Vergrößerung Detailaufnahmen anzufertigen. Hierbei wurde jeweils eine repräsentative Aufnahme des periostalen Knochens, eine des endokortikalen Knochens, eine eines Osteons mit Alizarin-Bande sowie eine eines Osteons mit Tetrazyklin-Bande angefertigt. In jede der digitalisierten Aufnahmen wurde mit Hilfe der „AxioVision“Software (Carl Zeiss AG, Oberkochen, Deutschland) außerdem ein $100 \mu \mathrm{m}-\mathrm{Maß-}$ stabsbalken für spätere Kalibrierungszwecke eingefügt.

\subsubsection{Histomorphometrische Auswertung}

Zur Auswertung der digitalisierten Aufnahmen wurden zunächst drei Messbereiche definiert: Der periostale Knochen, der endokortikale Knochen und die Osteone. Für den periostalen und endokortikalen Knochen wurden die Alizarin- und die TetrazyklinBandenbreite gemessen sowie deren Abstand voneinander (Abbildung 8). Für die Osteone hingegen wurden nur die Bandenbreiten der beiden Farbstoffe ermittelt, da, wie bereits erwähnt, nur vereinzelt Banden beider Fluorochrome in ein und demselben Osteon zu finden waren.

Die Messungen erfolgten computergestützt mit Hilfe der Bildanalysesoftware „SigmaScan Pro 5“ (Systat Software GmbH, Erkrath, Deutschland). Im Einzelnen wurde hierzu nach Kalibrierung des Programms mit Hilfe des $100 \mu \mathrm{m}$-Maßstabbalkens die entsprechende Messlinie stets senkrecht zum Verlauf der Bande angelegt, um die minimale Bandenbreite zu erfassen. Für jedes Präparat wurden so pro Messbereich und Farbstoffbande beziehungsweise Bandenabstand 20 Messungen in gleichmäßigem Abstand voneinander durchgeführt.

\subsubsection{Berechnung der Knochenapposition}

Um die Knochenapposition beider Gruppen insgesamt sowie zu unterschiedlichen Versuchszeitpunkten genauer vergleichen zu können, wurden die ermittelten Bandenbreiten und Bandenabstände rechnerisch ausgewertet.

Zur globalen Einschätzung der postinterventionellen Knochenbildung wurden dazu zunächst für jeden Messbereich jeweils die Breiten aller Alizarin- und TetrazyklinBanden gruppenintern addiert. Für den periostalen und endokortikalen Knochen wurden außerdem die entsprechenden Bandenabstände zu den entstandenen Summen aufaddiert. Dieser letzte Rechenschritt war im Bereich der Osteone nicht möglich, da 


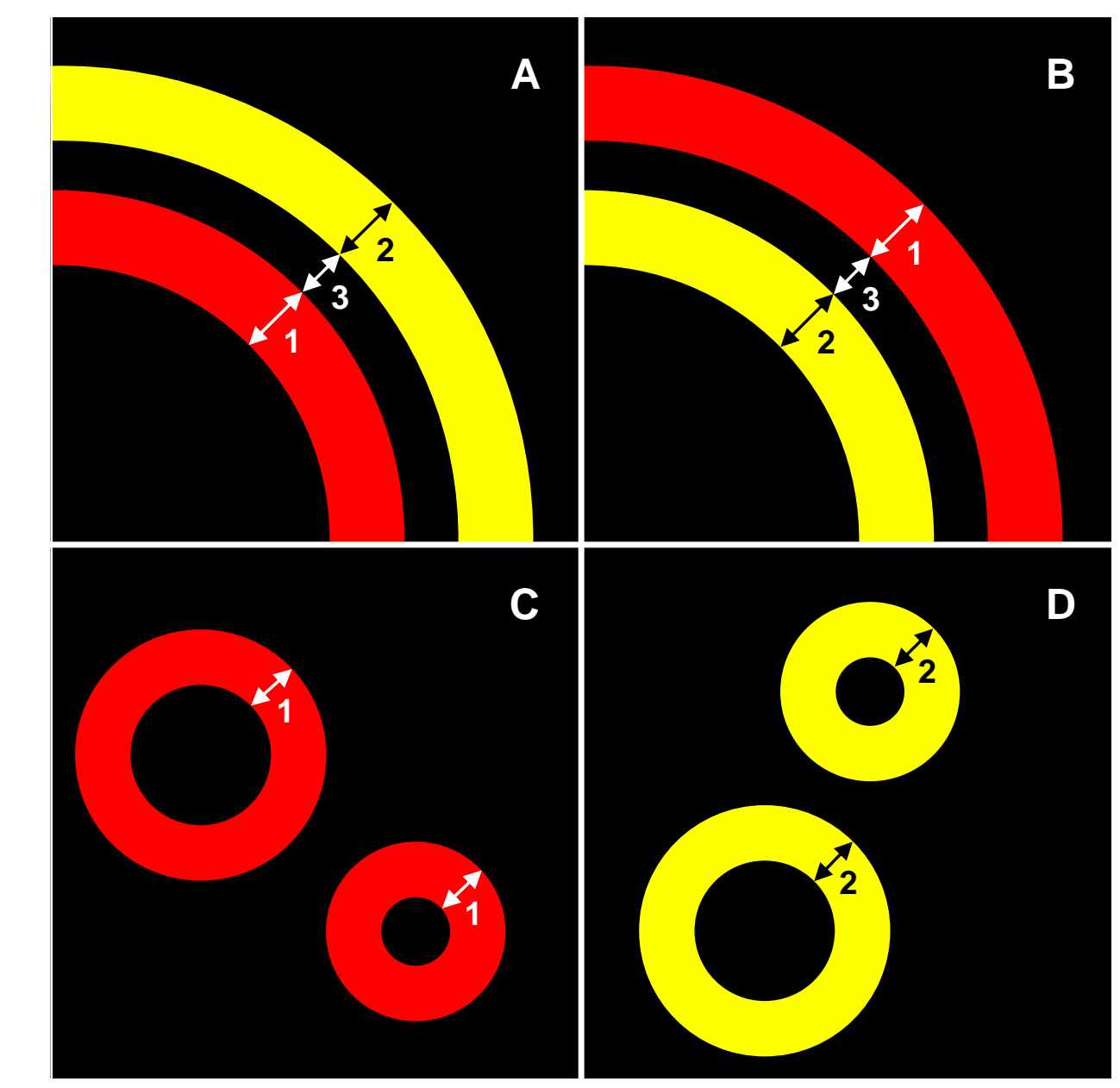

Abb. 8: Schematische Darstellung der fluoreszenzmikroskopisch sichtbaren Farbstoffbanden. Für den periostalen Knochen $(A)$, den endokortikalen Knochen $(B)$ und die Osteone $(C$ und $D)$ wurden die ermittelten Messgrößen mittels Pfeilen eingezeichnet und beschriftet (1: Alizarin-Bandenbreite, 2: Tetrazyklin-Bandenbreite, 3: Abstand Alizarin/Tetrazyklin). Periostal liegt die Tetrazyklin-Bande weiter peripher als die Alizarin-Bande, endokortikal ist es umgekehrt.

sich hier in der Regel nur ein Fluorochrom pro Osteon zeigte. Für die im Bereich der Osteone aus beiden Farbstoffbanden gebildeten Summen sowie die im Bereich des periostalen und endokortikalen Knochens aus beiden Farbstoffbanden und den Bandenabständen gebildeten Summen wurden anschließend die zugehörigen Mittelwerte berechnet.

Um genauere Erkenntnisse über den zeitlichen Verlauf der Apposition während des Versuchszeitraumes auch innerhalb einer Gruppe zu erlangen, wurden die Bandenbreiten zudem auch getrennt voneinander betrachtet. Die Alizarin-Bande erlaubt dabei Rückschlüsse auf die Knochenformation etwa 20 Wochen nach Ovarektomie, während 
die Tetrazyklin-Bande Aussagen über die Formation rund 30 Wochen nach Versuchsbeginn zulässt. Unter Berücksichtigung der von Merten und Wiese gemachten Beobachtung, dass ein s.c. injiziertes Alizarin-Depot den Urin von Ratten und Minischweinen drei Tage lang rot einfärbt (persönliche Mitteilung Wiese KG, Göttingen 13. Juni 2017), wurden für beide Fluorochrome jeweils die mittleren täglichen Appositionsraten der drei Messbereiche berechnet. Dazu wurden die gemittelten Breiten der jeweiligen Farbstoffbanden durch drei dividiert.

\subsection{Statistische Auswertung}

Die statistische Auswertung und graphische Aufbereitung der Messergebnisse erfolgte mit Hilfe des Programms SigmaPlot (Systat Software Inc., San Jose, USA). Die Daten der einzelnen Messreihen wurden dazu in Tabellenform angeordnet. Zum Vergleich der beiden Versuchstiergruppen wurden die rechnerisch ermittelten Mittelwerte herangezogen. Mittels t-Test wurde untersucht, wie sich die jeweiligen Mittelwerte zueinander verhalten. Ab einem $p$-Wert $\leq 0,05$ wurden etwaige Unterschiede als signifikant, ab einem Wert $\leq 0,01$ als hochsignifikant gewertet. Um den Zusammenhang zwischen zwei Datensätzen zu untersuchen wurden Korrelationsanalysen durchgeführt, wobei das Maß der Korrelation anhand des Bestimmtheitsmaßes $r^{2}$ beziehungsweise des Korrelationskoeffizienten $r$ beurteilt wurde. 


\section{Ergebnisse}

Für die im Rahmen dieser Arbeit durchgeführten Untersuchungen kamen zehn weibliche Göttinger Minischweine zum Einsatz, aufgeteilt in zwei Gruppen zu je fünf Tieren. Die Schweine der Versuchsgruppe waren anfangs durchschnittlich vier Jahre alt und 67,8 kg schwer, im Vergleich zu 3,2 Jahren und 63 kg in der Kontrollgruppe.

Nach Beendigung der Versuche erfolgte die Auswertung der erhobenen Daten. Im Zuge dieses Arbeitsschrittes wurden die Serumanalysen, die pQCT sowie die polychrome Sequenzmarkierung jeweils getrennt voneinander betrachtet.

\subsection{Laborchemische Serumanalysen}

Die einzelnen Laborparameter werden nachfolgend in jeweils zwei Schritten ausgewertet. Zunächst wird ein Vergleich der absoluten Werte zwischen Versuchs- und Kontrollgruppe gezogen (Abbildung 9) und im Anschluss daran wird für die ovarektomierten Tiere ein genauerer Blick auf den zeitlichen Verlauf der einzelnen relativen Serumspiegel geworfen (Abbildung 10). Hierzu wurden für die in Abbildung 10 dargestellten Diagramme zusätzlich die entsprechenden Regressionsgeraden bestimmt und eingezeichnet.

\subsubsection{7 $\beta$-Östradiol (E2)}

Im Anschluss an die Ovarektomie beziehungsweise Sham-OP fanden sich sowohl in der Versuchs- als auch in der Kontrollgruppe im Vergleich zum Ausgangswert erniedrigte E2-Serumkonzentrationen. Die Werte der OVX-Gruppe erreichten dabei jedoch erwartungsgemäß ein deutlich niedrigeres Niveau als die der Kontrollgruppe. Nach Tag 143, an dem die Alizarin-Applikation und die Zahnimplantateinbringung erfolgt waren, stiegen die E2-Konzentrationen der ovarektomierten Tiere kurzzeitig an, während die der Kontrolltiere abfielen. So erreichte die OVX-Gruppe an Tag 167 einmalig einen geringfügig höheren Wert als die Kontrollgruppe, um im Anschluss erneut deutlich und bis Versuchsende fortlaufend zu sinken. Die scheinoperierten Tiere zeigten im weiteren Verlauf hingegen tendenziell ansteigende E2-Konzentrationen, welche zum Versuchsende erneut ihr Niveau von Tag 84 und 143 erreichten. 


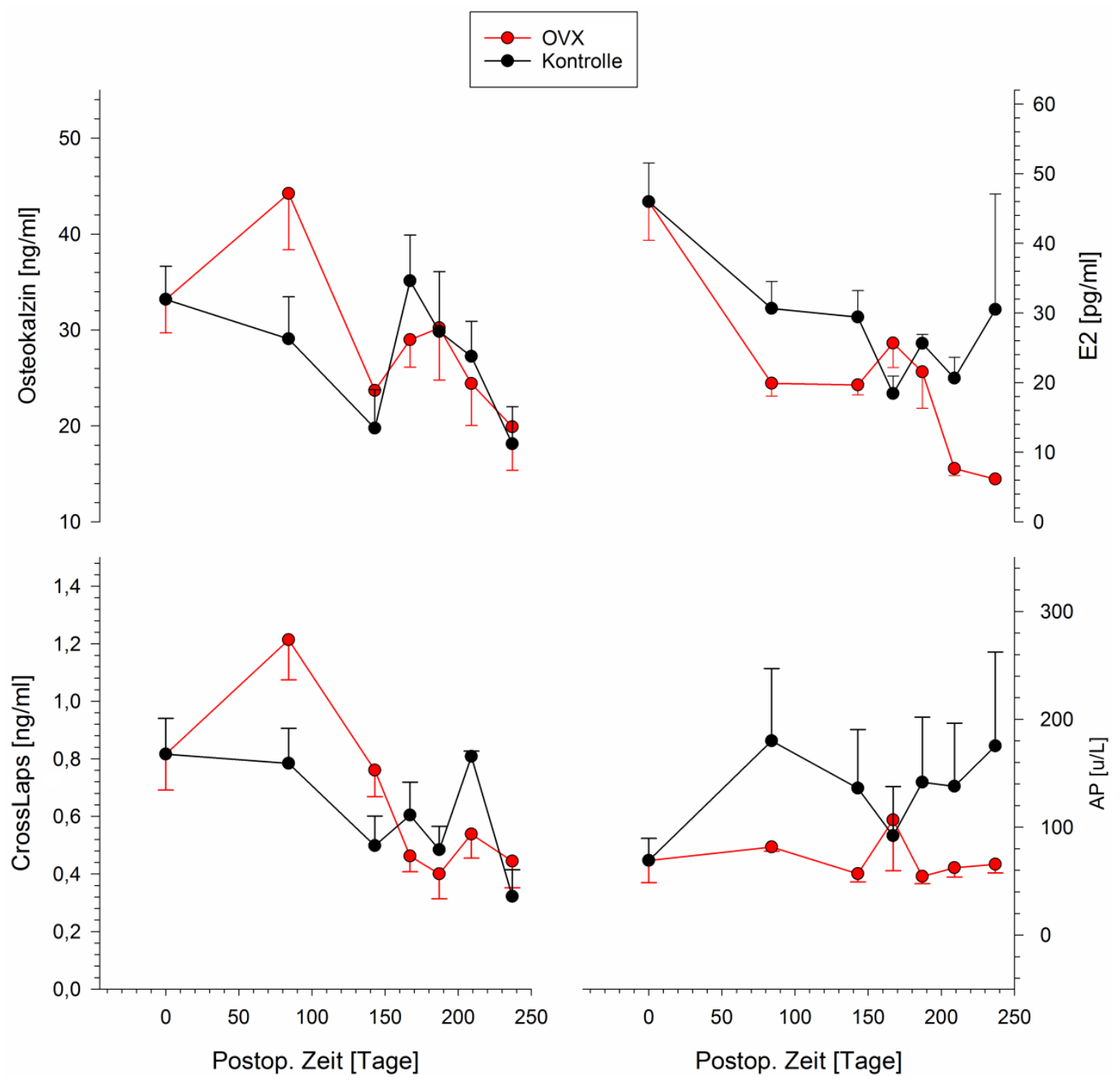

Abb. 9: Postoperativer Verlauf von OC, E2, CTX und AP. Zu erkennen ist die zeitabhängige Darstellung der absoluten Serumkonzentrationen nach OVX bzw. Sham-OP (Tag 0). Angegeben sind jeweils die Mittelwerte mit ihren Standardfehlern (1 $\leq n \leq 20)$.

Betrachtet man nun die für die relativen E2-Werte der OVX-Schweine errechnete Regressionsgerade in Abbildung 10, so ist zu erkennen, dass der Zusammenhang zwischen prozentualen Serumwerten und Zeit relativ gut durch eine negativ lineare Funktion beschrieben werden kann. Es ergibt sich dabei ein Bestimmtheitsmaß von 0,77. Die E2-Spiegel der Versuchstiere sind folglich ab dem Zeitpunkt der Ovarektomie über den gesamten Versuchszeitraum tendenziell fortlaufend zurückgegangen. 

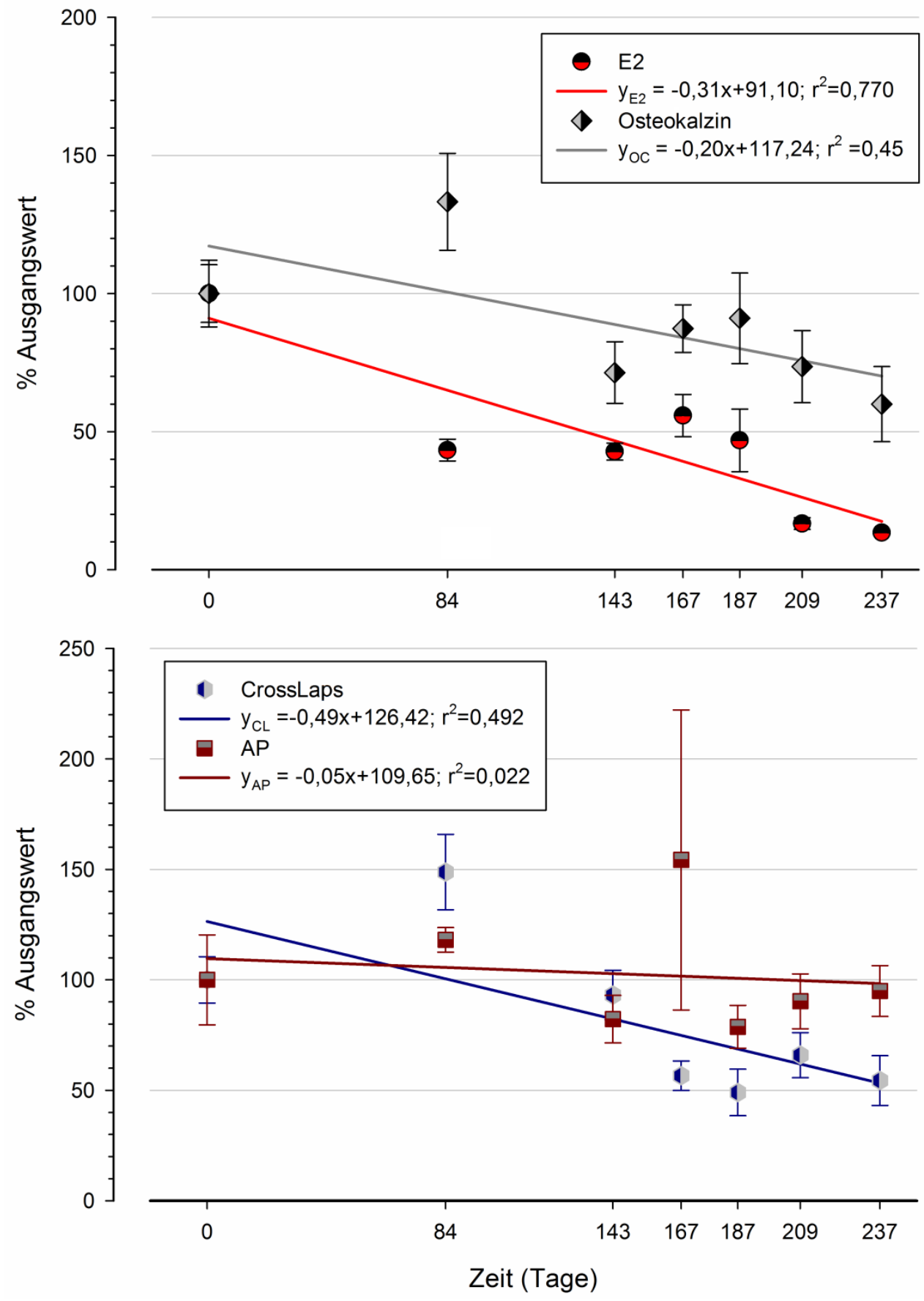

Abb. 10: Relative Laborwerte nach Ovarektomie im zeitlichen Verlauf. Zu erkennen ist die zeitabhängige Darstellung der relativen Serumkonzentrationen von E2 und OC (oben) sowie CTX und AP (unten) innerhalb der Versuchsgruppe nach OVX (Tag 0). Angegeben sind jeweils die Mittelwerte mit ihren Standardfehlern sowie die linearen Regressionen. Die errechneten Regressionsgeraden sind als $y=f(x)$ in den entsprechenden Legenden mit zugehörigem Bestimmtheitsmaß $r^{2}$ aufgeführt $(1 \leq n \leq 20)$. 


\subsubsection{Osteokalzin (OC)}

Die OC-Analysen innerhalb der Versuchsgruppe ergaben in der frühen postoperativen Phase einmalig stark ansteigende Konzentrationen, während die der scheinoperierten Tiere sanken. Bis Tag 143 setzte sich dieser Trend in der Kontrollgruppe fort. Die zunächst erhöhten OC-Werte der OVX-Tiere fielen im gleichen Zeitraum nun allerdings ebenfalls deutlich ab, blieben dabei jedoch leicht über den Werten der Kontrollgruppe. Im Anschluss an den zweiten operativen Eingriff konnten in beiden Gruppen zunächst ansteigende OC-Serumkonzentrationen beobachtetet werden, wobei dieser Trend bei den Kontrolltieren etwas deutlicher ausfiel. Ab Tag 187 gingen die Werte beider Gruppen bis Versuchsende erneut zurück und glichen sich dabei an.

Unter Berücksichtigung des gesamten Versuchszeitraumes zeigt sich für die relativen OC-Werte innerhalb der Versuchsgruppe trotz der zwei postoperativen Konzentrationsanstiege ein generell abfallender Trend. Dieser ist auch anhand der in Abbildung 10 dargestellten Regressionsgeraden erkennbar, welche ein Bestimmtheitsmaß von 0,45 erreicht. Im Vergleich zu den E2-Spiegeln sind die OC-Werte jedoch langsamer abgefallen.

\subsection{3 $\beta$-CrossLaps (CTX)}

Ähnlich dem Verlauf der OC-Werte zeigten auch die CTX-Serumkonzentrationen der ovarektomierten Schweine bis zum 143. Versuchstag deutlich höhere Werte als die der Kontrollgruppe. Ihren Gipfel erreichten die CTX-Konzentrationen der Versuchsgruppe dabei am 84. Tag, um dann im Folgenden deutlich abzufallen. Ab Tag 167 lagen die Werte dann sogar unter denen der scheinoperierten Tiere. Jene hatten bis zu diesem Zeitpunkt ausschließlich zurückgehende Spiegel gezeigt. Während sich die Werte der OVX-Gruppe im weiteren Verlauf relativ stabil auf einem Niveau von ungefähr $0,5 \mathrm{ng} / \mathrm{ml}$ hielten, ergab sich bei den Kontrolltieren am 209. Tag ein Konzentrationsanstieg bis auf Ausgangsniveau, um jedoch zum Versuchsende erneut auf Werte leicht unterhalb des Niveaus der Versuchsgruppe abzufallen.

Der bei den OVX-Schweinen innerhalb der ersten 84 Tage aufgetretene CTX-Anstieg fiel deutlich aus. Bei Betrachtung der gesamten Versuchszeit wird jedoch ersichtlich, dass nach Erreichen dieser Maximalkonzentration die Werte tendenziell absanken. Daher ergibt sich für die relativen CTX-Werte insgesamt eine abfallende Regressionsgerade mit einem Bestimmtheitsmaß von 0,492. 


\subsubsection{Alkalische Phosphatase (AP)}

Für die im Serum ermittelte Volumenaktivität der AP zeigten sich innerhalb der Versuchsgruppe im Anschluss an die Ovarektomie konstant Werte auf einem Niveau um $70 \mathrm{u} / \mathrm{l}$. Diese Werte lagen damit unterhalb der Werte der scheinoperierten Tiere. Im Anschluss an die zweite Operation stieg die AP-Aktivität am 167. Tag in der Versuchsgruppe an, während die der Kontrollgruppe fiel. Hierdurch erlangten die ovarektomierten Tiere einmalig eine geringfügig höhere Aktivität als die Kontrollgruppe. Im weiteren Verlauf erreichten sie allerdings erneut das vorherige stabile und deutlich unterhalb der Werte der Kontrollgruppe liegende Niveau.

Analog zu den absoluten AP-Werten zeigt auch der relative zeitliche Verlauf eine weitgehend stabile AP-Aktivität innerhalb der Versuchsgruppe. Die entsprechende Regressionsgerade mit einem Bestimmtheitsmaß von nur 0,022 lässt keinen Anhalt für einen linearen Zusammenhang zwischen AP-Serumaktivität und Zeit erkennen.

\subsection{Periphere quantitative Computertomographie (pQCT)}

Im Folgenden werden Diaphyse und Epihyse getrennt voneinander betrachtet. Für beide Tibiaabschnitte wurden Knochendichte und -fläche erfasst. Die computertomographischen Messergebnisse geben dabei jeweils Auskunft über Dichte beziehungsweise Fläche des kortikalen Knochens und der Trabekel. Rechnerisch ermittelte Gesamtwerte fassen außerdem die jeweiligen kortikalen und trabekulären Daten zusammen.

\subsubsection{Diaphysäre Knochendichte und -fläche}

Für die an der Diaphyse ermittelte Gesamtknochendichte ergibt sich mit einem Mittelwert von 1023,6 mg/cm 3 in der Versuchsgruppe ein geringfügig höherer Wert als bei den Kontrolltieren (Abbildung 11). Der Unterschied zwischen beiden Gruppen ist jedoch nicht signifikant. Aufgrund der in der Diaphyse deutlich vorherrschenden kortikalen Knochenstruktur spielt der trabekuläre Knochen für die Gesamtdichte nur eine untergeordnete Rolle. Betrachtet man die Messergebnisse für kortikalen und trabekulären Knochen dennoch getrennt, so ist die Knochendichte in beiden Fällen in der Versuchsgruppe minimal höher als bei den Tieren der scheinoperierten Kontrollgruppe. Signifikante Unterschiede zeigen sich jedoch nicht. 


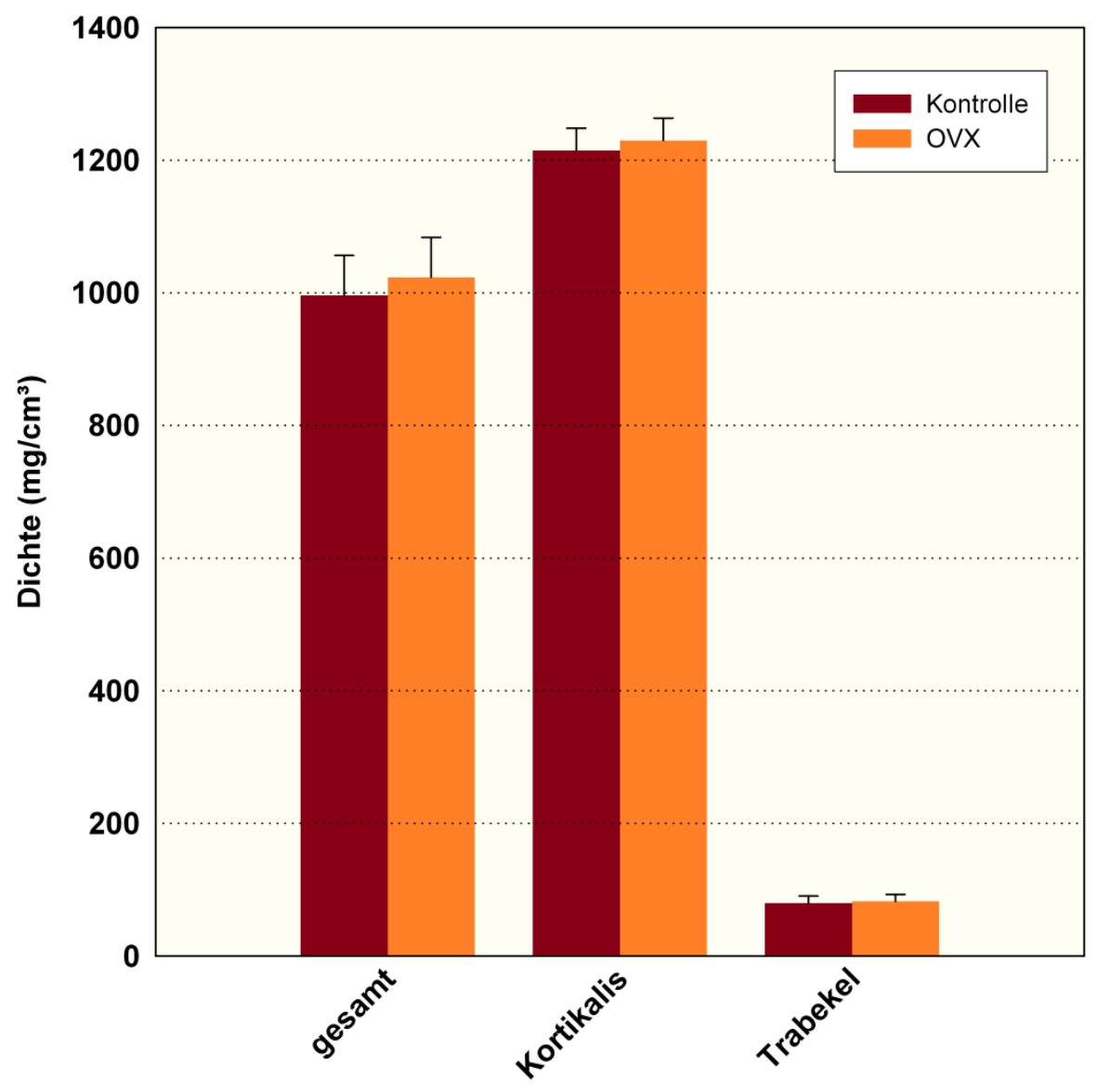

Abb. 11: Knochendichte im Bereich der Diaphyse bei Versuchsende. Dargestellt sind die Mittelwerte der gesamten, der kortikalen und der trabekulären Knochendichte mit zugehörigen Standardfehlern im Vergleich zwischen Kontroll- und Versuchsgruppe $(n=15)$.

Auch die diaphysär gemessene Gesamtknochenfläche zeigt zwischen beiden Versuchstiergruppen keinen signifikanten Unterschied (Abbildung 12). Der Mittelwert liegt bei den OVX-Tieren geringfügig unter dem der scheinoperierten Tiere. Der sich hier zeigende Unterschied ist dabei auf eine etwas größere trabekuläre Fläche der Kontrollgruppe zurückzuführen, während die mittleren Flächenwerte des kortikalen Knochens für beide Gruppen nahezu identisch ausfallen. 


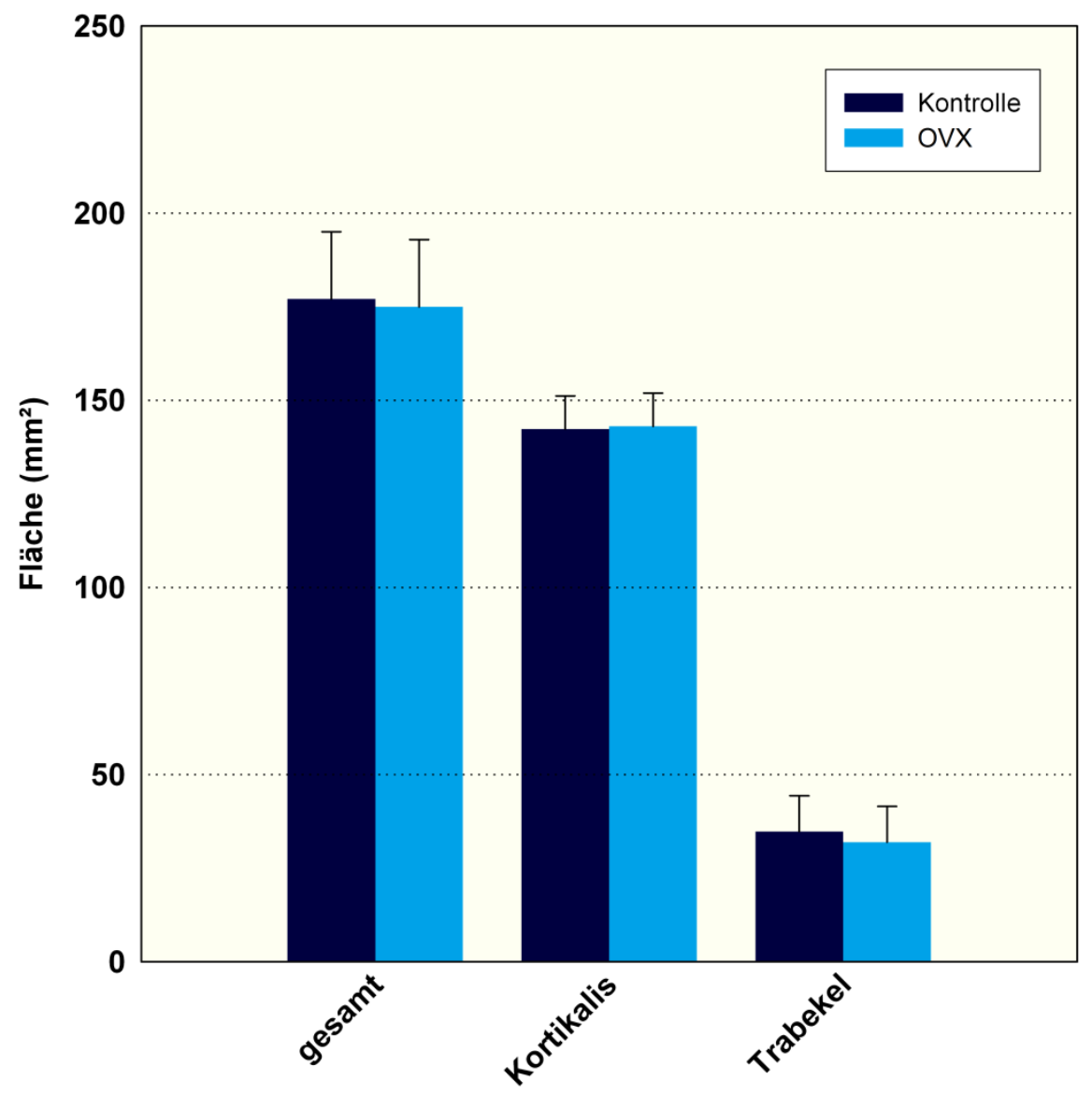

Abb. 12: Knochenfläche im Bereich der Diaphyse bei Versuchsende. Dargestellt sind die Mittelwerte der gesamten, der kortikalen und der trabekulären Knochenfläche mit zugehörigen Standardfehlern im Vergleich zwischen Kontroll- und Versuchsgruppe $(n=15)$.

\subsubsection{Epiphysäre Knochendichte und -fläche}

Bei Betrachtung der Werte der epiphysären Gesamtknochendichte lässt sich zunächst auch hier kein nennenswerter Unterschied zwischen beiden Gruppen erkennen (Abbildung 13). Unter Hinzunahme der für die verschiedenen Knochenbereiche getrennt erfassten Messergebnisse zeigt sich jedoch ein signifikanter Unterschied für die kortikale Dichte im Bereich der Epiphyse: Diese fällt bei den ovarektomierten Minischweinen mit einem Mittelwert von $692 \mathrm{mg} / \mathrm{cm}^{3}$ höher aus als bei den Kontrolltieren, welche im Durchschnitt nur 660,4 mg/cm³ erreichen. Die trabekuläre Knochendichte liegt dagegen in der Kontrollgruppe etwas höher als in der ovarektomierten Versuchsgruppe. Der hier feststellbare Unterschied erweist sich jedoch als nicht signifikant. 


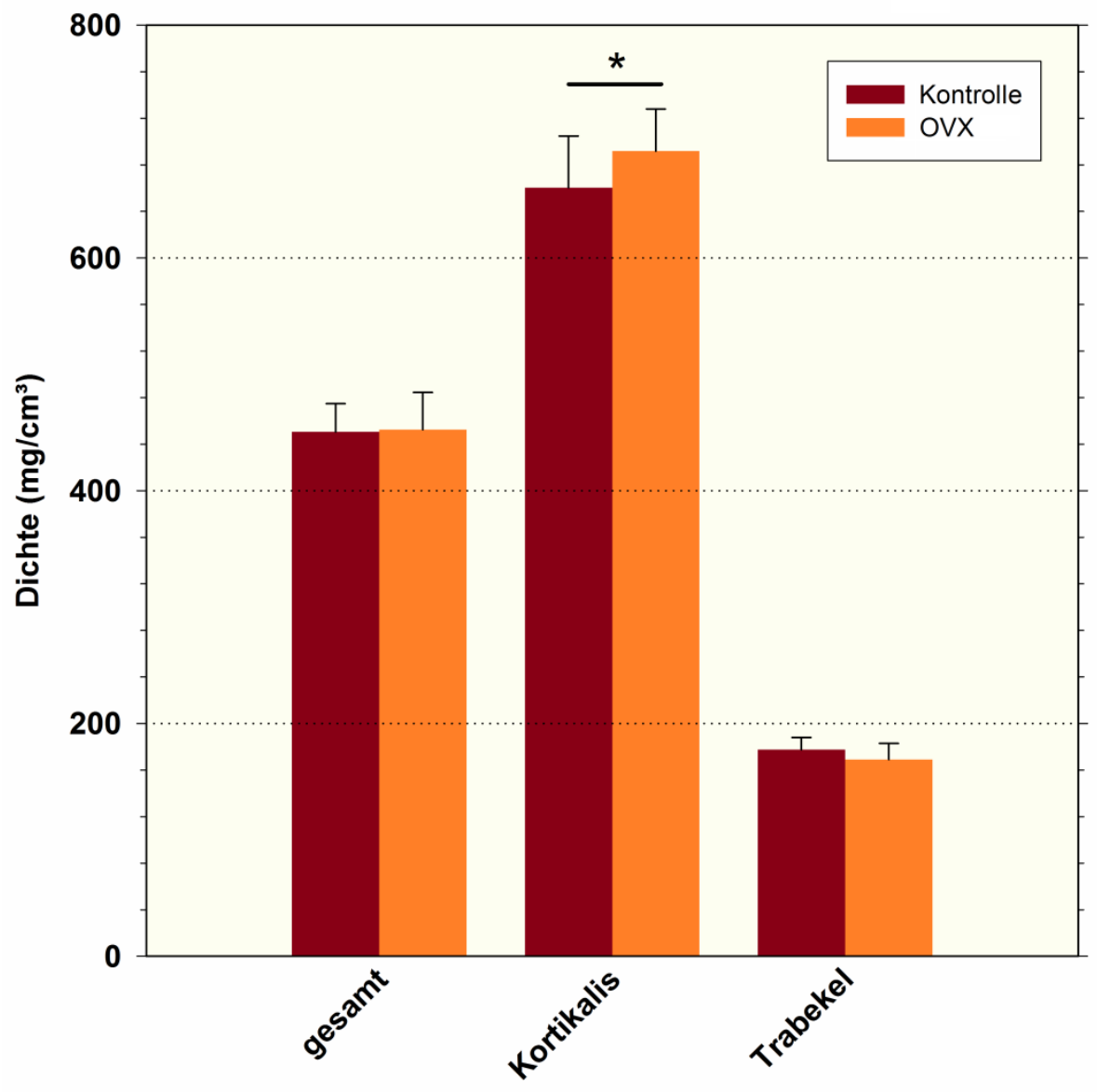

Abb. 13: Knochendichte im Bereich der Epiphyse bei Versuchsende. Dargestellt sind die Mittelwerte der gesamten, der kortikalen und der trabekulären Knochendichte mit zugehörigen Standardfehlern im Vergleich zwischen Kontroll- und Versuchsgruppe $(n=15)$. An der Kortikalis ergibt sich ein signifikanter Unterschied zwischen beiden Gruppen (*).

Die an der Epiphyse gemessene Gesamtknochenfläche liegt für die OVX-Tiere mit einem Mittelwert von 794,19 $\mathrm{mm}^{2}$ unterhalb der der scheinoperierten Minischweine, welche durchschnittlich 836,13 $\mathrm{mm}^{2}$ erreichen (Abbildung 14). Auch bei Betrachtung der kortikalen Fläche sehen die Unterschiede zwischen beiden Gruppen ähnlich aus, erneut erreicht die Kontrollgruppe höhere Werte. In beiden Fällen sind die Unterschiede bezüglich der Fläche jedoch als nicht signifikant zu werten. Die trabekuläre Knochenfläche unterscheidet sich epiphysär kaum zwischen beiden Versuchstiergruppen. 


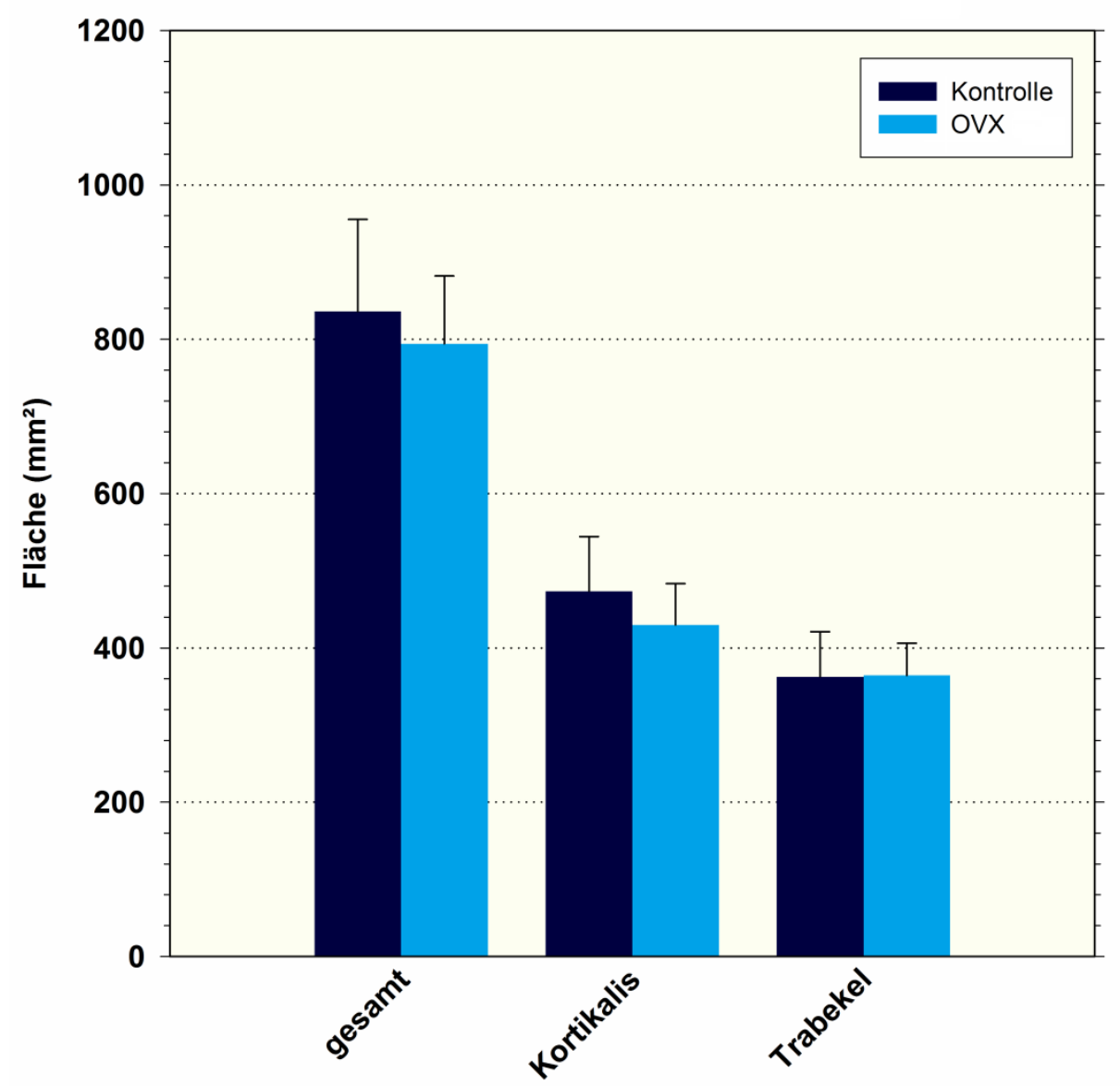

Abb. 14: Knochenfläche im Bereich der Epiphyse bei Versuchsende. Dargestellt sind die Mittelwerte der gesamten, der kortikalen und der trabekulären Knochenfläche mit zugehörigen Standardfehlern im Vergleich zwischen Kontroll- und Versuchsgruppe $(n=15)$.

\subsubsection{Korrelation zwischen Knochendichte und -fläche}

Um den Zusammenhang zwischen Knochendichte und -fläche genauer beurteilen zu können, wurden die entsprechenden epiphysären Messergebnisse in zwei Streudiagrammen gegeneinander aufgetragen. In Abbildung 15 ist dies zunächst für den kortikalen Knochen dargestellt, in Abbildung 16 dann für die Trabekel. Zusätzlich wurden die linearen Regressionsgeraden rechnerisch ermittelt und in die jeweiligen Graphen eingezeichnet. 


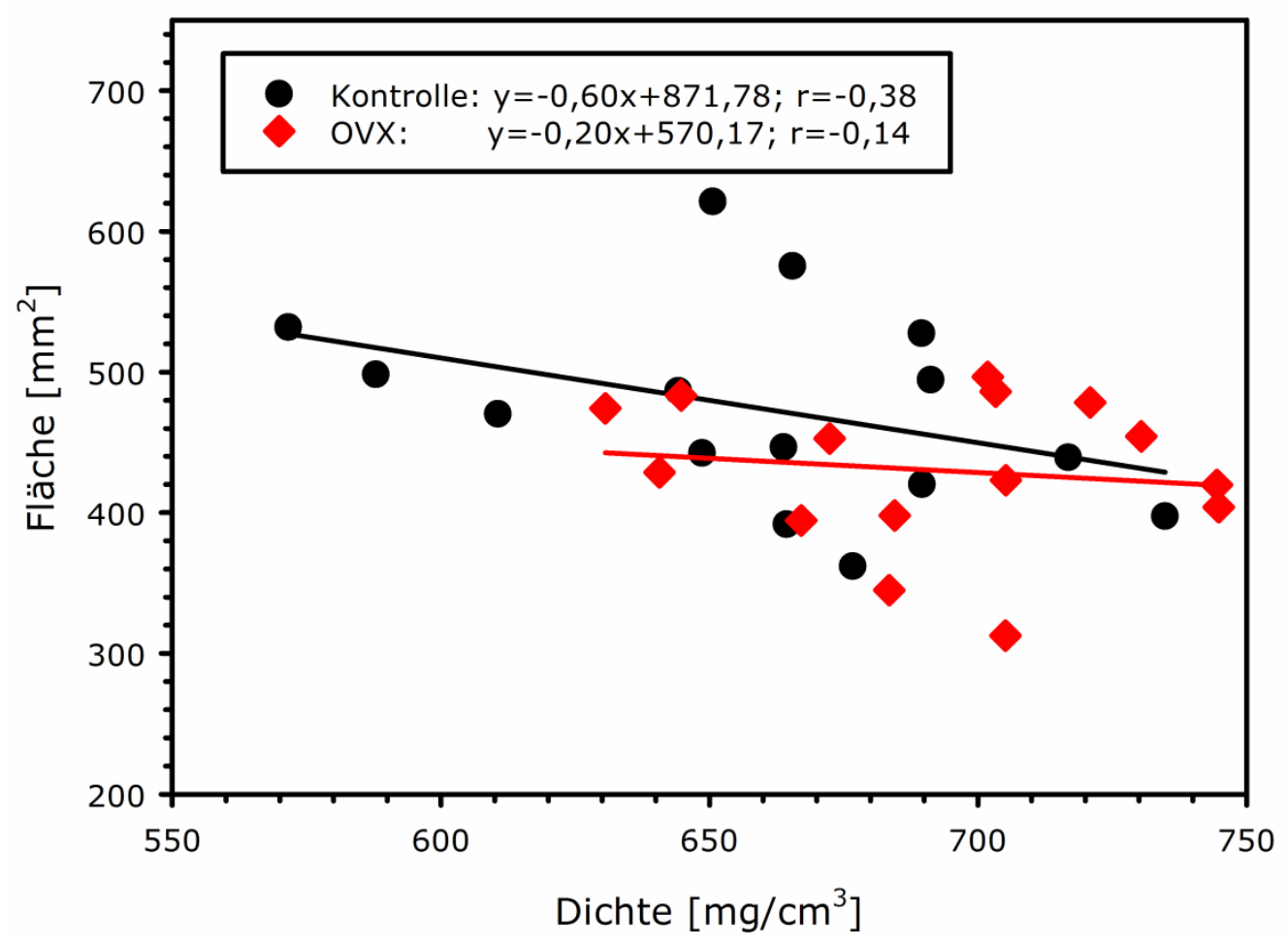

Abb. 15: Korrelation zwischen kortikaler Knochendichte und -fläche. Zu erkennen ist die graphische Auftragung der an der Epiphyse gemessenen kortikalen Knochenfläche gegen die entsprechende Knochendichte innerhalb der Versuchs- und Kontrollgruppe. Zusätzlich dargestellt sind die linearen Regressionen. Die errechneten Regressionsgeraden sind als $y=f(x)$ in der Legende mit zugehörigem Korrelationskoeffizienten $r$ angegeben $(n=15)$.

Bei Betrachtung des kortikalen Knochens zeigt sich, dass innerhalb beider Versuchsgruppen mit zunehmender Knochendichte die Fläche tendenziell abnimmt. Es ergibt sich demnach in beiden Fällen ein negativ linearer Zusammenhang zwischen den Messgrößen. Dieser Zusammenhang ist insgesamt nicht besonders stark ausgeprägt, fällt allerdings in der Kontrollgruppe stärker aus als in der OVX-Gruppe. Der Korrelationskoeffizient erreicht für die scheinoperierten Schweine einen Wert von -0,38, während sich der entsprechende Koeffizient für die ovarektomierten Tieren auf nur $-0,14$ beläuft. Auch die Steigung der errechneten Regressionsgeraden fält mit -0,6 für die Kontrollgruppe im Betrag höher aus als für die Versuchsgruppe, für die sich lediglich ein Wert von -0,2 ergibt. 


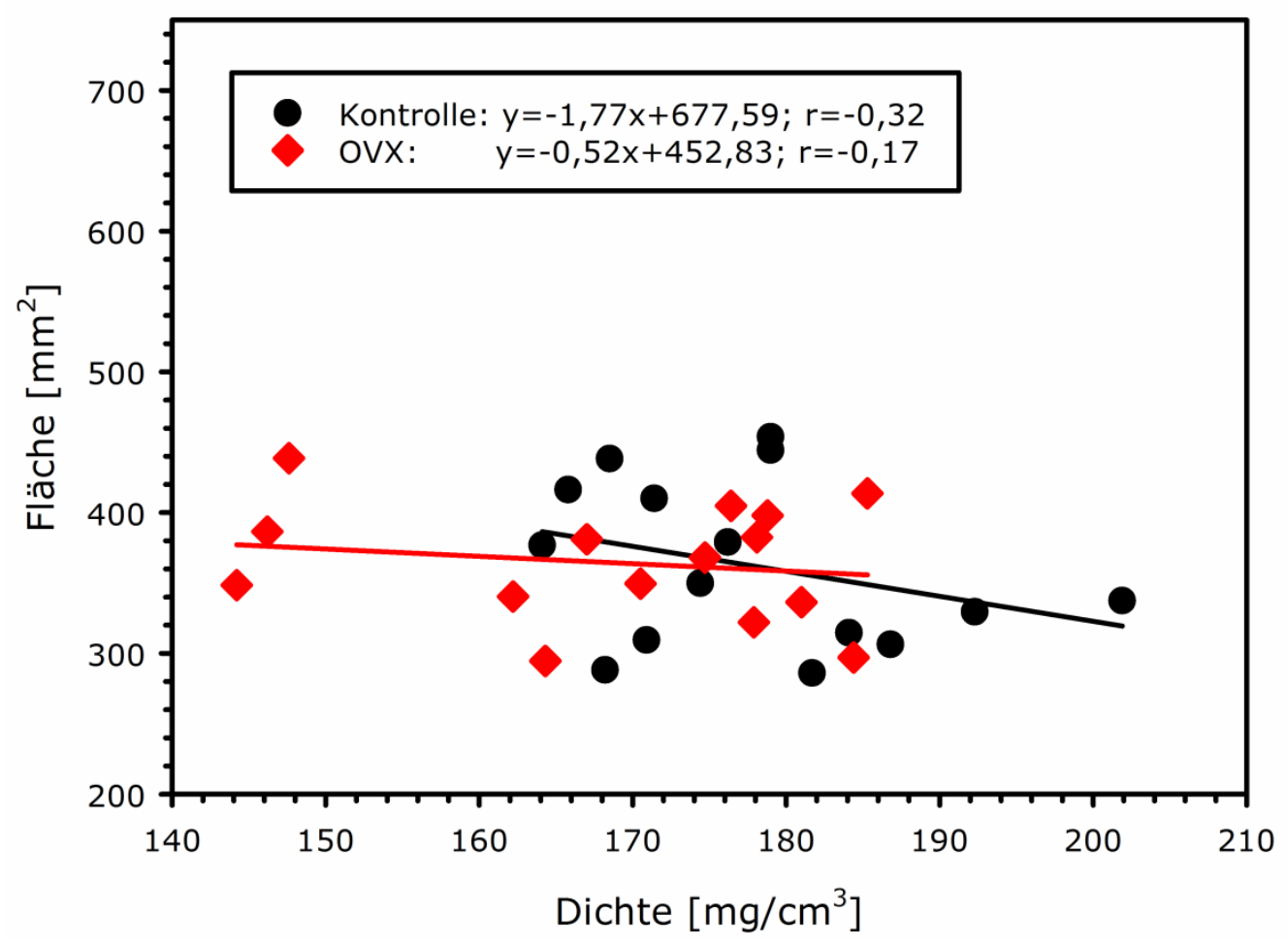

Abb. 16: Korrelation zwischen trabekulärer Knochendichte und -fläche. Zu erkennen ist die graphische Auftragung der an der Epiphyse gemessenen trabekulären Knochenfläche gegen die entsprechende Knochendichte innerhalb der Versuchs- und Kontrollgruppe. Zusätzlich dargestellt sind die linearen Regressionen. Die errechneten Regressionsgeraden sind als $y=f(x)$ in der Legende mit zugehörigem Korrelationskoeffizienten $r$ angegeben $(n=15)$.

Am trabekulären Knochen zeigt sich ein ähnliches Bild. Auch hier ist der Zusammenhang zwischen Knochendichte und -fläche in der Kontrollgruppe mit einem Korrelationskoeffizienten von -0,32 stärker ausgeprägt als in der Versuchsgruppe, für die sich diesbezüglich nur ein Wert von -0,17 errechnet. Erneut ist dieser Zusammenhang am ehesten als negativ linear zu werten. Die Steigung der ermittelten Regressionsgeraden beläuft sich für die scheinoperierten Tiere auf $-1,77$ und für die OVX-Schweine auf $-0,52$. Somit fällt die Steigung abermalig für die Kontrollgruppe im Betrag höher aus als für die Versuchsgruppe. Im Vergleich zur Kortikalis ergeben sich am trabekulären Knochen für beide Gruppen im Betrag größere Steigungswerte. 


\subsection{Polychrome Sequenzmarkierung}

Unter fluoreszenzmikroskopischer Betrachtung der angefertigten Trenn-DünnschliffPräparate zeigten sich in allen drei Messbereichen fluoreszierende Farbstoffbanden (Abbildungen 17, 18 und 19). Das im Knochen fixierte Alizarin war dabei anhand seiner rötlichen Farbe zu erkennen, während das abgelagerte Tetrazyklin gelblich fluoreszierte. Erwartungsgemäß lag die Tetrazyklin-Bande im Bereich des periostalen Knochens weiter peripher als die Alizarin-Bande, am endokortikalen Knochen war es umgekehrt. Die angefärbten Osteone wiesen in der Regel nur eine Farbstoffbande auf.
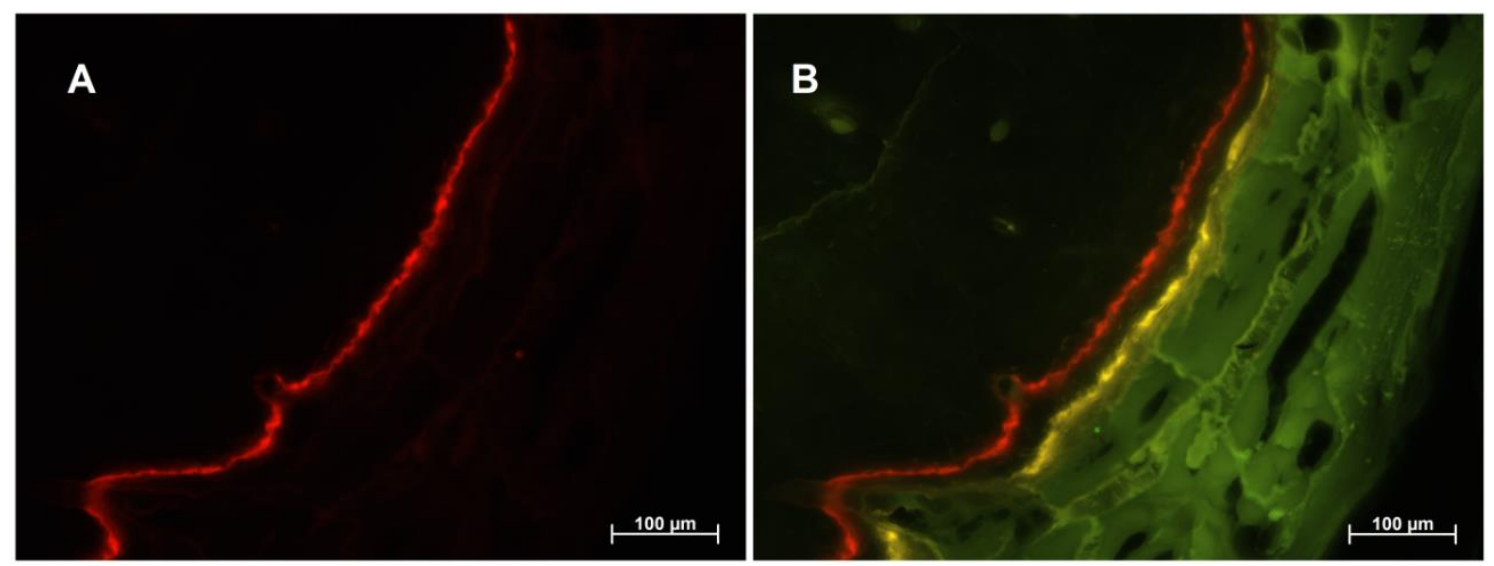

Abb. 17: Fluoreszenzmikroskopische Betrachtung des periostalen Knochens. Während in A nur die rötliche durch Alizarin hervorgerufene Farbstoffbande erkennbar ist, wird innerhalb desselben Präparatausschnittes bei Verwendung eines weniger selektiven Anregungsfilters auch die gelbliche Tetrazyklin-Bande sichtbar (B). Die breite grüne Bande stellt die Eigenfluoreszenz der Kollagene des Knochens dar.
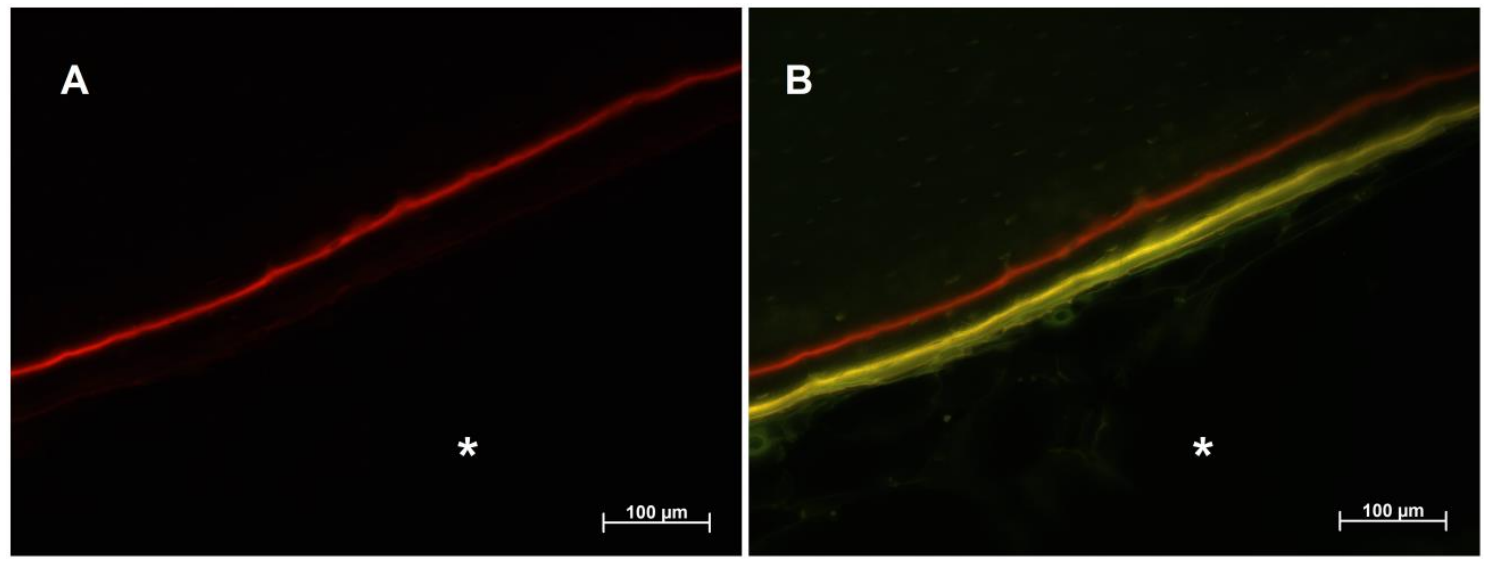

Abb. 18: Fluoreszenzmikroskopische Betrachtung des endokortikalen Knochens. Ana$\log z u$ Abbildung 17 ist unter Verwendung eines selektiven Anregungsfilters lediglich die rötliche Alizarin-Bande zu erkennen (A), während mit einem weniger selektiven Filter auch die gelbliche Tetrazyklin-Bande ersichtlich wird (B). In beiden Ausschnitten ist die Markhöhle jeweils mit einem Stern $\left({ }^{*}\right)$ markiert. 


\subsubsection{Totale Knochenapposition}

Mit dem Begriff „totale Apposition“ wird im Folgenden für den periostalen und endokortikalen Knochen die aus beiden Farbstoffbandenbreiten und dem zwischen ihnen gemessenen Abstand gebildete Summe bezeichnet. Da sich pro Osteon meist nur ein Fluorochrom zeigte, wurde für diesen Bereich des Knochens die Summe lediglich aus den Breiten zweier in unterschiedlichen Osteonen gefundener, verschiedenfarbiger Banden gebildet. Hierdurch erklärt sich die an den Osteonen eindeutig am niedrigsten ausfallende Knochenapposition (Abbildung 20). Ein direkter Vergleich der periostalen und endokortikalen Apposition mit der der Osteone ist daher nicht zielführend.

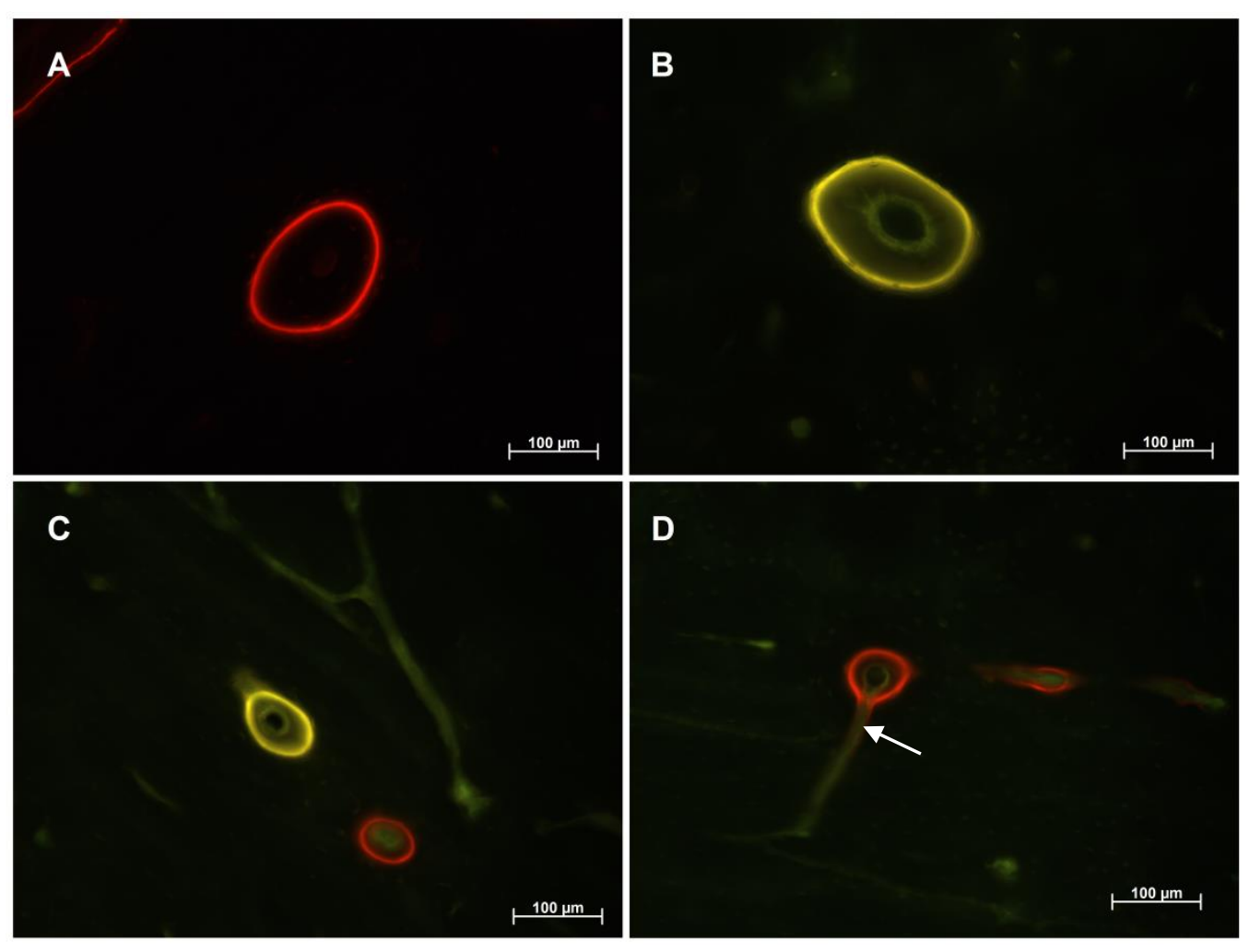

Abb. 19: Fluoreszenzmikroskopische Betrachtung der angefärbten Osteone. Zu erkennen sind ein Alizarin-markiertes (A) und ein Tetrazyklin-markiertes (B) Exemplar. Von den beiden in Ausschnitt $C$ erfassten Osteonen weist eines eine gelbliche Tetrazyklin-bedingte Fluoreszenz auf, während das zweite aufgrund der gebundenen Alizarin-Moleküle rötlich fluoresziert. In Ausschnitt $D$ ist ein von einem markierten Osteon ausgehender akzidentiell angeschnittener Volkmann-Kanal (Pfeil) erkennbar. 
Die totale Apposition erreicht innerhalb beider Gruppen für den endokortikalen Knochen höhere Werte als für den periostalen. Wirft man einen Blick auf die Unterschiede zwischen ovarektomierten und scheinoperierten Tieren, so kann periostal eine in der Versuchsgruppe hochsignifikant niedrigere Knochenapposition beobachtet werden, während endokortikal im Vergleich zur Kontrollgruppe hochsignifikant höhere Werte auftreten. Im Bereich der Osteone zeigt sich wie am periostalen Knochen bei den ovarektomierten Tieren eine geringere Apposition. Auch dieser Unterschied erweist sich als hochsignifikant.

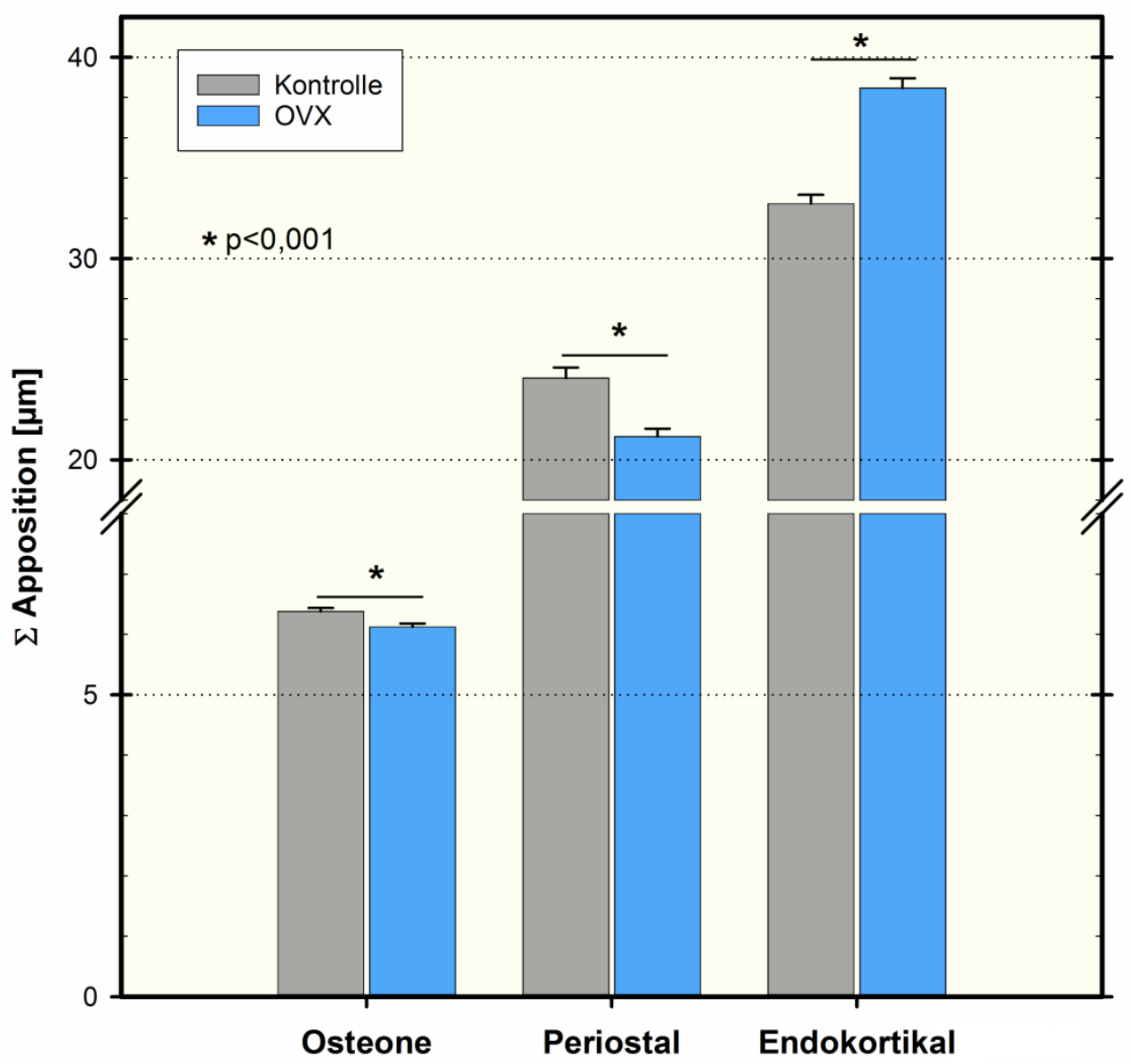

Abb. 20: Totale Knochenapposition im Bereich der Osteone, des periostalen und des endokortikalen Knochens. Dargestellt sind die Mittelwerte und Standardfehler von jeweils 300 Messungen bei fünf scheinoperierten und fünf ovarektomierten Minischweinen. Da bei der Markierung der Osteone in der Regel nur eine Farbstoffbande pro Osteon auftrat, konnte zwischen den Banden keine Apposition gemessen werden, so dass hier nur die Bandenbreiten berücksichtigt wurden. Daher ergeben sich in diesem Bereich deutlich niedrigere Werte für die totale Apposition. Die Appositionen der ovarektomierten Tiere unterscheiden sich in allen drei Bereichen hochsignifikant von den Werten der Kontrolltiere $\left({ }^{*}\right)(t-T e s t, n=300 ; p<0,001)$. 


\subsubsection{Knochenapposition pro Tag}

Die aus den Alizarin- und Tetrazyklin-Bandenbreiten errechneten täglichen Appositionsraten werden in Abbildung 21 dargestellt. Durch die unterschiedlichen Applikationszeitpunkte der beiden Farbstoffe wird eine Beurteilung des zeitlichen Verlaufs der Knochenapposition möglich.

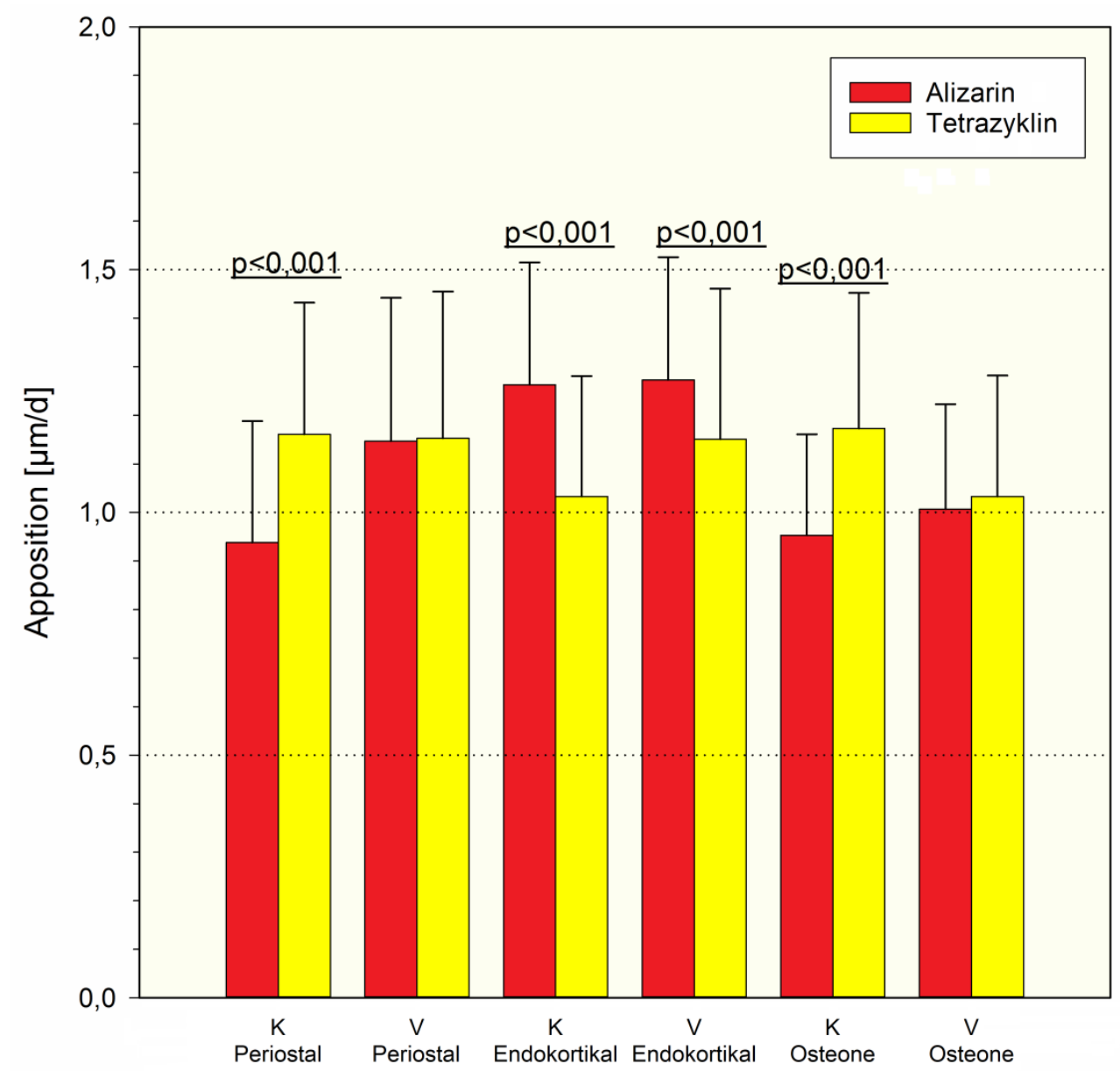

Abb. 21: Apposition pro Tag für Alizarin und Tetrazyklin. Die täglichen Knochenappositionsraten wurden aus den Breiten der Alizarin- (Tag 143) beziehungsweise Tetrazyklin-Banden (Tag 209) berechnet. Dargestellt sind die Mittelwerte und Standardfehler der Kontrollgruppe (K) und der ovarektomierten Versuchsgruppe (V) für die periostale und endokortikale Apposition sowie für die Apposition der Osteone. Angegeben sind ferner die Signifikanzen nach $t$-Test zwischen beiden Fluorochromen $(n=300$ Messungen). 
Die aus der Alizarin-Bandenbreite errechnete tägliche Appositionsrate gibt Auskunft über die Knochenformation zum Zeitpunkt der Alizarin-Applikation (Tag 143), die aus der Tetrazyklin-Bandenbreite errechnete Rate lässt Rückschlüsse auf die Apposition zum Zeitpunkt der Tetrazyklin-Applikation (Tag 209) zu. Vergleicht man gruppenintern diese beiden Appositionsraten miteinander, so zeigen sich für die Kontrollgruppe in allen drei Messbereichen, also periostal, endokortikal und im Bereich der Osteone, hochsignifikante Unterschiede: Am periostalen Knochen und an den Osteonen finden sich zum Zeitpunkt der Tetrazyklin-Applikation höhere Appositionsraten als zum Zeitpunkt der Alizarin-Applikation, was auf einen sich im Versuchsverlauf steigernden Knochenanbau in diesen Bereichen schließen lässt. Am endokortikalen Knochen hingegen zeigt sich die Appositionsrate rückläufig. Dies weist auf eine hier im Versuchsverlauf abnehmende Knochenanlagerung hin.

Innerhalb der Versuchsgruppe kann lediglich am endokortikalen Knochen ein signifikanter Unterschied zwischen den beiden täglichen Appositionsraten ausgemacht werden. Hier zeigt sich die Appositionsrate im Versuchsverlauf hochsignifikant rückläufig, ähnlich wie es an gleicher Stelle auch für die Kontrollgruppe zu beobachten ist. Die Appositionsrate scheint bei den ovarektomierten Tieren allerdings etwas weniger stark abzufallen als bei den scheinoperierten. Im Bereich des periostalen und des osteonalen Knochens lassen sich für die Versuchsgruppe keine signifikanten Unterschiede zwischen den beiden errechneten Appositionsraten erkennen.

Es lässt sich folglich feststellen, dass periostal und osteonal die tägliche Appositionsrate innerhalb der Kontrollgruppe zugenommen hat, während für die ovarektomierte Versuchsgruppe eine solche Steigerung der Appositionsrate nicht beobachtet werden konnte. Die endokortikale Appositionsrate zeigte sich in beiden Gruppen rückläufig. 


\section{Diskussion}

Die hohe Prävalenz der Osteoporose in unserer Gesellschaft geht mit einer großen sozialen und ökonomischen Bedeutung der Erkrankung einher. Im Sinne einer möglichst umfassenden Aufklärung der ihr zugrundeliegenden Prozesse wurde im Rahmen dieser Arbeit das osteoporotisch veränderte Knochenremodeling unter Einsatz eines ovarektomierten Tiermodells untersucht.

\subsection{Diskussion der Methodik}

Präklinische Studien mit Hilfe von Tiermodellen ermöglichen eine Annäherung an humane Krankheitsprozesse und sind daher essentiell für die medizinische Forschung (Reinwald und Burr 2008). Das herausragende Potential von Tiermodellen in der Osteoporoseforschung kann allerdings nur dann zur Geltung kommen, wenn der Auswahl von Tierart und -alter sowie der Versuchsgestaltung hohe Aufmerksamkeit gewidmet wird (Turner et al. 2001). Ein geeignetes Tiermodell sollte dabei den individuellen Anforderungen der jeweiligen Untersuchung gerecht werden und zugleich auch ethische sowie ökonomische Aspekte berücksichtigen. Außerdem gilt es, die Erkenntnisse vorangegangener Studien in die Versuchsplanung einfließen zu lassen.

\subsubsection{Tiermodell}

Im Rahmen der Osteoporoseforschung stellt die ovarektomierte Ratte das am häufigsten eingesetzte Tiermodell dar (Egermann et al. 2005). Die Vorteile eines solchen Nagetiermodells gegenüber anderen Säugetierarten ergeben sich vor allem aus den geringen Kosten in Anschaffung und Haltung, der leichten Handhabung sowie der weitreichenden Erfahrung mit dem Einsatz dieser Tiere in der medizinischen Forschung. Im Zuge tiefer greifender Untersuchungen stößt das Nagetiermodell jedoch hinsichtlich seiner Übertragbarkeit auf den Menschen schnell an seine Grenzen. So mangelt es inm unter anderem an intrakortikalem Remodeling (Jee und Yao 2001; Reinwald und Burr 2008; Lelovas et al. 2008), obwohl gerade dies eine für den menschlichen Knochen maßgebliche Eigenschaft darstellt (Reinwald und Burr 2008).

Wenn das Nagetiermodell den Versuchsanforderungen nicht genügt, so wird ein Großtiermodell erforderlich, das in der Regel die humane Physiologie besser widerspiegelt. Würde man bei der Versuchstierauswahl ausschließlich diesen Aspekt berücksichtigen, 
so wäre der Einsatz nicht-humaner Primaten die naheliegende Konsequenz. Von allen größeren Säugetierarten sind diese unter physiologischen Gesichtspunkten dem Menschen am ähnlichsten, sie sind jedoch aufgrund der hohen Kosten für einen großflächigen Forschungseinsatz nicht geeignet (Reinwald und Burr 2008). Abgesehen davon stünden einem solchen Vorgehen weitreichende ethische Vorbehalte im Wege. Eine Alternative stellt neben Hunde- und Schafsmodellen das Schwein dar, das dem Menschen in Größe, Ernährung, Knochenstruktur und Mineralstoffwechsel ähnelt (Spencer 1979). Es verfügt außerdem über Lamellenknochen, weist trabekuläres sowie intrakortikales Remodeling auf und sein Östrogenzyklus erinnert in seinem Rhythmus an den des Menschen (Mosekilde et al. 1993a). Mit einem Schweinemodell kann folglich genau an dem Punkt angeknüpft werden, an dem das Nagetiermodell die Grenzen seiner Übertragbarkeit erreicht. Der tierexperimentelle Einsatz von Hausschweinen wird allerdings durch ihre Größe und den erheblichen Futter- sowie Platzbedarf erschwert (Beglinger et al. 1975). Mit dem Rückgriff auf Mini- oder Mikroschweine lassen sich viele dieser auf ihrer Größe beruhenden Probleme umgehen (Reinwald und Burr 2008). Das Minischwein eignet sich aufgrund seiner zweckmäßigen Größe, leichten Handhabung, relativ geringen Kosten und guten Verfügbarkeit insbesondere für Langzeitstudien und ist zudem als das Tier zu betrachten, das hinsichtlich Physiologie und Knochenstoffwechsel, abgesehen vom nicht-humanen Primaten, die ausgeprägtesten Ähnlichkeiten zum Menschen aufweist (Mardas et al. 2014). Im Rahmen der Osteoporoseforschung wurden ovarektomierte Mini- und Mikroschweine bereits mehrfach erfolgreich eingesetzt (Mosekilde et al. 1993a; Mosekilde et al. 1993b; Boyce et al. 1995; Borah et al. 2002; Kim et al. 2013).

Die Entwicklung des im Rahmen dieser Arbeit einsetzten Göttinger Minischweines begann in den 1960er-Jahren an der hiesigen Universität unter Zuhilfenahme des Minnesota Minischweines, des Vietnamesischen Hängebauchschweines und der Deutschen Landrasse (Simianer und Köhn 2010). Es stellt eine in der medizinischen Forschung gängige Minischwein-Rasse dar, die vor dem Hintergrund der vorangegangenen Überlegungen auch als osteoporotisches Großtiermodell geeignet erscheint.

Da die natürliche Entwicklung einer Osteoporose nur beim Menschen und beim nichthumanen Primaten auftritt (Egermann et al. 2005), ergibt sich für Tiermodelle in der Regel die Notwendigkeit, den angestrebten Knochenverlust auf andere Weise zu induzieren. Analog zum Rattenmodell kann dies auch am Großtiermodell durch eine bilaterale Ovarektomie geschehen. Durch diese lässt sich in Säugetieren eine Beendigung des Östrogenzyklus herbeiführen und ein die humane Postmenopause endokrinolo- 
gisch und teilweise auch skelettal imitierender Zustand induzieren (Reinwald und Burr 2008).

Dieser Effekt kann durch eine nutritive Calciumrestriktion weiter verstärkt werden. So konnten Mosekilde et al. (1993b) am Sinclair S-1-Minischwein einen signifikanten Knochendichterückgang an Wirbelkörpern, Femur und Radius nach Ovarektomie und Calciumrestriktion beobachten, während die alleinige Gonadenentfernung lediglich an den Wirbelkörpern zu einer signifikant reduzierten Knochendichte führte. Mosekilde et al. (1993a) beschreiben die Kombination von Ovarektomie und reduzierter Calciumzufuhr am Minischwein insofern als geeignetes Osteopenie-Modell und sehen darin einen vielversprechenden Ansatz für die Testung verschiedener Osteoporosetherapien. Sie beobachteten allerdings auch, dass ein nutritiver Calciumgehalt von 0,75 Prozent in Kombination mit einer Ovarektomie ausgeprägtere Effekte auf osteodensitometrische, histomorphometrische und biomechanische Untersuchungsparameter hervorrief als ein Calciumgehalt von nur 0,5 Prozent (Mosekilde et al. 1993b; Mosekilde et al. 1993a). Im Hinblick auf diese Ergebnisse wäre für die Versuchsgruppe der vorliegenden Untersuchung möglicherweise eine weniger drastische Calciumrestriktion als die gewählten 0,16 Prozent sinnvoll gewesen.

Hinsichtlich der Einschätzung von Knochendichte und Knochenstoffwechselparametern gilt es, auch das Alter der eingesetzten Versuchstiere zu berücksichtigen. So hat an der adulten Ratte die skelettale Reife zum Zeitpunkt der Ovarektomie einen starken Einfluss auf die induzierten Knochenmasseveränderungen (Bonjour et al. 1999). Im Zuge der Untersuchung der Lendenwirbelkörper und Femora von 53 weiblichen Göttinger Minischweinen war es Tsutsumi et al. (2004b) nicht möglich, das Erreichen der PBM innerhalb einer Altersspanne von drei bis 76 Monaten zu beobachten. Für Bouchard et al. (1996) war hingegen am Sinclair S-1-Minischwein eine maximale Knochenmineraldichte im Lebensalter zwischen zwei und vier Jahren mit anschließender Abnahme ersichtlich. Ob mit einem anfänglichen Alter von durchschnittlich vier Jahren in der Versuchs- und 3,2 Jahren in der Kontrollgruppe möglicherweise Tiere vor Erreichen ihrer PBM eingesetzt wurden, bleibt im Hinblick auf die widersprüchliche Literatur insofern unklar.

Auch Knochenbildungs- und Knochenresorptionsmarker weisen eine starke Korrelation mit dem Lebensalter auf (Tsutsumi et al. 2004b). Im Sinne einer besseren Vergleichbarkeit der Ergebnisse zwischen den einzelnen Gruppen wäre für künftige Untersuchungen insofern ein homogeneres Versuchstieralter anzustreben. Der Einsatz von älteren beziehungsweise weitgehend gleichaltrigen Tieren ist jedoch, insbesondere am 
Großtiermodell, auch mit steigenden Kosten verbunden, welche es bei der Versuchsplanung stets in Relation zu den erwünschten Vorteilen zu setzen gilt.

Angesichts des Umstandes, dass am adulten Schweinemodell bisher vor allem die osteopenen Veränderungen am Wirbelkörper im Fokus standen, scheint es sinnvoll, auch die Auswirkungen einer Ovarektomie auf die Extremitätenknochen genauer zu untersuchen (Reinwald und Burr 2008). Mit der Tibia wurde für die Versuche dieser Arbeit ein eben solcher Extremitätenknochen gewählt. Das Augenmerk der osteodensitometrischen und histomorphometrischen Analysen lag damit auf einem maßgeblich gewichttragenden Abschnitt der hinteren Gliedmaße. Kim et al. (2013) äußern nach Untersuchung von Lendenwirbel, Femur und Tibia ovarektomierter Mikroschweine den Verdacht, dass die Tibia sensibler auf eine Ovarektomie reagiert als andere Knochenregionen. Im Hinblick auf den zeitlich begrenzten Versuchszeitraum erscheint eine Fokussierung auf die Tibia folglich besonders sinnvoll.

Es lässt sich somit feststellen, dass mit dem Göttinger Minischwein ein Tiermodell gewählt wurde, das dem etablierten Nagetiermodell in mehreren Punkten überlegen ist und dem Menschen in besonderer Weise ähnelt. Sein Einsatz als Großtiermodell für die Osteoporoseforschung erscheint daher besonders sinnvoll. Für die in den vorliegenden Versuchen eingesetzten Tiere konnte Bartels (2010) bereits histomorphometrisch eine signifikante Reduktion des Trabekelvolumens an fünftem Lendenwirbelkörper, rechtem Femur sowie rechter Tibia als Ovarektomiefolge nachweisen. Die angestrebte Induktion einer osteoporotischen Knochenkonfiguration wurde folglich, zumindest auf feingeweblicher Ebene, erreicht.

\subsubsection{Laborchemische Serumanalysen}

Mit der Aufnahme von Serumanalysen in den Versuchsaufbau wurde das Ziel verfolgt, den Sexualhormonspiegel nach Ovarektomie zu überwachen und Einblick in die skelettalen Resorptions- und Formationsvorgänge zu erhalten.

Die im Zuge der Postmenopause reduzierte Ovarialfunktion hat einen Rückgang der Östrogenkonzentration im Serum zur Folge. Auch nach bilateraler Ovarektomie ist von erniedrigten Serumspiegeln weiblicher Sexualhormone auszugehen. Der zum postinterventionellen Hormonmonitoring gemessene Parameter E2 weist eine circa dreifach höhere biologische Aktivität als Estron auf und eine circa neunfach höhere als Estriol (Pschyrembel 2007). Weiterhin zeigen postmenopausale Frauen im Vergleich zu prä- 
menopausalen deutlich stärkere Spiegelrückgänge für E2 als für Estron (Judd et al. 1976). Der ausgewählte Östrogenvertreter erscheint folglich als gut geeignet zur hormonellen Kontrolle nach Ovarektomie.

Schon aus Kostengründen ergibt sich die Notwendigkeit, aus der Vielzahl der mittlerweile zur Verfügung stehenden Knochenumsatzmarker eine geeignete Auswahl zu treffen. Mit der CTX-Bestimmung im Serum wurde dabei ein etablierter Marker gewählt, welcher auch von der International Osteoporosis Foundation (IOF) und der IFCC als Referenzmarker der Knochenresorption für klinische Studien empfohlen wird (Vasikaran et al. 2011b; Vasikaran et al. 2011a). Der in diesem Zuge für den Knochenaufbau empfohlene Referenzmarker, das im Serum ermittelte Prokollagen Typ I N-Propeptid (PINP) (Vasikaran et al. 2011b; Vasikaran et al. 2011a), kam allerdings nicht zum Einsatz. Zur Abschätzung der Knochenbildungsprozesse wurde stattdessen auf $\mathrm{OC}$ zurückgegriffen, das neben PINP ebenfalls zu den meistgenutzten Formationsmarkern gehört (Wheater et al. 2013) und das am Göttinger Minischwein die gleichen altersabhängigen Entwicklungsmuster wie am Menschen aufweist (Tsutsumi et al. 2004a). Zusätzlich wurde die Volumenaktivität der AP bestimmt. Während OC allerdings einen in hohem Maße knochenspezifischen Marker darstellt, sind im Serum gesunder Erwachsener nur circa 50 Prozent der AP-Aktivität skelettalen Ursprungs, die andere Hälfte entstammt größtenteils dem hepatischen Stoffwechsel (Schmolke 2001; Vasikaran et al. 2011b). Schmolke (2001) schreibt der AP jedoch trotz ihrer niedrigen Spezifität eine wichtige Rolle in der Diagnose und Differentialdiagnose von Knochenerkrankungen zu. Um zuverlässigere Rückschlüsse bezüglich des Knochenstoffwechsels ziehen zu können, wäre eine Differenzierung zwischen den einzelnen AP-Isoformen dennoch eine sinnvolle Ergänzung gewesen.

\subsubsection{Periphere quantitative Computertomographie (pQCT)}

Für die Beurteilung der Knochendichte hat sich im klinischen Alltag mittlerweile die DXA-Methode durchgesetzt. Mit ihrer Hilfe ist eine WHO-konforme Diagnosestellung der Osteoporose, eine Einschätzung des Frakturrisikos sowie ein Monitoring der Knochendichte möglich (Dimai 2009). Auch wenn die DXA somit das klinische Referenzverfahren darstellt, so werden doch für tierexperimentelle Untersuchungen dreidimensionale Verfahren wie die PQCT empfohlen (Egermann et al. 2005). Auf diese Messtechnik wurde auch im vorliegenden Versuch zurückgegriffen. Die ermittelten Knochendichtewerte lassen sich dadurch zwar nicht direkt mit den in der Literatur vielfach vertretenen DXA-Analysen vergleichen, was aber durch wesentliche Vorteile der PQCT kompensiert wird: Während die DXA die Röntgenabsorption über einer Fläche erfasst, 
stellt die PQCT ein volumenselektives Verfahren dar, welches die getrennte Ermittlung des Mineralsalzgehaltes für einzelne Knochenkompartimente ermöglicht (Kasperk 2008). So können kortikaler und trabekulärer Knochen unabhängig voneinander beurteilt werden (Issever und Link 2011; Bonjour et al. 1999). Als tomographisches Verfahren zeigt sich die pQCT zudem auch weniger anfällig für Falschmessungen durch Überlagerungen wie sie bei der DXA auftreten können (Issever und Link 2011).

\subsubsection{Polychrome Sequenzmarkierung}

Zusätzlich zum indirekten Einblick in den Knochenstoffwechsel mit Hilfe von Knochenumsatzmarkern und zur osteodensitometrischen Momentaufnahme mittels pQCT sollte das osteoporotische Knochenremodeling auch auf feingeweblicher Ebene untersucht werden.

Die Histomorphometrie widmet sich im Zuge mikroskopischer Untersuchungen Aspekten der skelettalen Mikroarchitektur. Mit ihrer Hilfe können so wichtige Erkenntnisse über ossäre Modifikationen gewonnen werden, die makroskopisch nicht erfassbar wären. Es handelt sich bei konventionell-histologischen Verfahren jedoch zunächst um ein statisches Bild. Erst der Einsatz intravital verabreichter Fluorochrome erlaubt die Einführung einer zeitlichen Dimension und somit dynamische Erkenntnisse zu Knochenbildung und -mineralisation (Rahn und Perren 1972; Bonjour et al. 1999). Die dem Organismus dabei zugeführten Farbstoffe bilden Chelatkomplexe mit dem knöchernen Hydroxylapatit (Rahn und Schweiz 1980; Rahn 2003) und lassen sich zu einem späteren Zeitpunkt nach Probenentnahme und histologischer Aufbereitung ohne Entkalkung oder weitere Färbung fluoreszenzmikroskopisch erfassen (van Gaalen et al. 2010). Durch die Verabreichung mehrerer farblich differenzierbarer Fluorochrome zu vorbestimmten Zeitpunkten wird es möglich, Mineralisationszeitpunkte gezielt zu bestimmen (Rahn und Schweiz 1980). Dieses auch als polychrome Sequenzmarkierung bezeichnete Vorgehen ist folglich der Gabe eines einzelnen Markers deutlich überlegen und insofern besonders gut geeignet, um knochenmorphologische Entwicklungen zu untersuchen (Rahn 2003).

Als eine für diesen Zweck geeignete Substanz hat sich das als Antibiotikum bekannte Tetrazyklin erwiesen (Frost 1968, 1969; Lee 1964; Mosekilde et al. 1993b; Iwaniec und Crenshaw 1998; Pautke et al. 2010). Es stellt mit seinen Derivaten das einzige auch am Menschen zugelassene Fluorochrom dar (Pautke et al. 2010) und kam in Form von Tetrazyklinhydrochlorid auch für die Untersuchungen dieser Arbeit zum Einsatz. Der zweite verwendete Farbstoff, Alizarin, lässt sich aufgrund seiner tiefroten Fluoreszenz 
in der Regel gut von anderen Fluorochromen differenzieren und eignet sich folglich auch zur gemeinsamen Anwendung mit Tetrazyklin im Sinne einer polychromen Sequenzmarkierung (Rahn und Perren 1972). Mit Alizarin wurde somit ein weiterer etablierter Fluoreszenzmarker eingesetzt (Rahn und Perren 1972; van de Braak und van't Klooster 1987; Pautke et al. 2007). Der gewählte s.c. Applikationsweg ist einer relativ risikoreichen intraperitonealen Verabreichung überlegen und wird für kleine Versuchstiere bis hin zur Größe von Minischweinen als geeignet erachtet, während für noch größere Tiermodelle aufgrund der hohen benötigten Fluorochrommengen eine langsame i.v.-Gabe empfohlen wird (van Gaalen et al. 2010).

In der skelettalen Forschung stellt die Fluoreszenzmarkierung mittlerweile eine Standardmethode zur Analyse dynamischer Aspekte der Knochenbildung dar (van Gaalen et al. 2010). Es wurde insofern auf eine bewährte Technik zurückgegriffen, um die Knochenapposition der Versuchstiere zu quantifizieren.

\subsection{Diskussion der Ergebnisse}

Die ovarektomierte Ratte stellt ein etabliertes und weit verbreitetes Tiermodell in der Osteoporoseforschung dar. Ihr Skelettsystem unterscheidet sich allerdings in einigen Punkten bedeutend von dem des Menschen. Vor diesem Hintergrund sind auch Erkenntnisse über die Pathophysiologie der Osteoporose nur begrenzt vom Nagetiermodell auf den Menschen übertragbar. Aus diesem Grund kam für die Untersuchungen dieser Arbeit mit dem Göttinger Minischwein ein Großtiermodell zum Einsatz, dessen Knochen in Form und Größe denen des Menschen wesentlich besser entsprechen. Inwieweit die gesammelten Ergebnisse tatsächlich dazu beitragen können, die der Osteoporose zugrundeliegenden ossären Vorgänge besser zu verstehen, soll im Folgenden erörtert werden.

\subsubsection{Laborchemische Serumanalysen}

Wie erwartet wiesen die ovarektomierten Schweine fast über den gesamten Versuchszeitraum hin geringere E2-Serumkonzentrationen auf als die Kontrolltiere. Die angestrebte systemische Reduktion weiblicher Sexualhormone wurde folglich erreicht. Die anfänglich auch in der Kontrollgruppe rückläufigen E2-Spiegel können möglicherweise auf allgemeine versuchsbedingte Einflussgrößen zurückgeführt werden, die den Stoffwechsel aller Tiere in gleichem Ausmaß betroffen haben. Vorrangig sind hier die Ernährungsumstellung auf sojafreies Futter und der postoperative Stress anzuführen. 
Weshalb im Anschluss an den zweiten operativen Eingriff die E2Serumkonzentrationen der ovarektomierten Tiere einmalig anstiegen, während die der Kontrollgruppe zurückgingen, lässt sich durch postoperativen Stress oder sonstige Faktoren jedoch nicht zufriedenstellend erklären. Denkbar wären individuell unterschiedlich stark ausgeprägte Reaktionen auf die Operation und die mit ihr einhergehenden Faktoren Gewebemanipulation, Operationszeit und eingesetzte Medikamentenmengen. Gerade bei vergleichsweise kleinen Versuchspopulationen können sich solche individuellen Einflüsse besonders stark auswirken, der verhältnismäßig niedrige Standardfehler steht dieser Deutung allerdings eher entgegen. Die genauen Auswirkungen der Zahnimplantateinbringung auf den Stoffwechsel der Tiere lassen sich im Nachhinein ohnehin nur schwer einschätzen. Entscheidend ist jedenfalls, dass sich im weiteren Verlauf nach der Zahnimplantation für die Versuchsgruppe erneut deutlich niedrigere E2-Spiegel einstellten als für die Kontrollgruppe. Die ovarektomierten Schweine erreichten zum Versuchsende dann die niedrigsten E2-Spiegel des gesamten Versuchszeitraumes. Erwartungsgemäß lassen auch die relativen E2-Werte dieser Gruppe eine eindeutig fallende Tendenz über den gesamten Versuchszeitraum hinweg erkennen. Die dabei trotz fehlender Ovarien im Blut zirkulierenden Östrogene sind wahrscheinlich größtenteils auf eine periphere Umwandlung von Androgenen zurückzuführen, die auch im Zuge der nachlassenden Ovarialfunktion während der Postmenopause den bedeutendsten Syntheseweg für Östrogene darstellt (Judd et al. 1976).

Betrachtet man den laborchemischen Verlauf der Knochenumsatzmarker, so zeigt sich, dass sich die Ovarektomie nicht nur auf den Östrogenhaushalt selbst sondern auch auf den ossären Stoffwechsel ausgewirkt hat. Bis einschließlich Tag 143 wiesen die ovarektomierten Tiere im Vergleich zur Kontrollgruppe erhöhte Serumspiegel sowohl für CTX als auch für OC auf. Dies lässt auf eine Steigerung der Knochenresorption und der Knochenformation während der ersten 20 Wochen nach Ovarektomie schließen. Die Aktivität der AP hingegen lag bei den OVX-Schweinen fast durchgehend unterhalb der der Kontrolltiere. Im Folgenden soll auf die einzelnen Marker detaillierter eingegangen werden.

So wie peri- und postmenopausale Frauen gesteigerte CTX-Konzentrationen als Ausdruck beschleunigter knochenresorptiver Prozesse aufweisen (Schmolke 2001), so sind auch die erhöhten CTX-Spiegel der ovarektomierten Versuchstiere dieser Arbeit als Zeichen eines vermehrten, auf Östrogenmangel beruhenden Knochenabbaus zu verstehen. Erhöhte CTX-Serumkonzentrationen nach Ovarektomie konnten auch am 
Tiermodell der Ratte bereits nachgewiesen werden (Yoon et al. 2012). Die Ergebnisse der vorliegenden Untersuchung zeigen darüber hinaus, dass dieser gesteigerte Knochenabbau im Großtiermodell insbesondere während der ersten vier bis fünf Monate nach Einleitung des Östrogendefizits stattfindet und im Anschluss daran deutlich abnimmt.

Ähnlich wie die ermittelten CTX-Konzentrationen stiegen auch die OC-Werte der OVXSchweine in den ersten Monaten nach Versuchsbeginn deutlich an und lagen dabei weit über den Werten der Kontrollgruppe. Wie schon erwähnt dokumentiert diese Beobachtung für die ovarektomierten Tiere eine parallel zur Knochenresorption gesteigerte Knochenneubildung. In der Klinik lassen sich bei etwa einem Drittel der Osteoporosepatienten erhöhte OC-Serumspiegel im Sinne eines beschleunigten Knochenumbaus finden (Schmolke 2001). Die tierexperimentelle Literatur ergibt hinsichtlich der OC-Entwicklung nach Ovarektomie ein uneinheitliches Bild: So fanden auch Yoon et al. (2012) an der ovarektomierten Sprague Dawley Ratte erhöhte OC-Spiegel, während Kim et al. (2013) am Mikroschwein erniedrigte OC-Konzentrationen nach Ovarektomie beobachteten. Kim et al. hatten das Blut der untersuchten Tiere allerdings bereits sechs Wochen nach Ovarektomie analysiert, während die ersten postoperativen Serumkontrollen der vorliegenden Untersuchung erst zwölf Wochen nach Versuchsbeginn, also nach der doppelten Zeitspanne, erfolgten. Die trotz des ähnlichen Tiermodells widersprüchlichen Ergebnisse könnten folglich darauf beruhen, dass die Aktivierung der Knochenbildung nach Ovarektomie am Großtiermodell einen Zeitraum von mehr als sechs Wochen beansprucht. Belegen ließe sich diese Vermutung allerdings nur im Rahmen weiterer Versuchsreihen mit engmaschigen Serumkontrollen innerhalb der ersten Monate nach Ovarektomie.

Neben OC wurde mit der AP ein weiterer Knochenaufbaumarker eingesetzt. Während die OC-Analysen eine zunächst gesteigerte Knochenbildung nach Ovarektomie anzeigen, legen die vergleichsweise niedrigen AP-Werte eine eher geringe osteoanabole Aktivität in der Versuchsgruppe nahe. Dies lässt sich allerdings nicht nur schwer mit den beobachteten OC-Konzentrationen vereinbaren, es widerspricht auch den Ergebnissen von Scholz-Ahrens et al. (1996), die an ovarektomierten Schweinen eine signifikant gesteigerte AP-Aktivität nachweisen konnten. Yoon et al. (2012) fanden an Ratten nach Ovarektomie ebenfalls erhöhte AP-Spiegel, wenngleich sich diese als nicht signifikant erwiesen. Wirft man einen genaueren Blick auf die einzelnen Messwerte der APAktivität unserer Untersuchung (Tabelle A-5), so wird ersichtlich, dass innerhalb der Kontrollgruppe zwei Versuchstiere beinahe ununterbrochen um ein Vielfaches höhere AP-Aktivitäten aufwiesen als alle anderen Schweine. Dies lässt sich auch anschaulich 
anhand der in Abbildung 12 dargestellten Standardfehler beobachten, die für diesen Parameter innerhalb der Kontrollgruppe durchgehend deutlich höher ausfallen als innerhalb der Versuchsgruppe. Die genaue Ursache für die erhöhten AP-Aktivitäten der beiden Tiere lässt sich im Nachhinein nicht eindeutig ausmachen. Da es sich bei der AP jedoch um einen vergleichsweise unspezifischen Laborparameter handelt (Schmolke 2001) und lediglich die Gesamtaktivität des Enzyms, nicht jedoch die der knochenspezifischen Isoform bestimmt wurde, kommen als mögliche Ursachen insbesondere Leberfunktionsstörungen in Frage (Obermayer-Pietsch und Schwetz 2016; Schmolke 2001). Ungeachtet der genauen Ursache ist bei einer Gruppengröße von lediglich fünf Tieren folglich anzunehmen, dass es sich hier weniger um eine erniedrigte AP-Aktivität der Versuchsgruppe handelt als um atypisch erhöhte Werte einzelner Kontrolltiere. Tatsächlich ergäben sich bei Ausschluss der zu den beiden erwähnten Schweinen gehörenden Messwerte für die Kontrollgruppe im Mittel unauffällige beziehungsweise im Vergleich zur Versuchsgruppe sogar geringfügig niedrigere AP-Aktivitäten. Dies wäre gut vergleichbar mit den AP-Serumwerten der humanen Osteoporose, die in der Regel ebenfalls normwertig ausfallen (Schmolke 2001). So lässt sich auch bei Betrachtung der relativen AP-Werte innerhalb der OVX-Gruppe weder ein zu- noch ein abnehmender Trend erkennen. In Anbetracht der nur eingeschränkt beurteilbaren APAnalyseergebnisse liegt es insofern nahe, zur Einschätzung der Knochenformation im Wesentlichen die Serumspiegel des ohnehin knochenspezifischeren Parameters OC (Schmolke 2001; Schulte 1997) heranzuziehen.

Zusammenfassend lässt sich somit feststellen, dass die Ovarektomie am Göttinger Minischwein zu einem global gesteigerten Knochenumbau führt, der die Knochenresorption ebenso umfasst wie die Knochenneubildung. Ähnliche Beobachtungen konnten bereits am Nagetiermodell sowohl laborchemisch mit Knochenumsatzmarkern (Yoon et al. 2012) als auch histomorphometrisch anhand von Resorptions- und Formationsindices (Wronski et al. 1985) gemacht werden. Am Minischwein scheinen beide Remodelingvorgänge dabei insbesondere in den ersten 20 Wochen nach Induktion eines Östrogenmangels gesteigert zu sein und sich im Anschluss daran wieder zu normalisieren.

\subsubsection{Periphere quantitative Computertomographie (pQCT)}

Von der postmenopausalen Osteoporose des Menschen sind sowohl der trabekuläre als auch der kortikale Knochen betroffen (Arlot et al. 1990). Am Anfang des pathophysiologischen Prozesses stehen allerdings vor allem Veränderungen im trabekulären Knochenkompartiment (Riggs et al. 2002; Kasperk 2008; Seeman 2013). 
So konnten Ferretti et al. (2010) histomorphometrisch am ovarektomierten Nagetiermodell für Lendenwirbelkörper und distale Femurepiphyse signifikant erniedrigte relative trabekuläre Knochenvolumina nachweisen, während sich keine Unterschiede in der kortikalen Knochenfläche der femoralen Diaphyse ergaben. Mit Hilfe der MikroComputertomographie (Mikro-CT) fanden Yoon et al. (2012) am Lendenwirbelkörper der ovarektomierten Sprague Dawley Ratte eine signifikante Verminderung der relativen trabekulären Knochenvolumina, zusätzlich aber auch eine ebenfalls signifikante Reduktion der kortikalen Knochendichte. Am Großtiermodell erweist sich der radiologische Nachweis ovarektomieinduzierter ossärer Anpassungen als schwieriger. So gelang es Borah et al. (2002) im Rahmen mikrocomputertomographischer Untersuchungen nicht, am trabekulären Lendenwirbelkörper des Sinclair S-1-Minischweines nach Ovarektomie und Calciumrestriktion signifikante Veränderungen von Knochenvolumen und -architekturindices nachzuweisen. Mosekilde et al. (1993b) konnten mittels DXA dagegen am gleichen Versuchstier nach Ovarektomie eine signifikante Reduktion der spinalen Knochendichte ausmachen, in Kombination mit einer Calciumrestriktion gelang innen dies zusätzlich auch für den diaphysären Femur und Radius. Im Rahmen von Untersuchungen am Mikroschwein fanden Kim et al. (2013) wiederum mit Hilfe der Mikro-CT für Lendenwirbelkörper und distalen Femur keine signifikanten Unterschiede in der Knochendichte zwischen ovarektomierten und scheinoperierten Tieren, während sie jedoch an der Tibia eine signifikant verringerte Knochendichte nach Ovarektomie beobachten konnten.

Der von Kim et al. untersuchte Tibia-Abschnitt lässt sich am ehesten mit den diaphysären pQCT-Messungen dieser Arbeit vergleichen. Für die eingesetzten Göttinger Minischweine ließen sich jedoch an der Diaphyse weder für die Knochendichte noch für die Knochenfläche signifikante Unterschiede zwischen Versuchs- und Kontrollgruppe finden. Warum sich die Beobachtungen von Kim et al. in der vorliegenden Untersuchung trotz eines beinahe sechsmal längeren Versuchszeitraumes nicht bestätigen ließen, kann nicht eindeutig geklärt werden. Die Abbildungen in der von Kim et al. veröffentlichten Publikation legen nahe, dass von innen die Tibia am Übergang zwischen Meta- und Diaphyse untersucht wurde. Der hier im Vergleich zu unserer rein diaphysären Messung erhöhte Spongiosaanteil könnte das bessere Ansprechen auf die Ovarektomie erklären, wenn nicht auch bei unseren epiphysären Messungen ein solches Ansprechen ausgeblieben wäre, worauf weiter unten noch eingegangen wird. Denkbar wäre auch, dass das Mikro-CT für die an der Schweinetibia induzierten Veränderungen das sensiblere Messverfahren darstellt. Schließlich kann auch nicht ausgeschlossen werden, dass der Östrogenmangel am Mikroschwein einen schnelleren 
beziehungsweise ausgeprägteren Knochenmasseverlust bewirkt als am größeren Göttinger Minischwein.

Auch am trabekulären Knochen der Epiphyse waren mittels pQCT keine signifikanten Unterschiede zwischen ovarektomierten und scheinoperierten Minischweinen ersichtlich. Unter Berücksichtigung des bereits zuvor erwähnten Umstandes, dass im Zuge der postmenopausalen Osteoporose die Spongiosa in der Regel vor der Kortikalis vom osteoporotischen Krankheitsprozess betroffen ist (Riggs et al. 2002; Kasperk 2008; Seeman 2013), würde man folglich auch an der Kortikalis der Epiphyse keine Unterschiede erwarten. Entgegen dieser Erwartung konnte am kortikalen epiphysären Knochen jedoch eine signifikante Knochendichtezunahme nach Ovarektomie beobachtet werden, während die Knochenfläche abnahm. Die Reduktion der Knochenfläche erwies sich allerdings als nicht signifikant, obwohl sie durchaus deutlich ausfiel. Eine vergleichbare Reduktion der kortikalen Knochenfläche der Epiphyse bei gleichzeitiger Zunahme der entsprechenden Knochendichte ließ sich im Rahmen der Literaturrecherche nicht finden. Denkbar wäre allerdings, dass diese ungewöhnliche Beobachtung auf methodische Aspekte zurückzuführen ist. So unterschätzen aktuell gängige Untersuchungsmethoden die alters- beziehungsweise menopausenbedingte Zunahme der kortikalen Knochenporosität und damit in der Folge auch die Reduktion der spongiösen Knochendichte, da sie fälschlicherweise kortikale Überreste als trabekulären Knochen werten (Bala et al. 2015; Zebaze et al. 2010). Diese Überreste entstehen durch eine vermehrte endokortikal betonte Knochenresorption und können als eine Art Trabekularisierung der Kortikalis verstanden werden (Buenzli et al. 2013). Werden sie der Spongiosa und nicht der Kortikalis zugerechnet, kann es zu vielfältigen Fehlinterpretationen der Messergebnisse kommen. Insbesondere ist als Folge dieser Fehlinterpretation eine Überschätzung der trabekulären Knochendichte und -fläche zu erwarten und eine damit einhergehende Unterschätzung der kortikalen Knochenfläche, als deren Folge eine überhöht gemessene kortikale Knochendichte vorstellbar wäre. Die kortikale Dichte würde sich dabei zu hoch darstellen, weil die primär von Remodeling und Knochenverlust betroffenen endokortikalen Compacta-Abschnitte (Buenzli et al. 2013; Jee und Yao 2001; Jergas und Schmid 1999) aufgrund der Fehlinterpretation nicht mit in die entsprechende Berechnung einflössen und somit die periostalen, weniger porösen und dadurch prinzipiell dichteren Kortikalis-Bereiche eine zu große Gewichtung gewännen. Ob ein solcher Beurteilungsfehler tatsächlich ausschlaggebend für die Knochendichtezunahme der epiphysären Kortikalis war, kann nicht mit Sicherheit entschieden werden. Er würde aber eine plausible Erklärung für die nach Ovarektomie beobachtete kortikale Dichtezunahme darstellen. 
Wirft man einen weiteren, genaueren Blick auf die epiphysären Messergebnisse, so zeigt sich, dass in beiden Versuchstiergruppen die Knochenfläche mit zunehmender Knochendichte tendenziell abnimmt, dies gilt sowohl für den kortikalen als auch für den trabekulären Knochen. Dieser am ehesten als negativ linear zu bezeichnende Zusammenhang erweist sich insgesamt als nur mäßig ausgeprägt. Die Korrelation zwischen Knochendichte und -fläche fällt für Kortikalis und Spongiosa innerhalb der Kontrollgruppe allerdings stärker aus als innerhalb der ovarektomierten Versuchsgruppe. Die Ovarektomie scheint demnach Auswirkungen auf den Zusammenhang zwischen den beiden betrachteten Messgrößen zu haben, und zwar in dem Sinne, dass er sie unabhängiger voneinander werden lässt. Dieser Umstand könnte als Hinweis darauf gedeutet werden, dass das Knochenremodeling unter Östrogenmangel in gewisser Weise weniger koordiniert abläuft als unter gewöhnlichen Stoffwechselbedingungen.

Bei zusammenfassender Betrachtung muss dennoch festgestellt werden, dass es im Rahmen der vorliegenden osteodensitometrischen Untersuchung nicht möglich war, acht Monate nach Gonadenentfernung an der Tibia des Göttinger Minischweines mit Hilfe der PQCT eine signifikante Reduktion von Knochendichte und -fläche nachzuweisen. Auch wenn im Tierversuch der mittels Osteodensitometrie gemessene relative Knochendichteabfall nach Ovarektomie im Vergleich zum osteoporotischen Menschen bekanntermaßen insgesamt geringer ausfällt (Egermann et al. 2005), überrascht der in unserer Untersuchung ausbleibende Knochendichte- und -flächeabfall durchaus, da entsprechende osteoporotische Knochenmasseverluste und reduzierte Knochendichten nach Ovarektomie in der Literatur vielfach für das Nagetiermodell (Yoon et al. 2012; Ferretti et al. 2010; Turner et al. 2001) und teilweise auch für das Großtiermodell (Mosekilde et al. 1993b; Kim et al. 2013) beschrieben werden. Im Bereich der epiphysären Kortikalis war in unserer Untersuchung sogar eine Knochendichtezunahme zu beobachten, die möglicherweise, wie oben erläutert, auf die methodisch schwierige Differenzierung zwischen Trabekeln und trabekularisierter Kortikalis zurückzuführen ist. Da an der kontralateralen Tibia, am Femur sowie am Lendenwirbelkörper derselben Versuchstierpopulation mit histomorphometrischen Methoden allerdings eine signifikante Abnahme des Trabekelvolumens nachgewiesen werden konnte (Bartels 2010), ist dennoch von einer osteoporotischen Stoffwechelsitutation mit damit einhergehendem Knochenverlust auszugehen, auch wenn sich dieser computertomographisch nicht erfassen ließ. Möglicherweise erweist sich hier die pQCT für die Osteoporosediagnostik an der Tibia des Göttinger Minischweines und vielleicht auch ganz allgemein am Großtiermodell als weniger gut geeignet. 


\subsubsection{Polychrome Sequenzmarkierung}

Die Auswirkungen eines Östrogenmangels auf den trabekulären Knochen waren bereits Gegenstand vielfältiger Untersuchungen, sowohl im Tiermodell (Wronski et al. 1985; Wen et al. 2015; Wang et al. 2017) als auch am Menschen (Parfitt et al. 1983; Ozan et al. 2017). Während in der Frühphase der Osteoporose strukturelle Veränderungen im Bereich der Spongiosa überwiegen, gewinnt mit dem Fortschreiten des Krankheitsprozesses der Stoffwechsel des kortikalen Knochens zunehmend an Bedeutung (Riggs et al. 2002). Die fluoreszenzmikroskopischen Untersuchungen dieser Arbeit richten ihren Fokus daher auf die Folgen der Ovarektomie für den kortikalen Knochen, der immerhin 80 Prozent des humanen Skelettsystems ausmacht (Bala et al. 2015; Seeman 2013; Langdahl et al. 2016).

Die adaptive kortikale Knochenbildung ist wesentlich auf die ungestörte Wirkung von Östrogenen angewiesen (Lee et al. 2003). So zeigte sich auch in dieser Untersuchung die fluoreszenzmikroskopisch gemessene totale Knochenapposition der unter Östrogenmangel stehenden Minischweine periostal sowie osteonal im Vergleich zur Kontrollgruppe hochsignifikant reduziert. Trotz des nach Ovarektomie insgesamt gesteigerten Knochenumsatzes hat der Östrogenmangel demnach hier zu einer Beeinträchtigung der Knochenbildung beziehungsweise -mineralisation geführt. Dieses Ergebnis lässt sich gut mit den Beobachtungen von Wu et al. (1970) vereinbaren, die bei Frauen mit symptomatischer Osteoporose eine reduzierte osteonale Knochenbildungsgeschwindigkeit festgestellt hatten. Szulc et al. (2006) beschreiben unter Bezug auf ein 821 Frauen umfassendes Patientenkollektiv für den periostalen Knochen einen Appositionsrückgang während der Postmenopause. Auch dies steht in Einklang mit unserem Ergebnis. Untersuchungen von Bagi et al. (1996) am Schenkelhals der Ratte hatten dagegen periostal keine signifikanten Appositionsdifferenzen zwischen ovarektomierten und scheinoperierten Tieren erkennen lassen.

Im Gegensatz zu den Osteonen und dem periostalen Knochen ließ sich endokortikal nach Ovarektomie eine gesteigerte totale Apposition beobachten, die sich ebenfalls als hochsignifikant erwies. Dieser Befund überrascht zunächst, zumal der kortikale Knochenverlust im Zuge eines postmenopausal beschleunigten Remodelings in der Regel insbesondere endokortikal stattfindet und in der Folge zu einer Aufweitung der Markhöhle (Buenzli et al. 2013) sowie einer verdünnten Kortikalis (Buenzli et al. 2013; Seeman 2013; Langdahl et al. 2016) führt. Auch im Tiermodell hat die Ovarektomie eine Erweiterung des Markraumes zur Folge (Jee und Yao 2001; Bagi et al. 1996; Mosekilde et al. 1993b). Es gilt jedoch zu beachten, dass die im Rahmen der polychromen Sequenzmarkierung gemessene Apposition lediglich über den Prozess der Knochen- 
formation Auskunft gibt, während Markhöhlendurchmesser, kortikale Dicke und sonstige histomorphometrische Größen, anhand derer eine Einschätzung der Knochenresorption möglich wäre, mit der Fluoreszenzmikroskopie nicht erfasst wurden. Durch bloße Betrachtung der Apposition ist daher nicht auszumachen, ob der beschleunigte Knochenumsatz netto einen Knochenverlust oder eine Knochenzunahme bewirkt. Auch muss berücksichtigt werden, dass die Alizarin-Applikation erst 143 Tage nach Anfang des Versuchszeitraumes erfolgte. Der fluoreszenzmikroskopisch beurteilbare Zeitraum beginnt folglich erst mehr als 20 Wochen nach Ovarektomie, obwohl die im Serum gemessenen Knochenumsatzmarker gerade während dieses frühen Blindbereiches einen beschleunigten Knochenumbau nahelegen. Für künftige Untersuchungen empfiehlt es sich daher, durch die Applikation zusätzlicher Fluorochrome einen Einblick auch in den frühen Post-Ovarektomie-Zeitraum zu ermöglichen.

Trotz dieser methodischen Einschränkungen ist die endokortikal erhöhte Apposition zunächst als mikroskopisches Korrelat eines endokortikal insgesamt beschleunigten Knochenumsatzes zu werten. Auch wenn die kortikale Knochenresorption histomorphometrisch nicht erfasst wurde, liegt es aufgrund der weitgehend parallel erhöhten OC- und CTX-Serumkonzentrationen nahe anzunehmen, dass endokortikal neben der gesteigerten Knochenformation innerhalb des Versuchszeitraumes auch eine erhöhte Knochenresorption stattgefunden hat. Arlot et al. (1990) hatten als Hinweis auf eine derartig erhöhte Resorption am endokortikalen Knochen von Osteoporosepatientinnen im Vergleich zu einem altersangepassten Kontrollkollektiv viermal höhere Osteoklastenzahlen ausgemacht und außerdem für die erkrankten Frauen endokortikal einen signifikant höheren Knochenumsatz als am trabekulären Knochen beobachtet. Zugleich war es innen jedoch nicht möglich, endokortikal Unterschiede hinsichtlich der Knochenapposition oder sonstiger Formationsparameter zwischen den beiden Gruppen festzustellen.

Von einer gesteigerten Knochenapposition nach Ovarektomie berichten dagegen Wronski et al. (1985). Sie konnten am trabekulären Knochen der proximalen Rattentibia nach Tetrazyklin-Markierung eine Erhöhung der Mineralisationsrate sowie der aktiv knochenbildenden Oberfläche ausmachen. Außerdem beobachteten sie histomorphometrisch sowohl höhere Osteoblasten- als auch Osteoklastenzahlen als Indiz für einen insgesamt gesteigerten Knochenumsatz bei gleichzeitig deutlich rückgängigem Trabekelvolumen. Natürlich darf nicht außer Acht gelassen werden, dass Wronski et al. die Spongiosa und nicht den endokortikalen Knochen untersuchten und außerdem ein Kleintiermodell einsetzten. Dennoch verdeutlichen ihre Erkenntnisse anschaulich, dass auch bei gesteigerter Apposition ein erheblicher Knochenverlust möglich ist. Zu einem 
vergleichbaren Ergebnis kommen auch Bagi et al. (1996), die nach Ovarektomie am spongiösen Rattenschenkelhals ebenfalls eine gesteigerte Appositions- und Knochenformationsrate bei gleichzeitig reduzierter Trabekelzahl und -dicke ausmachten. Auch endokortikal fanden sie bei den östrogendefizienten Tieren eine gesteigerte Knochenformationsrate. Dies steht in Einklang mit den Ergebnissen dieser Arbeit. Ähnliche Beobachtungen machten auch Mosekilde et al. (1993b) am Großtiermodell: Nach Ovarektomie und milder Calciumrestriktion (0,75 Prozent nutritiver Calciumgehalt) beobachteten sie am Sinclair S-1-Minischwein femoral eine tendenzielle Erhöhung der endokortikalen Knochenformationsrate und eine ebenfalls tendenzielle Abnahme der kortikalen Knochenfläche mit entsprechender, gleichermaßen nicht signifikanter Zunahme der Markraumfläche. An der Rippe fanden sie eine kortikale Knochenflächenreduktion und eine Markraumflächensteigerung, die sogar beide das Signifikanzniveau erreichten. Diese Ergebnisse von Mosekilde et al. lassen sich gut mit der Annahme vereinbaren, dass Ovarektomie und Calciumrestriktion am Großtiermodell einen gesteigerten endokortikalen Stoffwechsel mit kortikalem Netto-Knochenverlust zur Folge haben können, als dessen Korrelat wahrscheinlich auch die in dieser Arbeit beobachtete endokortikale Appositionssteigerung zu werten ist.

Einige Autoren beschreiben einen Kompensationsmechanismus endokortikaler Knochenverluste im Sinne einer reaktiv gesteigerten periostalen Knochenbildung (Ahlborg et al. 2003; Buenzli et al. 2013). Geht man, wie zuvor erläutert, davon aus, dass auch die östrogendefizienten Versuchstiere dieser Arbeit einen endokortikalen Knochenverlust erlitten haben, wäre demnach auch hier eine gesteigerte periostale Knochenformation zu erwarten. Die von uns im Vergleich zur Kontrollgruppe beobachtete reduzierte periostale Apposition legt allerdings das genaue Gegenteil nahe. Ein derartiger Kompensationsmechanismus scheint folglich bei unseren Tieren nicht wirksam geworden zu sein. Vielmehr kann vermutet werden, dass die reduzierte periostale Apposition die Knochenstabilität zusätzlich beeinträchtigt hat. Zu einem vergleichbaren Ergebnis kommen auch Szulc et al. (2006), die bei postmenopausalen Frauen eine verringerte periostale Apposition bei gleichzeitig gesteigerter endokortikaler Resorption beobachtet hatten. Sie sehen in diesen beiden kortikalen Prozessen auch den Grund für die erhöhte Knochenbrüchigkeit bei Osteoporosepatientinnen.

Betrachtet man neben der totalen Apposition auch die aus den Bandenbreiten errechneten täglichen Appositionsraten, so ist zu bedenken, dass es sich hierbei um Momentaufnahmen handelt, die Aussagen bezüglich der Mineralisation zunächst nur zum Zeitpunkt der jeweiligen Markerapplikation erlauben. Die Appositionsraten eignen sich allerdings auch dazu, mögliche zeitliche Trends in der Entwicklung der Knochenapposi- 
tion innerhalb einer Gruppe auszumachen. So war periostal und osteonal für die scheinoperierten Tiere eine signifikante Zunahme der Appositionsraten zu beobachten, während die ovarektomierten Tiere an gleicher Stelle konstante Raten für den Knochenanbau erkennen ließen. Eine Erklärung für diese Beobachtung liegt möglicherweise in der östrogenabhängigen Fähigkeit des Knochens, adaptiv auf eine zunehmende Belastung mit vermehrter Knochenformation zu reagieren (Lee et al. 2003). In beiden Gruppen war im Versuchszeitraum eine Zunahme des durchschnittlichen Körpergewichts zu verzeichnen, weshalb für die untersuchten Tibiae durchaus von einer ansteigenden Belastung auszugehen ist. Dass die Gewichtszunahme periostal und osteonal bei den ovarektomierten Tieren der Versuchsgruppe keine gesteigerten Appositionsraten zur Folge hatte, steht in Einklang mit der von Lee beschriebenen Östrogenabhängigkeit des Adaptationsprozesses. Bei alleiniger Betrachtung der periostalen täglichen Apposition wäre auch eine im Laufe des Versuchszeitraumes alterungsbedingt gesteigerte periostale Knochenbildung (Einhorn 1992) innerhalb der Kontrollgruppe denkbar, die unter Östrogenmangel ausblieb.

Die tägliche endokortikale Appositionsrate erwies sich für beide Gruppen als rückläufig. Eine belastungsadaptierte Steigerung der Knochenformation scheint an dieser Stelle demnach weder bei den Kontrolltieren noch bei den ovarektomierten Schweinen stattgefunden zu haben. Wodurch dieser endokortikale Appositionsrückgang bedingt war und ob er beispielsweise auf den allgemeinen Alterungsprozess im Sinne einer Markhöhlenerweiterung (Buenzli et al. 2013) zurückzuführen ist, kann nicht eindeutig beantwortet werden. Die an dieser Stelle auch innerhalb der OVX-Gruppe rückläufige Appositionsrate sollte allerdings nicht unkritisch als Relativierung der im Vergleich zur Kontrollgruppe insgesamt gesteigerten totalen endokortikalen Apposition gewertet werden. Schließlich ist die totale Apposition als wesentlich aussagekräftiger anzusehen, da sie einen deutlich längeren Zeitraum repräsentiert als die täglichen Appositionsraten. Die auch in der Versuchsgruppe rückläufige endokortikale Appositionsrate lässt sich eventuell jedoch als Hinweis darauf interpretieren, dass sich die in diesem Kompartiment nach Ovarektomie beobachtete Appositionssteigerung eher in der frühen Zeit nach diesem Eingriff abspielt, wie es auch die frühen Knochenumsatzmarkererhöhungen nahelegen.

Bei zusammenfassender Betrachtung der fluoreszenzmikroskopischen Untersuchungen dieser Arbeit kann festgestellt werden, dass die Ovarektomie am Göttinger Minischwein periostal und osteonal eine reduzierte Knochenapposition zur Folge hat, während sie endokortikal eine Steigerung der Knochenapposition bewirkt. Unsere Knochenumsatzmarkeranalyse hatte einen als Folge der Ovarektomie intensivierten Kno- 
chenstoffwechsel erkennen lassen, der sowohl die Formation als auch die Resorption umfasst. Unter Einbeziehung dieser Beobachtung ist davon auszugehen, dass die fluoreszenzmikroskopisch erfasste endokortikale Appositionssteigerung Ausdruck dieses insgesamt beschleunigten Knochenstoffwechsels ist, in dessen Rahmen auch eine erhöhte Knochenresorption stattgefunden hat. Kompensationsmechanismen endokortikaler Resorptionsprozesse im Sinne einer gesteigerten periostalen Knochenbildung, wie sie von einigen Autoren beschrieben werden (Ahlborg et al. 2003; Buenzli et al. 2013), ließen sich in der vorliegenden Untersuchung angesichts der beobachteten reduzierten periostalen Apposition nicht bestätigen. Weiterhin konnte für die scheinoperierten Tiere periostal und osteonal im Laufe des Versuchszeitraumes eine wahrscheinlich östrogenabhängige Zunahme der täglichen Knochenappositionsrate verzeichnet werden, die in der Versuchsgruppe unter Östrogenmangel ausblieb. Für eine parallele Beurteilung von Knochenformation und -resorption im Bereich der Kortikalis und insbesondere ihres stoffwechselaktiven endokortikalen Kompartiments sind weiterführende Untersuchungen am osteoporotischen Großtiermodell erforderlich. Diese sollten durch den Einsatz einer größeren Anzahl von Fluoreszenzmarkern auch einen engmaschigen Einblick in den frühen Postovarektomie-Zeitraum erlauben und unter Einbeziehung geeigneter histomorphometrischer Untersuchungsmethoden zudem eine zuverlässige Erfassung der resorptiven Prozesse ermöglichen.

Das Göttinger Minischwein hat sich in der vorliegenden Untersuchung als geeignetes und verhältnismäßig leicht zu handhabendes Großtiermodel zur Untersuchung des kortikalen Remodelings bewährt. 


\section{Zusammenfassung}

Fragestellung: Das in der Osteoporoseforschung etablierte Nagetiermodell ist nur bedingt auf den Menschen übertragbar. Ziel der vorliegenden Arbeit war es daher, das der Osteoporose zugrundeliegende Knochenremodeling am ovarektomierten Göttinger Minischwein hinsichtlich zeitlicher und topographischer Aspekte detaillierter zu untersuchen und dabei zugleich die Eignung dieser Züchtung als Großtiermodell für die Osteoporoseforschung zu überprüfen.

Methode: Hierzu wurden zehn weibliche Göttinger Minischweine in zwei Gruppen mit jeweils fünf Tieren eingeteilt. Die Versuchsgruppe erhielt eine Ovarektomie mit anschließender Calcium-restriktiver Diät, während die Kontrollgruppe einer ShamOperation unterzogen wurde und Futter mit einem gewöhnlichen Calcium-Anteil bekam. Bei allen Versuchstieren wurden anhand regelmäßiger Serumanalysen die Östradiolspiegel (E2) und die Knochenumsatzmarker Osteokalzin (OC), $\beta$-CrossLaps (CTX) sowie Alkalische Phosphatase (AP) bestimmt. Außerdem wurde mit Hilfe der peripheren quantitativen Computertomographie ( $\mathrm{QQCT}$ ) eine Osteodensitometrie im Bereich der Tibia durchgeführt. Im Rahmen einer polychromen Sequenzmarkierung wurde schließlich die tibiale Knochenapposition untersucht.

Ergebnisse: Reduzierte E2-Serumspiegel bestätigen bei den Tieren der Versuchsgruppe einen Ovarektomie-induzierten Östrogenmangel, der insbesondere innerhalb der ersten 20 postoperativen Wochen einen global gesteigerten Knochenumsatz zur Folge hat, wie die in dieser Zeit erhöhten CTX- und OC-Spiegel zeigen. Trotz der laborchemischen Hinweise auf eine unter Östrogenmangel gesteigerte Knochenresorption lässt die PQCT keine signifikante Abnahme von Knochendichte oder -fläche innerhalb des Versuchszeitraumes erkennen. Mit Hilfe der polychromen Sequenzmarkierung ist dagegen an der tibialen Kortikalis der östrogendefizienten Versuchstiere periostal und osteonal eine verminderte Knochenapposition nachzuweisen. Die endokortikale Apposition ist indessen im Vergleich zur Kontrollgruppe gesteigert. Innerhalb des kortikalen Knochenkompartiments erweist sich der endokortikale Knochen somit auch im Rahmen des osteoporotischen Remodelings als besonders stoffwechselaktiv. Aufgrund der dabei deutlich erhöhten Knochenumsatzmarker ist davon auszugehen, dass an gleicher Stelle auch eine verstärkte Knochenresorption stattgefunden hat.

Die zusammenfassende Betrachtung der Ergebnisse dieser Arbeit legt somit einen insgesamt gesteigerten Knochenumsatz unter Östrogenmangel nahe, der innerhalb des kortikalen Knochenkompartiments in erster Linie den endokortikalen Knochen be- 
trifft und hier vermutlich netto mit einem Masseverlust einhergeht. Der Mangel an weiblichen Geschlechtshormonen führt außerdem zu einer reduzierten Knochenapposition im Bereich von Periost und Osteonen. Sofern sich diese Beobachtungen im Rahmen weiterführender Untersuchungen bestätigen lassen, könnten sich aus ihnen neue Ansätze für die Entwicklung gezielter antiosteoporotischer Therapien ergeben.

Schlussfolgerung: Das Göttinger Minischwein erweist sich im Rahmen der vorliegenden Untersuchung aufgrund seines östrogenabhängigen kortikalen Remodelings als ein für die Osteoporoseforschung gut geeignetes und vergleichsweise leicht zu handhabendes Großtiermodell. Allerdings sind die knöchernen Umbaureaktionen in Richtung einer Osteopenie oder Osteoporose erst wesentlich später nach Eintritt des Östrogenmangels zu beobachten als beim Nagetiermodell. Wegen der anatomischen und funktionellen Nähe seines Knochens zu dem des Menschen erscheint der Einsatz des Göttinger Minischweines dennoch für die weiterführende Erforschung der Osteoporose sinnvoll. 


\section{Anhang}

\subsection{Ergebnistabellen}

Tab. A-1: 17ß-Östradiol (E2). Angegeben sind Stichprobenumfang (N), Mittelwerte (MW) und Standardfehler (SEM) der laborchemischen Untersuchung für die Versuchsgruppe (OVX) sowie für die Kontrollgruppe (Kontrolle).

\begin{tabular}{c|r|r|r|r|r|r}
\multirow{2}{*}{ Tage } & \multicolumn{4}{|c|}{ OVX } & \multicolumn{3}{|c}{ Kontrolle } \\
\cline { 2 - 7 } & $\mathrm{N}$ & $\begin{array}{c}\mathrm{MW} \\
{[\mathrm{pg} / \mathrm{ml}]}\end{array}$ & \multicolumn{1}{c|}{ SEM } & $\mathrm{N}$ & $\begin{array}{c}\text { MW } \\
{[\mathrm{pg} / \mathrm{ml}]}\end{array}$ & \multicolumn{1}{c}{ SEM } \\
\hline 0 & 20 & 45,976 & 5,549 & 20 & 45,976 & 5,549 \\
\hline 84 & 10 & 19,900 & 1,835 & 10 & 30,633 & 3,886 \\
\hline 143 & 10 & 19,653 & 1,427 & 15 & 29,401 & 3,815 \\
\hline 167 & 10 & 25,667 & 3,516 & 10 & 18,429 & 2,521 \\
\hline 187 & 10 & 21,527 & 5,208 & 10 & 25,628 & 1,291 \\
\hline 209 & 5 & 7,650 & 0,976 & 10 & 20,620 & 3,034 \\
\hline 237 & 1 & 6,150 & -- & 10 & 30,493 & 16,584
\end{tabular}

Tab. A-2: N-MID Osteokalzin (OC). Angegeben sind Stichprobenumfang (N), Mittelwerte (MW) und Standardfehler (SEM) der laborchemischen Untersuchung für die Versuchsgruppe (OVX) sowie für die Kontrollgruppe (Kontrolle).

\begin{tabular}{c|r|r|r|r|r|r}
\multirow{2}{*}{ Tage } & \multicolumn{4}{|c|}{ OVX } & \multicolumn{3}{|c}{ Kontrolle } \\
\cline { 2 - 7 } & $\mathrm{N}$ & $\begin{array}{c}\mathrm{MW} \\
{[\mathrm{ng} / \mathrm{ml}]}\end{array}$ & SEM & $\mathrm{N}$ & $\begin{array}{c}\text { MW } \\
{[\mathrm{ng} / \mathrm{ml}]}\end{array}$ & \multicolumn{1}{c}{ SEM } \\
\hline 0 & 10 & 33,179 & 3,471 & 10 & 33,179 & 3,471 \\
\hline 84 & 5 & 44,214 & 5,830 & 5 & 29,068 & 4,396 \\
\hline 143 & 5 & 23,690 & 3,701 & 5 & 19,760 & 4,031 \\
\hline 167 & 5 & 28,980 & 2,858 & 5 & 35,120 & 4,778 \\
\hline 187 & 5 & 30,218 & 5,440 & 5 & 29,832 & 6,252 \\
\hline 209 & 5 & 24,402 & 4,330 & 5 & 27,246 & 3,668 \\
\hline 237 & 5 & 19,896 & 4,512 & 5 & 18,136 & 3,859
\end{tabular}


Tab. A-3: $\beta$-CrossLaps (CTX). Angegeben sind Stichprobenumfang (N), Mittelwerte (MW) und Standardfehler (SEM) der laborchemischen Untersuchung für die Versuchsgruppe (OVX) sowie für die Kontrollgruppe (Kontrolle).

\begin{tabular}{c|r|r|r|r|r|r}
\multirow{2}{*}{ Tage } & \multicolumn{3}{|c|}{ OVX } & \multicolumn{3}{|c}{ Kontrolle } \\
\cline { 2 - 7 } & $\mathrm{N}$ & $\begin{array}{c}\mathrm{MW} \\
{[\mathrm{ng} / \mathrm{ml}]}\end{array}$ & SEM & $\mathrm{N}$ & $\begin{array}{c}\mathrm{MW} \\
{[\mathrm{ng} / \mathrm{ml}]}\end{array}$ & \multicolumn{1}{c}{ SEM } \\
\hline 0 & 10 & 0,816 & 0,124 & 10 & 0,816 & 0,124 \\
\hline 84 & 5 & 1,214 & 0,139 & 5 & 0,784 & 0,122 \\
\hline 143 & 5 & 0,760 & 0,091 & 5 & 0,498 & 0,103 \\
\hline 167 & 5 & 0,462 & 0,054 & 5 & 0,604 & 0,115 \\
\hline 187 & 5 & 0,400 & 0,086 & 5 & 0,484 & 0,082 \\
\hline 209 & 5 & 0,538 & 0,083 & 5 & 0,808 & 0,019 \\
\hline 237 & 5 & 0,444 & 0,092 & 5 & 0,322 & 0,093
\end{tabular}

Tab. A-4: Alkalische Phosphatase (AP). Angegeben sind Stichprobenumfang (N), Mittelwerte (MW) und Standardfehler (SEM) der laborchemischen Untersuchung für die Versuchsgruppe (OVX) sowie für die Kontrollgruppe (Kontrolle).

\begin{tabular}{c|r|r|r|r|r|r}
\multirow{2}{*}{ Tage } & \multicolumn{4}{|c|}{ OVX } & \multicolumn{3}{|c}{ Kontrolle } \\
\cline { 2 - 7 } & $\mathrm{N}$ & $\mathrm{MW}[\mathrm{u} / \mathrm{L}]$ & \multicolumn{1}{c|}{ SEM } & $\mathrm{N}$ & $\mathrm{MW}[\mathrm{u} / \mathrm{L}]$ & \multicolumn{1}{c}{ SEM } \\
\hline 0 & 10 & 69,1 & 20,440 & 10 & 69,1 & 20,440 \\
\hline 84 & 5 & 81,6 & 3,855 & 5 & 180,0 & 67,007 \\
\hline 143 & 5 & 56,8 & 7,419 & 5 & 136,0 & 54,467 \\
\hline 167 & 5 & 106,6 & 46,922 & 5 & 92,0 & 45,715 \\
\hline 187 & 5 & 54,4 & 6,698 & 5 & 141,6 & 60,311 \\
\hline 209 & 5 & 62,4 & 8,577 & 5 & 137,8 & 58,557 \\
\hline 237 & 5 & 65,6 & 7,954 & 5 & 175,2 & 87,179
\end{tabular}


Tab. A-5: Alkalische Phosphatase (AP) - Enzymaktivität der einzelnen Versuchstiere. Angegeben ist die Volumenaktivität [u/L] der einzelnen Minischweine (S01 - S10) für die Versuchsgruppe (OVX) und die Kontrollgruppe (Kontrolle).

\begin{tabular}{c|r|r|r|r|r|r|r|r|r|r}
\multirow{2}{*}{ Tage } & \multicolumn{5}{|c|}{ OVX } & \multicolumn{5}{|c}{ Kontrolle } \\
\cline { 2 - 12 } & S01 & S02 & S05 & S07 & S09 & S03 & S04 & S06 & S08 & S10 \\
\hline 0 & 48 & 43 & 34 & 35 & 11 & 34 & 56 & 208 & 54 & 168 \\
\hline 84 & 81 & 78 & 86 & 70 & 93 & 56 & 78 & 369 & 81 & 316 \\
\hline 143 & 38 & 69 & 61 & 41 & 75 & 43 & 51 & 282 & 48 & 256 \\
\hline 167 & 55 & 293 & 81 & 50 & 54 & 48 & 70 & 36 & 33 & 273 \\
\hline 187 & 59 & 48 & 62 & 32 & 71 & 38 & 48 & 313 & 46 & 263 \\
\hline 209 & 81 & 55 & 67 & 33 & 76 & 31 & 51 & 231 & 54 & 322 \\
\hline 237 & 78 & 52 & 67 & 44 & 87 & 41 & 46 & 467 & 35 & 287
\end{tabular}

Tab. A-6: Vergleich der totalen Knochenapposition zwischen Kontrollgruppe und Versuchsgruppe im Bereich des periostalen sowie endokortikalen Knochens. Angegeben sind Stichprobenumfang (N), Mittelwerte (MW), Standardabweichung (SD), Konfidenzintervall (Cl) sowie die Signifikanztestungen (Signifikanz) zwischen Kontrollgruppe (Kontrolle) und Versuchsgruppe (OVX).

\begin{tabular}{c|c|r|r|r|r|r} 
Messbereich & Gruppe & $\mathrm{N}$ & $\mathrm{MW}$ & \multicolumn{1}{c|}{ SD } & \multicolumn{1}{c|}{$\mathrm{Cl}$} & Signifikanz \\
\hline \multirow{2}{*}{ Periostal } & Kontrolle & 300 & 24,065 & 9,018 & 1,025 & \multirow{2}{*}{$(\mathrm{p} \leq 0,001)$} \\
\cline { 2 - 5 } & OVX & 300 & 21,163 & 6,722 & 0,764 & \\
\hline \multirow{2}{*}{ Endokortikal } & Kontrolle & 300 & 32,726 & 7,514 & 0,854 & \multirow{2}{*}{$(\mathrm{p} \leq 0,001)$}
\end{tabular}




\section{Literaturverzeichnis}

Ahlborg HG, Johnell O, Turner CH, Rannevik G, Karlsson MK (2003): Bone loss and bone size after menopause. N Engl J Med 349, 327-334

Arlot ME, Delmas PD, Chappard D, Meunier PJ (1990): Trabecular and endocortical bone remodeling in postmenopausal osteoporosis: Comparison with normal postmenopausal women. Osteoporosis Int $1,41-49$

Bagi CM, DeLeon E, Ammann P, Rizzoli R, Miller SC (1996): Histo-anatomy of the proximal femur in rats: Impact of ovariectomy on bone mass, structure, and stiffness. Anat $\operatorname{Rec} \underline{245}, 633-644$

Bala Y, Zebaze R, Seeman E (2015): Role of cortical bone in bone fragility. Curr Opin Rheumatol $\underline{27}$, 406-413

Bartels F: Histomorphometrische Untersuchungen der Knochenstruktur am ovarektomierten Göttinger Minischwein zur Etablierung eines Großtiermodells zur Simulation der postmenopausalen Osteoporose. Med. Diss. Göttingen 2010

Bartl R (2012): Osteoporose - Diagnostik, Prävention und Therapie. Lege artis $\underline{2}, 174-$ 181

Bassan J, Frame B, Frost HM (1963): Osteoporosis: A Review of Pathogenesis and Treatment. Ann Intern Med $\underline{58}$, 539-550

Beglinger R, Becker M, Eggenberger E, Lombard C (1975): Das Göttinger Miniaturschwein als Versuchstier. 1. Mitteilung: Literaturübersicht, Zucht und Haltung, Kreislaufparameter. Res Exp Med $\underline{165}, 251-263$

Behre A, Janott J, Pfohl M, Schatz H, Pfeiffer A (2001): Sind Crosslinks klinisch aussagekräftige Osteoporosemarker? Evaluation in einem Bevölkerungsquerschnitt. Med Klin $\underline{96}, 378-382$

Bieglmayer C, Dimai HP, Gasser RW, Kudlacek S, Obermayer-Pietsch B, Woloszczuk W, Zwettler E, Griesmacher A (2012): Biomarkers of bone turnover in diagnosis and therapy of osteoporosis: A consensus advice from an Austrian working group. Wien Med Wochenschr 162, 464-477

Birkhäuser M (2013): Prävention der postmenopausalen Osteoporose. Teil 2: Medikamentöse Prävention und Therapie der Osteoporose in der Peri- und frühen Postmenopause. Gynakol Endokrinol 11, 289-298 
Bonjour JP, Ammann P, Rizzoli R (1999): Importance of preclinical studies in the development of drugs for treatment of osteoporosis: A review related to the $1998 \mathrm{WHO}$ guidelines. Osteoporos Int $\underline{9}, 379-393$

Bonnaire F, Lein T, Hohaus T, Weber A (2005): Prothetische Versorgung der proximalen Femurfrakturen. Unfallchirurg $\underline{108}, 387-399$

Borah B, Dufresne TE, Chmielewski PA, Gross GJ, Prenger MC, Phipps RJ (2002): Risedronate preserves trabecular architecture and increases bone strength in vertebra of ovariectomized minipigs as measured by three-dimensional microcomputed tomography. J Bone Miner Res $\underline{17}, 1139-1147$

Bouchard GF, Boyce RW, Paddock CL, Durham E, Reddy CS: Evaluation of Sinclair Miniature Swine as an Osteopenia Model. In: Tumbleson ME, Schook LB (Hrsg.): Advances in Swine in Biomedical Research. 2. Auflage; Springer US, Boston 1996, 647651

Boyce RW, Ebert DC, Youngs TA, Paddock CL, Mosekilde L, Stevens ML, Gundersen HJ (1995): Unbiased estimation of vertebral trabecular connectivity in calciumrestricted ovariectomized minipigs. Bone $\underline{16}, 637-642$

Buenzli PR, Thomas CDL, Clement JG, Pivonka P (2013): Endocortical bone loss in osteoporosis: The role of bone surface availability. Int J Numer Method Biomed Eng $\underline{29}, 1307-1322$

o. Verf. (1993): Consensus development conference: Diagnosis, prophylaxis, and treatment of osteoporosis. Am J Med $\underline{94}, 646-650$

Därr R, Ziller V, Hadji P, Hofbauer LC (2008): Klinik und Diagnostik der Osteoporose und Osteomalazie. Internist (Berl) $\underline{49}$, 1170, 1172-1177

Debus SE, Sailer MA, Fein M, Thiede A, Fuchs KH (1999): Defecation properties after low anterior resection and straight colo-anal anastomosis: An Experimental Study in Pigs. Coloproctology $\underline{21}, 281-286$

Dempster DW, Compston JE, Drezner MK, Glorieux FH, Kanis JA, Malluche H, Meunier PJ, Ott SM, Recker RR, Parfitt AM (2013): Standardized nomenclature, symbols, and units for bone histomorphometry: A 2012 update of the report of the ASBMR Histomorphometry Nomenclature Committee. J Bone Miner Res $\underline{28}$, 2-17

Dierkes C, Kreisel M, Schulz A, Steinmeyer J, Wolff J-C, Fink L (2009): Catabolic properties of microdissected human endosteal bone lining cells. Calcif Tissue Int $\underline{84}, 146-$ 155 
Dimai HP (2005): Strontiumranelat - ein neues Konzept zur Behandlung der Osteoporose. Wien Klin Wochenschr 117, 728-738

Dimai HP (2009): Diagnostik der Osteoporose. Wien Med Wochenschr 159, 241-246 Dören M, Schneider HPG (1996): Die postmenopausale Osteoporose aus gynäkologischer Sicht. Gynakologe 29, 735-741

Egermann M, Goldhahn J, Schneider E (2005): Animal models for fracture treatment in osteoporosis. Osteoporos Int 16 (Suppl 2), S129-S138

Einhorn TA (1992): Bone strength: The bottom line. Calcif Tissue Int 1ㅗ, 333-339 Ferretti M, Bertoni L, Cavani F, Zavatti M, Resca E, Carnevale G, Benelli A, Zanoli P, Palumbo C (2010): Influence of ferutinin on bone metabolism in ovariectomized rats. II: role in recovering osteoporosis. J Anat $\underline{217}, 48-56$

Förtsch M, Schmidt T, Feldmann C, Maurer T (2014): DVO-Leitlinie (DVO: Dachverband Osteologie) in der osteologischen Schwerpunktpraxis: Praktische Anwendung. Trauma Berufskrankh $\underline{16}, 110-121$

Foth D (2007): Alternative Therapiemöglichkeiten zur Hormontherapie in der Postmenopause. Gynakol Endokrinol $\underline{5}, 115-119$

Frost HM (1968): Tetracycline bone labeling in anatomy. Am J Phys Anthropol 29 , $183-195$

Frost HM (1969): Tetracycline-based histological analysis of bone remodeling. Calcif Tissue Res $\underline{3}, 211-237$

Gotte S (2001): Osteologie - 100 Jahre. Orthopade 프, 805-811

Hadji P, Klein S, Gothe H, Haussler B, Kless T, Schmidt T, Steinle T, Verheyen F, Linder R (2013): The epidemiology of osteoporosis - Bone Evaluation Study (BEST): An analysis of routine health insurance data. Dtsch Arztebl Int 110, 52-57

Harbeck B, Lehnert H (2016): Individualisierte Therapie der Osteoporose. rheuma plus $\underline{15}, 108-114$

Heinemann V, Parhofer K (2003): Risiken und Nutzen einer Hormonersatztherapie bei postmenopausalen Frauen: WHI-Studie. Internist (Berl) 444, 896-898 Issever AS, Link TM (2011): Radiologische Diagnostik der Osteoporose. Z Rheumatol $\underline{70}, 135-144$

Iwaniec UT, Crenshaw TD (1998): Distribution of mineralization indices of modeling and remodeling over eight months in middiaphyseal cross sections of femurs from adult swine. Anat Rec 250, 136-145 
Jakob F (2005): Primäre und sekundäre Osteoporose: Die wichtige Rolle des Internisten bei der Differenzialdiagnostik. Internist (Berl) 46 (Suppl 1), S24-S30

Jakob F, Genest F, Seefried L, Tsourdi E, Lapa C, Hofbauer LC (2016): Diagnostik in der Osteologie. Internist (Berl) $\underline{57}, 631-637$

Jee WS, Yao W (2001): Overview: animal models of osteopenia and osteoporosis. J Musculoskelet Neuronal Interact 1 , 193-207

Jeppesen G, Skydsgaard M (2015): Spontaneous background pathology in Göttingen minipigs. Toxicol Pathol $\underline{43}, 257-266$

Jergas M, Schmid G (1999): Konventionelle Radiologie der Osteoporose und Röntgenabsorptiometrie. Radiologe 39, 174-185

Judd HL, Lucas WE, Yen SS (1976): Serum 17 beta-estradiol and estrone levels in postmenopausal women with and without endometrial cancer. J Clin Endocrinol Metab $\underline{43}, 272-278$

Kanis JA: Assessment of osteoporosis at the primary health-care level. Technical Report. World Health Organization Collaborating Centre for Metabolic Bone Diseases, Sheffield 2007

Kanis JA (2010): Osteoporosis. J Med Sci $\underline{3}, 124-130$

Kanis JA, Harvey NC, Cooper C, Johansson H, Oden A, McCloskey EV (2016): A systematic review of intervention thresholds based on FRAX: A report prepared for the National Osteoporosis Guideline Group and the International Osteoporosis Foundation. Arch Osteoporos 11 (25), 1-48

Kasperk C (2008): Osteoporosescreening. Radiologe $\underline{48}, 63-70$

Kim S-W, Kim K-S, Solis CD, Lee M-S, Hyun B-H (2013): Development of osteoporosis animal model using micropigs. Lab Anim Res $\underline{29}, 174-177$

Kurth AA, Pfeilschifter J (2007): Diagnostik und Therapie der postmenopausalen Osteoporose und der Osteoporose des Mannes: Update der Leitlinien 2006. Orthopade $\underline{36}$, 683-690

Kyvernitakis I, Hadji P (2016): Postmenopausale Osteoporose: Diagnostik und Therapie gemäß S3-Leitlinie. Gynakol Endokrinol 14, 197-205

Langdahl B, Ferrari S, Dempster DW (2016): Bone modeling and remodeling: Potential as therapeutic targets for the treatment of osteoporosis. Ther Adv Musculoskelet Dis $\underline{8}$, 225-235 
Lange R, Erhard J, Garkuwa DA, Eigler FW, Sander A, Kemnitz J (1997): Tierexperimentelle Untersuchungen zur Arterialisierung der Pfortader bei der Lebertransplantation am Göttinger Miniaturschwein. Langenbecks Arch Surg 382, 277-283

Lange U (2006): Neues aus der Osteologie. Z Rheumatol $\underline{65}, 363$

Lange U, Müller-Ladner U, Pfeilschifter J (2011): Osteoporose: Leitliniengerechte Prophylaxe, Diagnostik und Therapie. Internist (Berl) $\underline{52}, 843-852$

Larena-Avellaneda A, Debus ES, Siegel R, Körner C, Dietz UA, Franke S, Thiede A (2004): Die Silikon-beschichtete Polyester-Prothese. Gefasschirurgie $\underline{9}$, 105-110

Larzul C (2013): Pig genetics: Insight in minipigs. Bilateral Symposion on Miniature Pigs for Biomedical Research in Taiwan and France, 13. Okt. 2013, Tainan/Taiwan. Hal.archives ouvertes 00958583, 1-6

Laube T, Schanze T, Brockmann C, Bolle I, Stieglitz T, Bornfeld N (2003): Chronically implanted epidural electrodes in Göttinger minipigs allow function tests of epiretinal implants. Graefe's Arch Clin Exp Ophthalmol 241, 1013-1019

Lee K, Jessop H, Suswillo R, Zaman G, Lanyon L (2003): Endocrinology: Bone adaptation requires oestrogen receptor-alpha. Nature $\underline{424}, 389$

Lee WR (1964): Appositional bone formation in canine bone: A quantitative microscopic study using tetracycline markers. J Anat $\underline{98}, 665-677$

Leibson CL, Tosteson ANA, Gabriel SE, Ransom JE, Melton LJ (2002): Mortality, disability, and nursing home use for persons with and without hip fracture: A populationbased study. J Am Geriatr Soc 므, 1644-1650

Leidenberger F, Strowitzki T, Ortmann O: Klinische Endokrinologie für Frauenärzte 4. Auflage; Springer, Heidelberg 2009

Leitlinie Osteoporose s. DVO-Leitlinie 2014 (Internetquelle).

Lelovas PP, Xanthos TT, Thoma SE, Lyritis GP, Dontas IA (2008): The laboratory rat as an animal model for osteoporosis research. Comp Med $\underline{58}, 424-430$

Mardas N, Dereka X, Donos N, Dard M (2014): Experimental model for bone regeneration in oral and cranio-maxillo-facial surgery. J Invest Surg 27, 32-49

Mikosch P, Gosch M (2013): Osteoporose - Therapie und sektorenubergreifendes Management. Wien Med Wochenschr 163, 455-461 
Mosekilde L, Weisbrode SE, Safron JA, Stills HF, Jankowsky ML, Ebert DC, Danielsen CC, Sogaard CH, Franks AF, Stevens ML et al. (1993a): Calcium-restricted ovariectomized sinclair S-1 minipigs: An animal model of osteopenia and trabecular plate perforation. Bone $\underline{14}, 379-382$

Mosekilde L, Weisbrode SE, Safron JA, Stills HF, Jankowsky ML, Ebert DC, Danielsen CC, Sogaard CH, Franks AF, Stevens ML (1993b): Evaluation of the skeletal effects of combined mild dietary calcium restriction and ovariectomy in Sinclair S-1 minipigs: A pilot study. J Bone Miner Res $\underline{8}, 1311-1321$

Neuerburg C, Stumpf U, Schmidmaier R, Kammerlander C, Pfeilschifter J, Mutschler W, Bocker W (2015): Neue Osteoporose-Leitlinie DVO 2014 und ihre Bedeutung für den Unfallchirurgen. Unfallchirurg 118, 905-912

Obermayer-Pietsch B, Schwetz V (2016): Biochemische Marker des Knochenstoffwechsels und ihre Bedeutung. Z Rheumatol $\underline{75}, 451-458$

Ortmann G, Schulz K-D, Diedrich K (2000): Hormone replacement therapy and risk of breast cancer. Gynakologe $\underline{33}, 402-407$

Ortmann O, Weiss JM, Diedrich K (2003): Nutzen und Risiken der Hormonersatztherapie im Klimakterium und in der Postmenopause. Gynakol Endokrinol 1, 6-9

Ozan F, Pekedis M, Koyuncu S, Altay T, Yildiz H, Kayali C (2017): Micro-computed tomography and mechanical evaluation of trabecular bone structure in osteopenic and osteoporotic fractures. J Orthop Surg (Hong Kong) $\underline{25}$, 1-6

Parfitt AM, Mathews CH, Villanueva AR, Kleerekoper M, Frame B, Rao DS (1983):

Relationships between surface, volume, and thickness of iliac trabecular bone in aging and in osteoporosis. Implications for the microanatomic and cellular mechanisms of bone loss. J Clin Invest $\underline{72}$, 1396-1409

Pautke C, Tischer T, Vogt S, Haczek C, Deppe H, Neff A, Horch H-H, Schieker M, Kolk A (2007): New advances in fluorochrome sequential labelling of teeth using seven different fluorochromes and spectral image analysis. J Anat 210, 117-121

Pautke C, Vogt S, Kreutzer K, Haczek C, Wexel G, Kolk A, Imhoff AB, Zitzelsberger H, Milz S, Tischer T (2010): Characterization of eight different tetracyclines: Advances in fluorescence bone labeling. J Anat $\underline{217}, 76-82$

Pietschmann P, Peterlik M (1999): Pathophysiologie und Therapie der Osteoporose. Radiologe 39, 228-234

Preisinger E (2014): Diagnose Osteoporose. Man Med 므, 214-219 
Pschyrembel - Klinisches Wörterbuch, 261., neu bearbeitete und erweiterte Auflage; de Gruyter, Berlin 2007

Rabe T, Mueck AO, Hadji P, Geisthövel F, Holst T von (2005): Hormonersatztherapie: Nutzen und Risiken. Gynakologe $\underline{38}, 243-253$

Radkohl W, Leb G (1996): Osteoporose und Hormonersatztherapie. Acta Chir Austriaca $\underline{28}, 263-265$

Rahn BA (2003): Fluorochrome labelling of bone dynamics. Eur Cell Mater $\underline{5}, 41$

Rahn BA, Perren SM (1972): Alizarinkomplexon - Fluorochrom zur Markierung von Knochen- und Dentinanbau. Experientia 28, 180

Rahn BA, Schweiz IJ (1980): Knochenumbaumechanismen und Kraftapplikation. Fortschr Kieferorthop ㄴ1, 186-195

Reinwald S, Burr D (2008): Review of nonprimate, large animal models for osteoporosis research. J Bone Miner Res 23, 1353-1368

Riggs BL, Khosla S, Melton LJ3 (2002): Sex steroids and the construction and conservation of the adult skeleton. Endocr Rev $\underline{23}, 279-302$

Rintelen B (2016): Die neue DVO Leitline 2014 für die postmenopausale Frau und die Osteoporose beim Mann über 60 Jahre: Wie praktikabel ist sie? rheuma plus $\underline{15}, 6-7$

o. Verf., Roche Informationsblatt: ALP: Alkalische Phosphatase flüssig nach IFCC. Roche Diagnostics $\mathrm{GmbH}$, Mannheim 2004

o. Verf., Roche Informationsblatt: $\beta$-CrossLaps/Serum: Elecsys $® \beta$-CrossLaps/Serum Immunoassay. Roche Diagnostics GmbH, Mannheim 1999

o. Verf., Roche Informationsblatt: Estradiol II: Estradiol - E2. Roche Diagnostics GmbH, Mannheim 2007

o. Verf., Roche Informationsblatt: N-MID Osteocalcin: Osteocalcin (OCN). Roche Diagnostics $\mathrm{GmbH}$, Mannheim 2007

Roth A, Kurth A, Böcker W (2015): Osteologie - den Knochen im Fokus. Orthopade 44, 661

Scheidt-Nave C (2001): Die sozioökonomische Bedeutung der Osteoporose. Bundesgesundheitsbl - Gesundheitsforsch - Gesundheitsschutz 44, 41-51

Schmolke B (2001): Labordiagnostik der Osteoporose. Orthopade 주, 425-436 
Scholz-Ahrens KE, Delling G, Jungblut PW, Kallweit E, Barth CA (1996): Effect of ovariectomy on bone histology and plasma parameters of bone metabolism in nulliparous and multiparous sows. Z Ernahrungswiss $\underline{35}, 13-21$

Schulte HM (1997): Osteoporose: Diagnose, Therapie und Prophylaxe. Gynakologe 30, 352-356

Scriba GKE (2000): Bisphosphonate im Überblick. Pharm Unserer Zeit 29, 50-56

Seeman E (2013): Age- and menopause-related bone loss compromise cortical and trabecular microstructure. J Gerontol A Biol Sci Med Sci $\underline{68}, 1218-1225$

Siggelkow H (2015): Die Osteoporose der Frau. MMW Fortschr Med 157, 73-80

Simianer H, Köhn F (2010): Genetic management of the Gottingen Minipig population. J Pharmacol Toxicol Methods $\underline{62}, 221-226$

Spencer GR (1979): Pregnancy and lactational osteoporosis. Animal model: Porcine lactational osteoporosis. Am J Pathol $\underline{95}, 277-280$

Stöckle U, Lucke M, Haas NP (2005): Der Oberschenkelhalsbruch. Dtsch Arztebl 102, A 3426-3433

Szulc P, Seeman E, Duboeuf F, Sornay-Rendu E, Delmas PD (2006): Bone fragility: Failure of periosteal apposition to compensate for increased endocortical resorption in postmenopausal women. J Bone Miner Res 21, 1856-1863

Tietz NW, Burtis CA, Duncan P, Ervin K, Petitclerc CJ, Rinker AD, Shuey D, Zygowicz ER (1983a): A reference method for measurement of alkaline phosphatase activity in human serum. Clin Chem $\underline{29}, 751-761$

Tietz NW, Rinker AD, Shaw LM (1983b): IFCC methods for the measurement of catalytic concentration of enzymes: Part 5. IFCC method for alkaline phosphatase (orthophosphoric-monoester phosphohydrolase, alkaline optimum, EC 3.1.3.1). Clinica Chimica Acta 135 , 339F-349F

Tsutsumi H, Katagiri K, Morimoto M, Nasu T, Tanigawa M, Mamba K (2004a): Diurnal variation and age-related changes of bone turnover markers in female Gottingen minipigs. Lab Anim 38, 439-446

Tsutsumi H, Katagiri K, Takeda S, Nasu T, Igarashi S, Tanigawa M, Mamba K (2004b): Standardized Data and Relationship between Bone Growth and Bone Metabolism in Female Göttingen Minipigs. Exp Anim $\underline{53}$, 331-337

Turner RT, Maran A, Lotinun S, Hefferan T, Evans GL, Zhang M, Sibonga JD (2001): Animal Models For Osteoporosis. Rev Endocr Metab Disord 2, 117-127 
van de Braak, A. E., van't Klooster AT (1987): Study of osteogenesis in adult sheep on a high and a low calcium ration by means of fluorescing bone markers. Vet Res Commun $\underline{11}, 101-108$

van Gaalen SM, Kruyt MC, Geuze RE, Bruijn JD de, Alblas J, Dhert WJA (2010): Use of fluorochrome labels in in vivo bone tissue engineering research. Tissue Eng Part $B$ $\operatorname{Rev} \underline{16}, 209-217$

Vasikaran S, Cooper C, Eastell R, Griesmacher A, Morris HA, Trenti T, Kanis JA (2011a): International Osteoporosis Foundation and International Federation of Clinical Chemistry and Laboratory Medicine position on bone marker standards in osteoporosis. Clin Chem Lab Med $\underline{49}, 1271-1274$

Vasikaran S, Eastell R, Bruyere O, Foldes AJ, Garnero P, Griesmacher A, McClung M, Morris HA, Silverman S, Trenti T et al. (2011b): Markers of bone turnover for the prediction of fracture risk and monitoring of osteoporosis treatment: A need for international reference standards. Osteoporos Int $\underline{22}, 391-420$

Wang Y, Liu Z, Wang Q, Feng Q, Chen W (2017): Early Detection of Tibial Cartilage Degradation and Cancellous Bone Loss in an Ovariectomized Rat Model. Biomed Res Int 2017, 1-7

Wen X-X, Xu C, Wang F-Q, Feng Y-F, Zhao X, Yan Y-B, Lei W (2015): Temporal changes of microarchitectural and mechanical parameters of cancellous bone in the osteoporotic rabbit. Biomed Res Int $\underline{2015}, 1-11$

Wheater G, Elshahaly M, Tuck SP, Datta HK, van Laar JM (2013): The clinical utility of bone marker measurements in osteoporosis. J Transl Med 11, 201-214

Wolff J: Das Gesetz der Transformation der Knochen. Hirschwald, Berlin 1892

Wronski TJ, Lowry PL, Walsh CC, Ignaszewski LA (1985): Skeletal alterations in ovariectomized rats. Calcif Tissue Int $\underline{37}, 324-328$

Wu K, Schubeck KE, Frost HM, Villanueva A (1970): Haversian bone formation rates determined by a new method in a mastodon, and in human diabetes mellitus and osteoporosis. Calc. Tis Res. $\underline{6}$, 204-219

Würzler KK, Heisterkamp M, Böhm H, Kübler NR, Sebald W, Reuther JF (2004): Unterkieferrekonstruktion mit autologem Knochen und einem induktiven Implantat beim Göttinger Minischwein. Mund Kiefer Gesichtschir $\underline{8}, 75-82$

Yoon K-H, Cho D-C, Yu S-H, Kim K-T, Jeon Y, Sung J-K (2012): The Change of Bone Metabolism in Ovariectomized Rats: Analyses of MicroCT Scan and Biochemical Markers of Bone Turnover. J Korean Neurosurg Soc $\underline{51}$, 323-327 
Zebaze RMD, Ghasem-Zadeh A, Bohte A, luliano-Burns S, Mirams M, Price RI, Mackie EJ, Seeman E (2010): Intracortical remodelling and porosity in the distal radius and post-mortem femurs of women: A cross-sectional study. Lancet $\underline{375}, 1729-1736$

Ziller V (2013): Osteoporose: Leitliniengerechte Diagnostik und Therapie. Gynakologe $\underline{46}, 225-231$

Internetquellen:

DVO-Leitlinie 2014 zur Prophylaxe, Diagnostik und Therapie der Osteoporose bei Männern ab dem 60. Lebensjahr und bei postmenopausalen Frauen.

http://www.dv-osteologie.org/uploads/Leitlinie\%202014/DVO-Leitlinie\%20Osteoporose \%202014\%20Kurzfassung\%20und\%20Langfassung\%20Version\%201a\%2012\%2001 \%202016.pdf, abgerufen am: 17.10.2016 


\section{Danksagung}

Mein herzlicher Dank gilt Herrn Prof. Dr. Dr. Karl Günter Wiese für die Überlassung des Themas dieser Arbeit und für seine engagierte Betreuung. Er hat durch seine stetige Unterstützung bei Fragen und Problemen aller Art und seine konstruktiven Anregungen ganz maßgeblich zur Fertigstellung dieser Arbeit beigetragen.

Herrn Prof. Dr. Dr. Franz-Josef Kramer und Frau Dr. Vera Stock danke ich für die Überlassung der OP- und Laborprotokolle und für das Knochenmaterial, das sie Herrn Prof. Wiese für weitere Untersuchungen zur Verfügung gestellt hatten und das dadurch von mir ausgewertet werden konnte.

Bedanken möchte ich mich außerdem bei dem gesamten Forschungsteam der Abteilung Mund-, Kiefer- und Gesichtschirurgie der Universitätsmedizin Göttingen für die umfassende Unterstützung und Hilfe. Hier sei vor allem Frau Christina Schäfer genannt, die mich geduldig in die Herstellung von Trenn-Dünnschliff-Präparaten eingewiesen hat.

Bei Frau Ramona Castro-Machguth bedanke ich mich schließlich für die Einweisung in die Technik der peripheren quantitativen Computertomographie. 